JEFFERSON OLIVEIRA AMARO

\title{
ANÁLISE DOS PARÂMETROS ANALÓGICOS DO DISPOSITIVO SOI DTMOS
}

Dissertação apresentada à Escola

Politécnica da Universidade de São Paulo para a obtenção do título de Mestre em Engenharia

Área de concentração:

Engenharia Elétrica / Microeletrônica

São Paulo 
JEFFERSON OLIVEIRA AMARO

\section{ANÁLISE DOS PARÂMETROS ANALÓGICOS DO DISPOSITIVO SOI DTMOS}

Dissertação apresentada à Escola

Politécnica da Universidade de São Paulo para a obtenção do título de Mestre em Engenharia

Área de concentração:

Engenharia Elétrica / Microeletrônica

Orientador:

Prof. Dr. João Antonio Martino

São Paulo 
FICHA CATALOGRÁFICA

Amaro, Jefferson Oliveira

Análise dos parâmetros analógicos do dispositivo SOI

DTMOS / J.O. Amaro. -- São Paulo, 2009.

95 p. Edição revisada.

Dissertação (Mestrado) - Escola Politécnica da Universidade de São Paulo. Departamento de Engenharia de Sistemas Eletrônicos.

1. Microeletrônica 2. Circuitos integrados MOS 3. Transistores (Modelagem) 4. Circuitos analógicos 5. Dispositivos eletrônicos 6. Medidas elétricas I. Universidade de São Paulo. Escola Politécnica. Departamento de Engenharia de Sistemas Eletrônicos II. t. 
Dedico este trabalho a minha mãe Maria de Fátima Oliveira Amaro e especialmente a meu grande e saudoso pai Hélio Amaro (in memorian) que de algum lugar está observando os meus sonhos se realizarem e aos meus irmãos Tiago Oliveira Amaro e Hélio Amaro Júnior (in memorian), e a querida Luciana e ao Henry pelo incentivo incondicional à minha formação profissional. 


\section{Agradecimentos}

Ao grande amigo e professor Dr. João Antonio Martino pela dedicada orientação, apoio, amizade, paciência, confiança e pela oportunidade da realização deste trabalho.

Ao grande amigo e professor Dr. Victor Sonnenberg pela indicação e apresentação ao grupo SOI CMOS.

Ao Dr. Marcelo Antonio Pavanello, pelo incentivo e algumas discussões no decorrer do trabalho.

Ao Laboratório de Sistemas Integráveis da Escola Politécnica de São Paulo pela infraestrutura disponibilizada ao longo do trabalho.

Aos amigos (as) Carolina Davanzo, Milene Galeti, Luciano Mendes Camilo, Sara Dereste, Vinícius Heltai, Paula Ghedini Der Agopian e Talita Nicoletti pela inestimável ajuda e confiança, companheirismo e as diversas discussões, muito obrigado. A ajuda que vocês me ofereceram não tem preço.

Aos demais amigos do grupo SOI CMOS e do LSI-EPUSP pela colaboração, atenção e solidariedade dispensadas durante a elaboração do trabalho e que involuntariamente foram aqui omitidas o meu enorme agradecimento.

À minha querida mãe e solidário irmão pelo apoio incondicional permitindo que eu tivesse formação técnica e pessoal para aproveitar essa oportunidade, além do incentivo constante para alcançar esse grande objetivo.

À amada Luciana por toda a compreensão despendida durante a execução do trabalho e ao pequeno Henry. Como sempre vocês sempre me apoiaram muito e foram coresponsáveis pela execução deste. 
À amiga Amanda Rossi Mascaro que por muitas vezes me deu grande apoio seja pessoalmente ou por telefone, um muito obrigado.

Aos meus familiares que sempre me apoiaram e torceram por mim, e que sempre me compreenderam, em especial para a minha tia Neusa e Ismar e meus primos Mazinho e Guilherme, um muitíssimo obrigado.

A todas as pessoas que colaboraram para a realização, seja com um sorriso, uma palavra de ânimo, ou um olhar, e que involuntariamente foram omitidas, deixo aqui o meu agradecimento. 


\section{RESUMO}

Este trabalho apresenta o estudo do desempenho analógico do transistor SOI MOSFET com tensão de limiar dinamicamente variável (DTMOS). Esse dispositivo é fabricado em tecnologia SOI parcialmente depletado (PD). A tensão de limiar desta estrutura varia dinamicamente porque a porta do transistor está curto-circuitada com o canal do mesmo, melhorando significativamente suas características elétricas quando comparadas aos transistores PD SOI MOSFET convencionais.

Entre as características principais desse dispositivo, pode-se citar a inclinação de sublimiar praticamente ideal $(60 \mathrm{mV} / \mathrm{dec})$, devido ao reduzido efeito de corpo, resultando num aumento significativo da corrente total que corresponde à soma da corrente do transistor principal com a corrente do transistor bipolar parasitário inerente à estrutura.

Diversas simulações numéricas bidimensionais, utilizando o simulador ATLAS, foram executadas a fim de se obter um melhor entendimento do dispositivo DTMOS, quando comparado com o SOI convencional. As características elétricas analisadas através da simulação numérica bidimensional apresentam a corrente de dreno em função da polarização da porta considerando $\mathrm{V}_{\mathrm{D}}$ baixo e alto $(25 \mathrm{mV}$ e $1 \mathrm{~V})$. O canal teve uma variação de 1 até $0,15 \mu \mathrm{m}$. Através dessas simulações foram obtidos as principais características elétricas e parâmetros analógicos para estudo do DTMOS em comparação com o SOI convencional como: transcondutância $\left(\mathrm{g}_{\mathrm{m}}\right)$, tensão de limiar $\left(\mathrm{V}_{\mathrm{TH}}\right)$, inclinação de sublimiar $(\mathrm{S})$. Considerando a polarização de dreno em $1 \mathrm{~V}$ foi obtido a transcondutância e a inclinação de sublimiar. Na etapa seguinte foi feito simulações para obter as curvas características de $\mathrm{I}_{\mathrm{DS}} \mathrm{x} \mathrm{V}_{\mathrm{DS}}$, onde a tensão aplicada na porta variou de 0 a $200 \mathrm{mV}\left(\mathrm{V}_{\mathrm{GT}}\right)$, onde se obteve a tensão Early $\left(\mathrm{V}_{\mathrm{EA}}\right)$, a condutância de saída $\left(\mathrm{g}_{\mathrm{D}}\right)$ dos dispositivos, bem como o ganho intrínseco de tensão $\mathrm{DC}\left(\mathrm{A}_{V}\right)$ e a freqüência de ganho unitário $\left(\mathrm{f}_{\mathrm{T}}\right)$.

Os resultados experimentais foram realizados em duas etapas: na primeira, extraíram-se todas as curvas variando o comprimento do canal (L) de 10 à $0,15 \mu \mathrm{m}$ e na segunda, manteve-se um valor fixo do comprimento do canal $(10 \mu \mathrm{m})$, variando somente a largura do canal (W) entre 10 e $0,8 \mu \mathrm{m}$, para identificar quais seriam os impactos nos resultados. A relação da transcondutância pela corrente de dreno do DTMOS foi $40 \mathrm{~V}^{-1}$ na média, independentemente do comprimento do canal e observou- 
se um aumento de $14 \mathrm{~dB}$ no ganho intrínseco quando usado o comprimento de canal de $0,22 \mu \mathrm{m}$, em comparação com SOI convencional.

Foi verificado uma melhora na performance dos parâmetros analógicos do DTMOS quando comparado com o PDSOI e têm sido muito utilizado em aplicações de baixa tensão e baixa potência.

Palavras-chave: SOI, PDSOI, DTMOS, ganho intrínseco DC, freqüência de ganho unitário, caracterização elétrica, simulação bidimensional. 


\begin{abstract}
This work presents the study of analog performance parameters of PDSOI (Partially-depleted) transistor in comparison with a Dynamic Threshold MOS transistor (DTMOS). The DTMOS is a partially-depleted device with dynamic threshold voltage. This variation of threshold voltage is obtained when the gate is connected to the silicon film (channel) of the PDSOI device, improving the electrical characteristics of a conventional SOI.

The characteristics of this device is an ideal subthreshold slope $(60 \mathrm{mV} / \mathrm{dec})$, due to the reduced body effect and improved current drive. When the gate voltage increases in DTMOS (body tied to gate), there is a body potential increase, which results in a higher drain current due to the sum of the MOS current with the bipolar transistor (BJT) one.

Several two-dimensional numerical simulations were done with the ATLAS Simulator to obtain a better knowledge of DTMOS device to compare with PDSOI. The electrical characteristics analyzed through two-dimensional numerical simulations are the drain current as a function of $\left(\mathrm{V}_{\mathrm{GS}}\right)$ with drain bias fixed at $25 \mathrm{mV}$ and $1 \mathrm{~V}$. The channel length varied from 10 to $1 \mathrm{um}$. Through these simulations the main electrical characteristics and the analog performance parameters were obtained of DTMOS in comparison with conventional SOI, as: transconductance $\left(\mathrm{g}_{\mathrm{m}}\right)$, threshold $\left(\mathrm{V}_{\mathrm{TH}}\right)$ voltage, and subthreshold slope $(\mathrm{S})$. Considering the drain bias of $1 \mathrm{~V}$, transconductance and subthreshold voltage were obtained. In the next step, the characteristics curves of drain current $\left(\mathrm{I}_{\mathrm{DS}}\right)$ as a function of $\left(\mathrm{V}_{\mathrm{DS}}\right)$, where the gate bias varied from 0 to $200 \mathrm{mV}$ of $\left(\mathrm{V}_{\mathrm{GT}}\right)$, to obtain the Early voltage $\left(\mathrm{V}_{\mathrm{EA}}\right)$ and output conductance $\left(\mathrm{g}_{\mathrm{D}}\right)$, the intrinsic gain $\mathrm{DC}\left(\mathrm{A}_{\mathrm{V}}\right)$ and a unit-gain frequency to both devices were simulated.

The experimental results were measured in two steps: in the first step all electrical characteristics and parameters considering a channel length $(\mathrm{L})$ variation were obtained and in the second step a channel length was fixed and varied the width (W) was varied to study if this variation had any effects on the results. The $g_{m} / I_{D S}$ ratio of DTMOS was $40 \mathrm{~V}^{-1}$, independent of channel length and a increase of $14 \mathrm{~dB}$ in intrinsic gain, when using a channel length of $0,22 \mu \mathrm{m}$, compared with the conventional SOI was obtained.
\end{abstract}


Improvement was observed in the performance of analog parameters when compared whit conventional SOI and DTMOS has been widely used in Low-PowerLow-Voltage applications.

Keywords: SOI, PDSOI, DTMOS, intrinsic gain DC, unit-gain frequency, electrical characterization, two-dimensional simulation 


\section{LISTA DE FIGURAS}

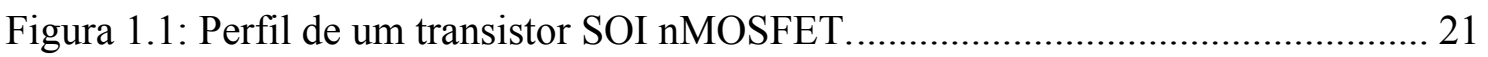

Figura 1.2: Desenho esquemático da estrutura do SOI DTMOS com vista superior (A) e seção transversal (B e C).

Figura 2.1: Diagrama de Bandas de Energia de dispositivos MOS convencional (A),

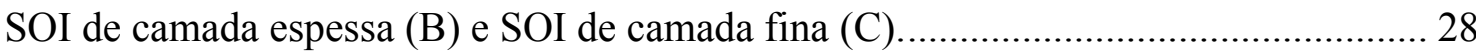

Figura 2.2: Modos de operação do transistor SOI nMOSFET considerando as tensões aplicadas em $\mathrm{V}_{\mathrm{GS}}$ e $\mathrm{V}_{\mathrm{GB}}$, com baixa tensão no dreno. A região hachurada representa os modos de operação mais comum [20].

Figura 2.3: Distribuição das cargas de depleção em dispositivos MOSFET

convencionais de canal longo (A) e de canal curto (B) [20].

Figura 2.4: Gráfico mono logaritmo da corrente $\mathrm{I}_{\mathrm{DS}} \times \mathrm{V}_{\mathrm{GS}}$, indicando a inclinação de sublmiar (S).

Figura 2.5: Curva de transcondutância $\left(\mathrm{g}_{\mathrm{m}}\right)$ em função da tensão aplicada na porta $\left(\mathrm{V}_{\mathrm{GS}}\right)$ com baixo valor de $\mathrm{V}_{\mathrm{DS}}[24]$

Figura 2.6: Elevação abrupta da corrente de dreno "kink effect" na característica de saída do transistor SOI nMOSFET [20].

Figura 2.7: Transistor Bipolar Parasitário (BJT) (A) e o fluxo da corrente de corpo do transistor bipolar parasitário do dispositivo SOI MOSFET parcialmente depletado (B) $[10]$.

Figura 2.8: Obtenção da tensão Early através da curva de corrente de dreno em função da tensão aplicada no dreno.

Figura 2.9: Curva característica da relação da transcondutância em função da corrente normalizada $\left(\mathrm{I}_{\mathrm{DS}} /(\mathrm{W} / \mathrm{L})\right)$ de um dispositivo SOI convencional.

Figura 2.10: Bloco amplificador formado por um único transistor nMOSFET.

Figura 2.11: Curva de Bode representando a resposta em freqüência de um transistor $[32]$.

Figura 2.12: Dispositivo SOI DTMOS. O contato de corpo está curto-circuitado com a porta.

Figura 2.13: Esquema do contato de corpo em formato de porta tipo I (A); dispositivo com porta tipo $\mathrm{H}(\mathrm{B})$, dispositivo com porta tipo $\mathrm{T}$ (C) [20]. 
Figura 3.1: Curva do potencial elétrico em função da espessura do filme de silício do SOI convencional.

Figura 3.2: Curva $I_{D S}$ em função da tensão de porta $V_{G S}$ para diferentes comprimentos de canais do dispositivo SOI convencional e DTMOS considerando $\mathrm{V}_{\mathrm{DS}}=25 \mathrm{mV}$ (A) e $\mathrm{V}_{\mathrm{DS}}=1 \mathrm{~V}(\mathrm{~B})$.

Figura 3.3: Curva de Transcondutância em função da tensão aplicada à porta para

diferentes comprimentos de canais do SOI convencional e DTMOS. 56

Figura 3.4: Curva da segunda derivada da corrente em função da tensão aplicada na porta do transistor SOI parcialmente depletado (A) e DTMOS (B) para diversos valores

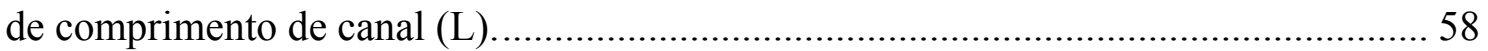

Figura 3.5: Variação da Tensão de limiar em função do comprimento do canal para o SOI convencional e DTMOS

Figura 3.6: Corrente de dreno para ambos os dispositivos considerando vários comprimentos de canais. 60

Figura 3.7: Curva da inclinação de sublimiar (S) comparativa entre os resultados obtidos através da simulação para diferentes comprimentos de canais do PDSOI e do DTMOS.

Figura 3.8: Curva da corrente de dreno em função da tensão aplicada na porta para comprimento de canal de $1 \mu \mathrm{m}$

Figura 3.9: Curva da corrente de dreno em função da tensão aplicada na porta para comprimento de canal de $1 \mu \mathrm{m}$.

Figura 3.10: Curva de $g_{m}$ em função da corrente normalizada $I_{D S}$ parra os dispositivo SOI convencional e DTMOS para diversos valores de comprimento e canal.

Figura 3.11: Curva do ganho de tensão DC em função da corrente normalizada $\mathrm{I}_{\mathrm{DS}} /(\mathrm{W} / \mathrm{L})(\mathrm{A})$ e, da freqüência de ganho unitário $\left(\mathrm{f}_{\mathrm{T}}\right)$ com uma capacitância de carga de $14 \mathrm{pF}(\mathrm{B})$ para diferentes comprimentos de canais do PDSOI e do DTMOS. 66

Figura 4.1: Curva de $\mathrm{I}_{\mathrm{DS}}$ em função da tensão aplicada na porta $\mathrm{V}_{\mathrm{GS}}$ obtidos experimentalmente para diferentes comprimentos de canais do PDSOI e do DTMOS para $\mathrm{V}_{\mathrm{DS}}=25 \mathrm{mV}(\mathrm{A})$ e $\mathrm{V}_{\mathrm{DS}}=1 \mathrm{~V}(\mathrm{~B})$

Figura 4.2: Curvas experimentais da transcondutância em função da tensão aplicada na porta para diferentes comprimentos de canais para o PDSOI e DTMOS considerando $\mathrm{V}_{\mathrm{DS}}=25 \mathrm{mV}(\mathrm{A})$ e $\mathrm{V}_{\mathrm{DS}}=1 \mathrm{~V}(\mathrm{~B})$. 
Figura 4.3: Curvas da corrente de dreno (A) e inclinação de sublimiar (B) obtidas experimentalmente para diferentes comprimentos de canais do PDSOI e do DTMOS. 72 Figura 4.4: Valores da tensão de limiar em função do comprimento de canal (L). ....... 74 Figura 4.5:Curva da corrente de dreno em função da tensão aplicada no dreno para comprimento de canal de $10 \mu \mathrm{m}(\mathrm{A}), 1 \mu \mathrm{m}$ (B) e 0,2 $\mu \mathrm{m}$ (C).

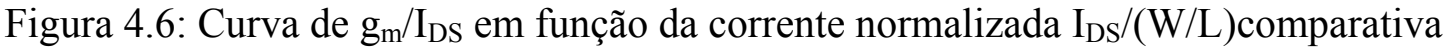
dos resultados obtidos através da simulação e experimentalmente para o PDSOI e DTMOS para diferentes comprimentos de canais.

Figura 4.7: Curva do ganho DC em função da corrente normalizada $\mathrm{I}_{\mathrm{DS}}$ (A) e da freqüência de ganho unitário com uma capacitância de carga de 14 pF (B) obtido experimentalmente para diferentes comprimentos de canais.

Figura 4.8: Curva da corrente $\mathrm{I}_{\mathrm{DS}}$ em função de $\mathrm{V}_{\mathrm{GS}}$ do dispositivo SOI e DTMOS para várias larguras $\mathrm{W}$. 80

Figura 4.9: Curva da transcondutância em função da tensão aplicada na porta $\mathrm{V}_{\mathrm{GS}}$ para diversas larguras do PDSOI e do DTMOS.

Figura 4.10: Curva da corrente de dreno em função da tensão aplicada na porta $\mathrm{V}_{\mathrm{GS}}$ do PDSOI e do DTMOS para diversas larguras (W).

Figura 4.11: Curva da segunda derivada da corrente em função da tensão aplicada na porta do dispositivo PDSOI e DTMOS para diversas larguras (W) (A) e valores da tensão de limiar em função de W (B).

Figura 4.12: Curva da corrente de dreno em função da tensão aplicada no dreno do dispositivo PDSOI e DTMOS para largura (W) de $1 \mu \mathrm{m}$.

Figura 4.13: Curva da condutância de saída $\left(\mathrm{g}_{\mathrm{D}}\right)$ em função da tensão aplicada no dreno do dispositivo PDSOI e DTMOS para largura (W) de $1 \mu \mathrm{m}$.

Figura 4.14: Curva da relação $g_{m} / I_{D S}$ em função da corrente normalizada $I_{D S}$ do dispositivo PDSOI e DTMOS para largura (W) de $1 \mu \mathrm{m}$.

Figura 4.15: Curva do ganho DC em função da corrente normalizada $\mathrm{I}_{\mathrm{DS}}(\mathrm{A})$ e da freqüência de ganho unitário $\left(\mathrm{f}_{\mathrm{T}}\right)$ do dispositivo PDSOI e DTMOS para largura $(\mathrm{W})$ de $1 \mu \mathrm{m}$ e capacitância de carga de $14 \mathrm{pF}(\mathrm{B})$. 


\section{LISTA DE TABELAS}

Tabela 3.1:Valores da corrente de dreno do SOI convencional e do DTMOS por considerando $\mathrm{V}_{\mathrm{GT}}=50 \mathrm{mV}$ e $\mathrm{V}_{\mathrm{DS}}=25 \mathrm{mV}$. 56

Tabela 3.2: Valores da transcondutância máxima do dispositivo SOI convencional e DTMOS considerando $\mathrm{V}_{\mathrm{DS}}=25 \mathrm{mV}$.

Tabela 3.3: Tensão de limiar obtida a partir da figura 3.5 para todos os dispositivos. .. 59 Tabela 3.4: Valores da inclinação de sublimiar para vários comprimentos de canal..... 61 Tabela 3.5: Valores da tensão Early $\left(\mathrm{V}_{\mathrm{EA}}\right)$ considerando $\mathrm{V}_{\mathrm{GT}}=50 \mathrm{mV}$

Tabela 3.6: Valores da relação da transcondutância $g_{m}$ em função da corrente normalizada $\mathrm{I}_{\mathrm{DS}} / \mathrm{W}$ considerando o $\mathrm{V}_{\mathrm{GT}}$ de $50 \mathrm{mV}$. 64

Tabela 4.1: Características físicas do dispositivo utilizado para obtenção dos resultados experimentais.

Tabela 4.2: Valores da transcondutância máxima do dispositivo SOI convencional e DTMOS considerando $\mathrm{V}_{\mathrm{DS}}=25 \mathrm{mV}$.

Tabela 4.3: Valores da tensão de limiar para o dispositivo SOI convencional e DTMOS com $\mathrm{V}_{\mathrm{DS}}=25 \mathrm{mV}$ 73

Tabela 4.4: Valores da tensão Early $\left(\mathrm{V}_{\mathrm{EA}}\right)$ e $\mathrm{g}_{\mathrm{D}}$ considerando $\mathrm{V}_{\mathrm{GT}}=50 \mathrm{mV}$. 75

Tabela 4.5: Valores da relação da transcondutância $g_{m}$ em função da corrente normalizada $\mathrm{I}_{\mathrm{DS}} / \mathrm{W}$ considerando o $\mathrm{V}_{\mathrm{GT}}$ de $50 \mathrm{mV}$. 


\section{LISTA DE SÍMBOLOS}

$A_{V} \quad$ Ganho da tensão em malha aberta para baixas freqüências $(\mathrm{dB})$

$\mathrm{C}_{\mathrm{B}} \quad$ Capacitância por unidade do corpo $\left(\mathrm{F} / \mathrm{cm}^{2}\right)$

$\mathrm{C}_{\mathrm{D}} \quad$ Capacitância por unidade de área da região de depleção $\left(\mathrm{F} / \mathrm{cm}^{2}\right)$

$\mathrm{C}_{\mathrm{it}} \quad$ Capacitância das armadilhas de interface $\left(\mathrm{F} / \mathrm{cm}^{2}\right)$

$\mathrm{C}_{\mathrm{L}} \quad$ Carga capacitiva do circuito amplificador com transistor unitário (F)

$\mathrm{C}_{\mathrm{ox}} \quad$ Capacitância do óxido de porta por unidade de área $\left(\mathrm{F} / \mathrm{cm}^{2}\right)$

$\mathrm{E}_{\mathrm{C}} \quad$ Nível energético da banda de condução $(\mathrm{eV})$

$\mathrm{E}_{\mathrm{F}} \quad$ Nível energético de Fermi $(\mathrm{eV})$

$\mathrm{E}_{\mathrm{i}} \quad$ Nível Energético intrínseco $(\mathrm{eV})$

$\mathrm{E}_{\mathrm{V}} \quad$ Nível energético da banda de valência $(\mathrm{eV})$

$\mathrm{f}_{0} \quad$ Freqüência de corte do transistor $(\mathrm{Hz})$

$\mathrm{f}_{\mathrm{T}} \quad$ Freqüência de ganho de tensão unitário $(\mathrm{Hz})$

$\mathrm{g}_{\mathrm{D}} \quad$ Condutância de dreno $\left(\Omega^{-1}\right)$

gm Transcondutância $\left(\Omega^{-1}\right)$

$g_{\operatorname{mmax}}$ Transcondutância máxima $\left(\Omega^{-1}\right)$

I Corrente (A)

$\mathrm{I}_{\mathrm{B}} \quad$ Corrente de alimentação do circuito amplificador com transistor unitário (A)

I corpo Corrente de corpo do transistor bipolar parasitário (A)

$\mathrm{I}_{\text {canal }} \quad$ Corrente de canal do transistor MOSFET (A)

I $\quad$ Corrente de dreno (A)

$\mathrm{I}_{\text {Dsat }} \quad$ Corrente de dreno na região de saturação (A)

$\mathrm{I}_{\text {lac }} \quad$ Corrente de lacunas geradas próximo ao dreno (A)

I $\quad$ Corrente de Saturação do diodo (A)

K Constante de Boltzman $\left(1,38 \times 10^{-23} \mathrm{~J} / \mathrm{K}\right)$

L Comprimento de máscara do canal do dispositivo $(\mu \mathrm{m})$

M Fator de multiplicação da corrente de corpo

n $\quad$ Fator ideal do diodo

$\mathrm{N}_{\mathrm{A}} \quad$ Concentração de dopantes aceitadores na camada de silício $\left(\mathrm{cm}^{3}\right)$

$\mathrm{n}_{\mathrm{i}} \quad$ Concentração intrínseca de portadores $\left(\mathrm{cm}^{-3}\right)$

$\mathrm{q} \quad$ Carga elementar do elétron $\left(\mathrm{q}=1,6 \times 10^{-19} \mathrm{C}\right)$

QDPL Carga de depleção (C) 
QDPLef Carga efetiva total (C)

$\mathrm{Q}_{\text {it }} \quad$ Cargas de armadilhas de interface $\left(\mathrm{C} / \mathrm{cm}^{2}\right)$

Qox Cargas de armadilhas do óxido por unidade de área $\left(\mathrm{C} / \mathrm{cm}^{2}\right)$

$\mathrm{r}_{\mathrm{DS}} \quad$ Resistência de saída entre dreno e fonte $(\Omega)$

$\mathrm{r}_{\mathrm{j}} \quad$ Profundidade da junção de fonte e dreno

$\mathrm{S} \quad$ Inclinação de sublimiar ( $\mathrm{mV} /$ década de corrente)

$\mathrm{t}_{\mathrm{oxb}} \quad$ Espessura da camada de óxido enterrado $(\mu \mathrm{m})$

$\mathrm{t}_{\mathrm{oxf}} \quad$ Espessura da camada de óxido de porta $(\mu \mathrm{m})$

$\mathrm{t}_{\mathrm{Si}} \quad$ Espessura da camada de silício $(\mu \mathrm{m})$

T Temperatura absoluta $(\mathrm{K})$

V Tensão (V)

$\mathrm{V}_{\mathrm{BS}} \quad$ Potencial de substrato (V)

$\mathrm{V}_{\mathrm{D}} \quad$ Potencial de dreno $(\mathrm{V})$

$\mathrm{V}_{\mathrm{DD}}$ Tensão de alimentação do OTA (V)

$\mathrm{V}_{\mathrm{DS}} \quad$ Tensão aplicada ao dreno do transistor (V)

$\mathrm{V}_{\mathrm{ds}} \quad$ Parcela alternada do sinal aplicado ao dreno do transistor (V)

$\mathrm{V}_{\mathrm{EA}}$ Tensão Early (V)

$\mathrm{V}_{\mathrm{G} 0}$ Tensão aplicada na porta igual ao valor da tensão de limiar

$\mathrm{V}_{\mathrm{G} 1}$ Tensão aplicada na porta maior que $\mathrm{V}_{\mathrm{G} 0}$

$\mathrm{V}_{\mathrm{G} 2}$ Tensão aplicada na porta maior que $\mathrm{V}_{\mathrm{G} 1}$

$\mathrm{V}_{\mathrm{G} 3}$ Tensão aplicada na porta maior que $\mathrm{V}_{\mathrm{G} 2}$

$\mathrm{V}_{\mathrm{G} 4}$ Tensão aplicada na porta maior que $\mathrm{V}_{\mathrm{G} 3}$

$\mathrm{V}_{\mathrm{G}} \quad$ Potencial de porta $(\mathrm{V})$

$\mathrm{V}_{\mathrm{GB}} \quad$ Tensão de substrato $(\mathrm{V})$

$\mathrm{V}_{\mathrm{GS}}$ Tensão aplicada à porta do transistor (V)

$\mathrm{V}_{\mathrm{gs}} \quad$ Parcela alternada do sinal aplicada à porta do transistor (V)

$\mathrm{V}_{\mathrm{GT}}$ Tensão de "overdrive"

$\mathrm{V}_{\mathrm{TH} 0}$ Tensão de Limiar com o substrato polarizado em zero volts (V)

$\mathrm{V}_{\mathrm{TH} 1}$ Tensão de Limiar do DTMOS (V)

$\mathrm{V}_{\mathrm{TH}} \quad$ Tensão de limiar (V)

$\mathrm{X}_{\mathrm{dmax}} \quad$ Largura máxima da região de depleção $(\mu \mathrm{m})$

$\mathrm{X}_{\mathrm{dmax} 1}$ Largura máxima da região de depleção em dispositivos SOI próxima da depleção total $(\mu \mathrm{m})$ 
W Largura do canal $(\mu \mathrm{m})$

$\beta_{\mathrm{F}} \quad$ Ganho de corrente do emissor comum

$\beta_{\mathrm{N}} \quad$ Fator de ganho do transistor NMOS

$\gamma \quad$ Coeficiente do efeito de corpo do transistor

$\partial \quad$ Operador lógico da derivada

$\Delta_{\mathrm{Id}} \quad$ Variação da corrente de dreno (A)

$\Delta_{\mathrm{V} 0} \quad$ Variação da tensão de saída (V)

$\Delta_{\mathrm{V} 1} \quad$ Variação da tensão de entrada $(\mathrm{V})$

$\varepsilon_{\mathrm{ox}} \quad$ Permissividade do óxido $(\mathrm{F} / \mathrm{cm})$

$\varepsilon_{\mathrm{Si}} \quad$ Permissividade do silício $(\mathrm{F} / \mathrm{cm})$

$\theta \quad$ Coeficiente da degradação de mobilidade pelo campo elétrico transversal

$\mu_{0} \quad$ Mobilidade dos elétrons na camada de inversão do canal para campo elétrico transversal baixo $\left(\mathrm{cm}^{2} / \mathrm{V} . \mathrm{s}\right)$

$\mu_{\mathrm{n}} \quad$ Mobilidade dos elétrons na camada de inversão $\left(\mathrm{cm}^{2} / \mathrm{V} . \mathrm{s}\right)$

$\phi_{\mathrm{F}} \quad$ Potencial de Fermi (V)

$\phi_{\mathrm{MS}} \quad$ Diferença da função trabalho entre o metal e o semicondutor (eV) 


\section{ÍNDICE}

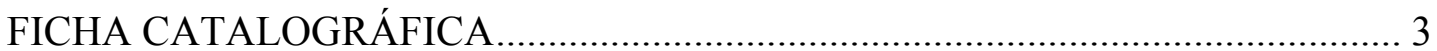

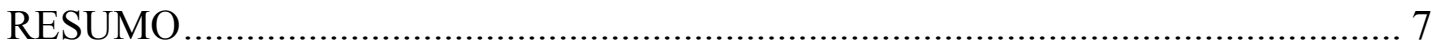

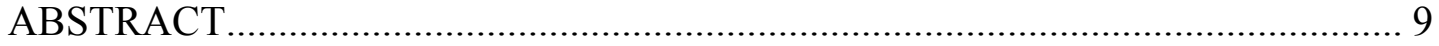

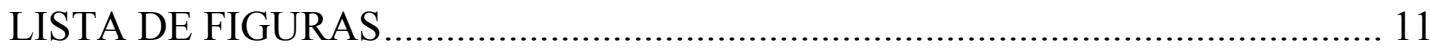

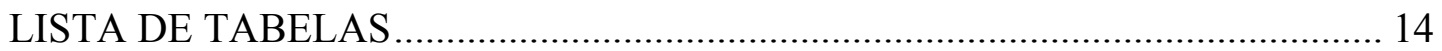

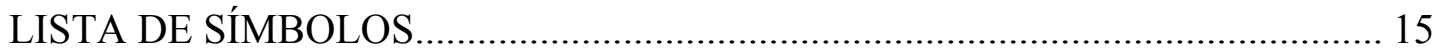

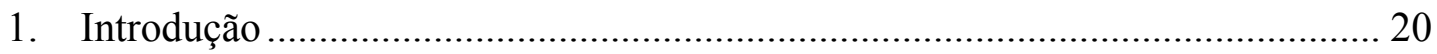

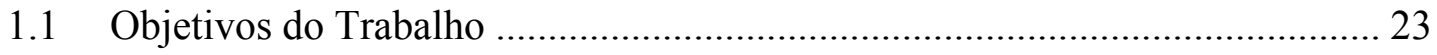

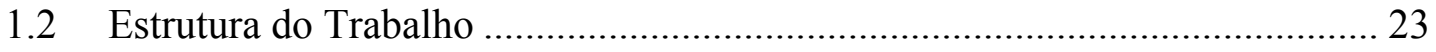

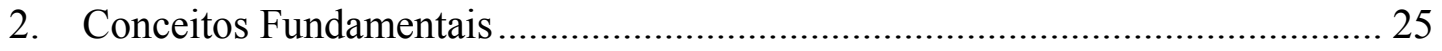

2.1 Características dos Transistores SOI MOSFET ............................................. 25

2.1.1 Estruturas dos dispositivos SOI MOSFET …......................................... 25

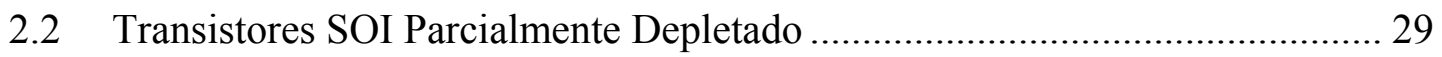

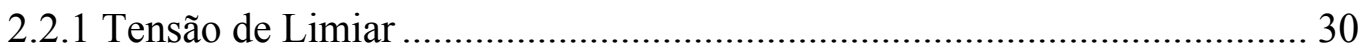

2.2.2 Efeito de Canal Curto ........................................................................... 31

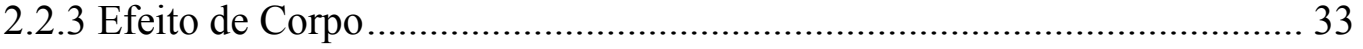

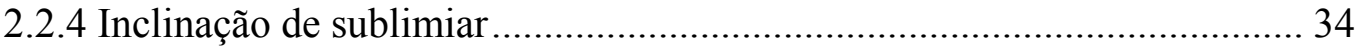

2.2.5 Transcondutância de um nMOSFET ……................................................. 35

2.2.6 Efeito de Elevação Abrupta da Corrente de Dreno .................................... 38

2.2.7 Transistor Bipolar Parasitário ........................................................................ 40

2.2.8 Condutância de Saída $\left(\mathrm{g}_{\mathrm{D}}\right)$ e Tensão Early $\left(\mathrm{V}_{\mathrm{EA}}\right)$.................................... 42

2.2.9 Razão da transcondutância pela corrente de dreno $-\mathrm{g}_{\mathrm{m}} / \mathrm{I}_{\mathrm{DS}}$..................... 43

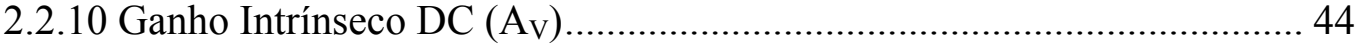

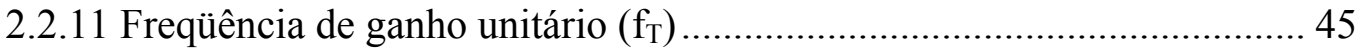

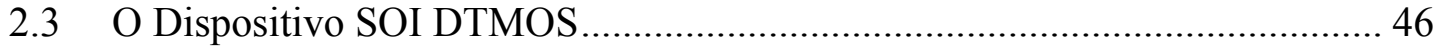

2.3.1 Estrutura do Dispositivo SOI DTMOS ...................................................... 47

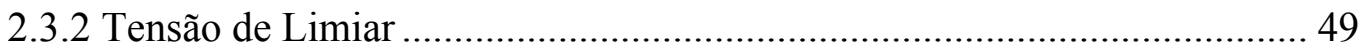

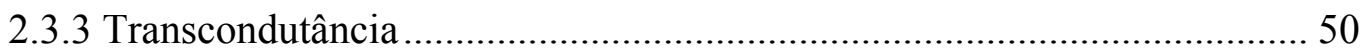

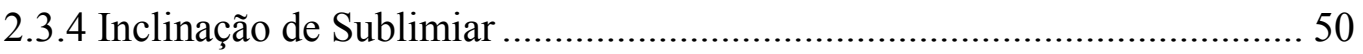

3. Resultados de Simulações Numéricas e Análises................................................ 51

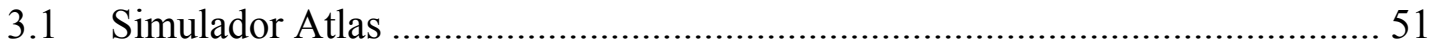

3.1.1 Modelos Físicos Utilizados no Simulador ATLAS ................................. 51 
3.2 Resultados Gerados Através das Simulações ............................................... 52

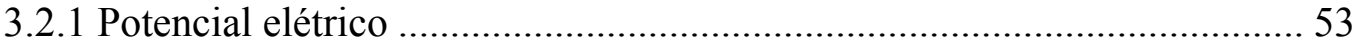

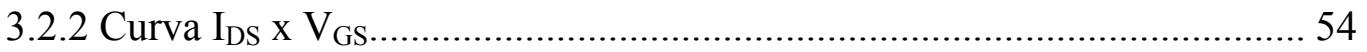

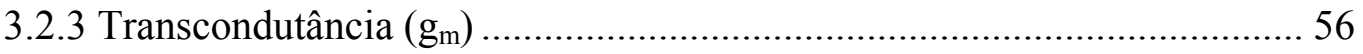

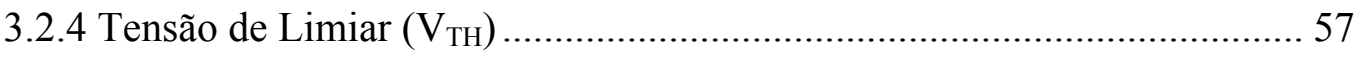

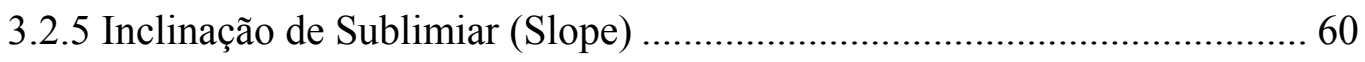

3.2.6 Tensão Early $\left(\mathrm{V}_{\mathrm{EA}}\right)$ e Condutância de Saída $\left(\mathrm{g}_{\mathrm{D}}\right)$...................................... 61

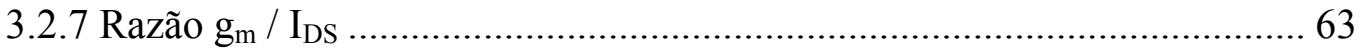

3.2.8 Ganho de Tensão Intrínseco $\left(\mathrm{A}_{\mathrm{V}}\right)$ e freqüência de ganho unitário $\left(\mathrm{f}_{\mathrm{T}}\right) \ldots . . .64$

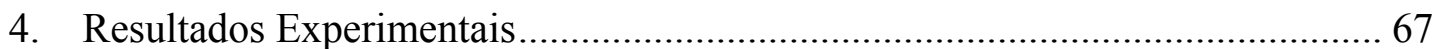

4.1 Resultados considerando a variação do comprimento de canal (L)................. 68

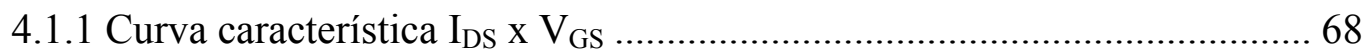

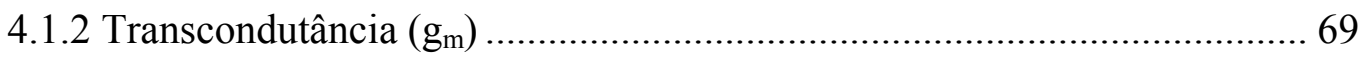

4.1.3 Inclinação de sublimiar (S) ..................................................................... 71

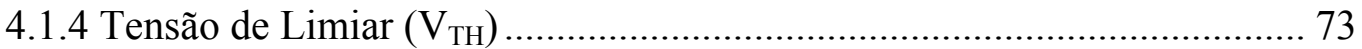

4.1.5 Tensão Early e condutância de saída ........................................................ 74

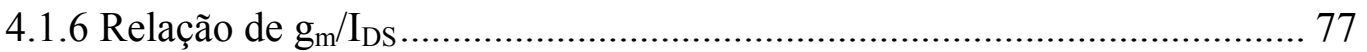

4.1.7 Ganho intrínseco DC $\left(\mathrm{A}_{\mathrm{V}}\right)$ e freqüência de ganho unitário $\left(\mathrm{f}_{\mathrm{T}}\right) \ldots \ldots \ldots \ldots \ldots . . . . .78$

4.2 Resultados obtidos considerando a variação da largura do dispositivo (W) ....... 79

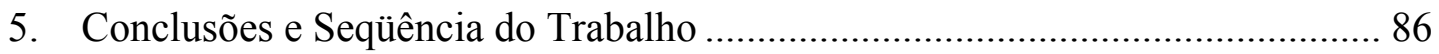

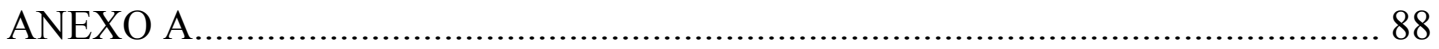

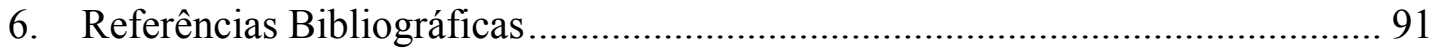




\section{Introdução}

Nas últimas décadas, houve um grande avanço tecnológico na área de microeletrônica motivado pela crescente necessidade de uma maior integração dos circuitos alcançada principalmente pela redução do tamanho dos dispositivos. Com isso, a comunidade científica começou a estudar os diversos efeitos de canal curto [1] que surgiram com o escalamento para dispositivos ultra-submicrométricos [2].

Em busca de uma nova tecnologia que permitisse menores efeitos de canal curto, surge a tecnologia SOI (Silício sobre Isolante) como alternativa na fabricação de circuitos integrados com alta densidade de integração (ULSI - "Ultra Large Scale Integration"), mas, sua utilização em escala industrial foi inviabilizada pelo alto custo para sua produção, e foi somente após diversos estudos que esses custos puderam ser reduzidos, possibilitando assim o uso desta tecnologia em escala industrial para a fabricação de componentes e microprocessadores [3].

Esta tecnologia consiste na fabricação de dispositivos integrados em uma camada de silício (chamada de região ativa do transistor) isolada por uma camada de óxido enterrado. Esse transistor com óxido enterrado possibilitou a diminuição das capacitâncias entre fonte e dreno [4], dos efeitos de canal curto [1], aumento da mobilidade efetiva dos portadores [5], e transcondutância, e proporcionou uma melhora significativa na inclinação de sublimiar, bem como a diminuição da corrente de fuga, quando comparados com o MOSFET convencional.

Na Figura 1.1, pode-se observar o perfil de um transistor SOI nMOSFET onde $\mathrm{t}_{\mathrm{oxf}}$ é a espessura do óxido de porta, $\mathrm{t}_{\mathrm{Si}}$ é a espessura da camada de silício, $\mathrm{t}_{\mathrm{oxb}}$ é a espessura do óxido enterrado, $\mathrm{V}_{\mathrm{GS}}$ indica a tensão aplicada na porta, $\mathrm{V}_{\mathrm{DS}}$, a tensão aplicada no dreno e $\mathrm{V}_{\mathrm{GB}}$, a tensão aplicada no substrato. 


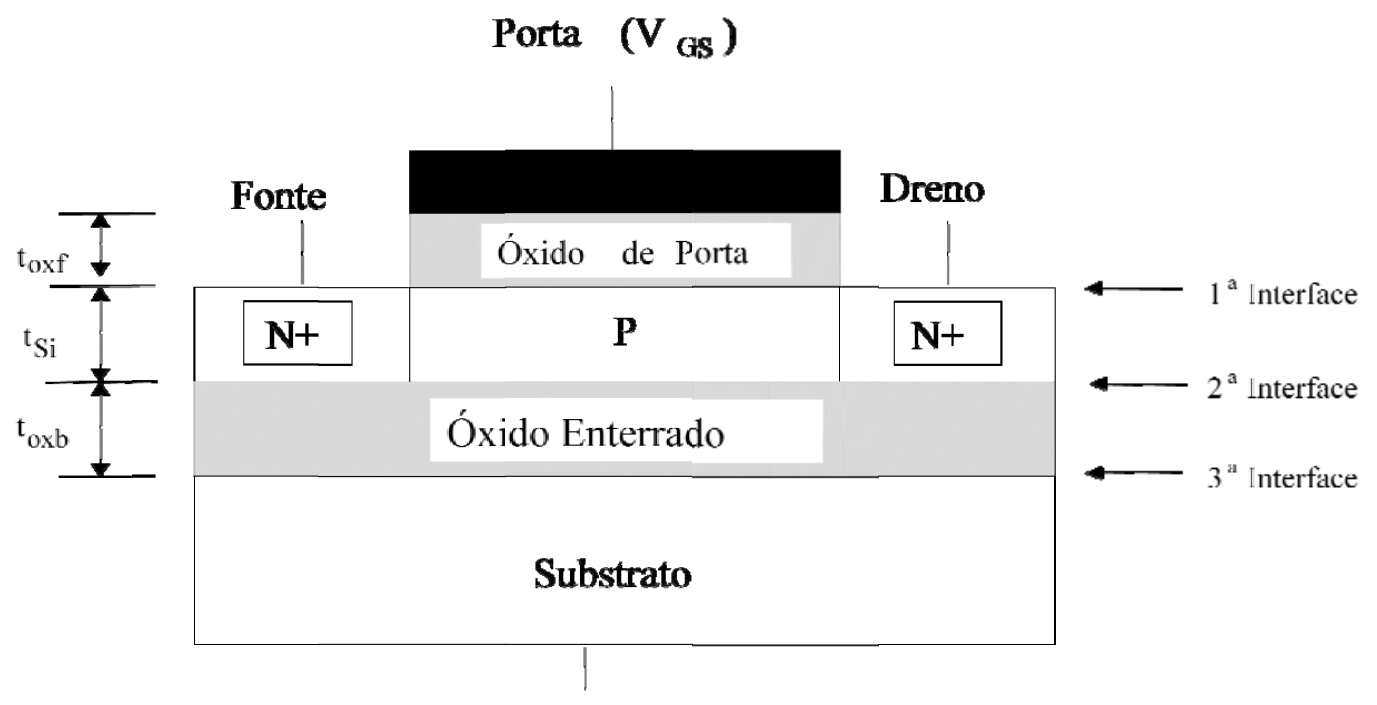

\section{Substrato $\left(\mathrm{V}_{\mathbf{G B}}\right)$}

Figura 1.1: Perfil de um transistor SOI nMOSFET.

Como o dispositivo SOI possui um transistor bipolar parasitário inerente à estrutura, Colinge propôs uma nova topologia para o SOI parcialmente depletado, onde o canal flutuante fosse curto-circuitado com a porta do SOI MOSFET [6].

Inicialmente, esse dispositivo foi denominado de transistor SOI com controle do transistor bipolar VCBMOS ("Voltage-Controlled Bipolar MOS") [7]. Após a proposta de Colinge, outras equipes científicas fabricaram este dispositivo para mais estudos e classificaram-no como um transistor bipolar híbrido (HBMOS - "Hybrid BipolarMOS")[8,9] ou de transistor bipolar lateral controlado pela porta ("Gate controlled lateral BJT") [10]. Após diversos estudos em que se comprovou o aumento de corrente neste dispositivo, a comunidade científica o renomeou novamente, passando a chamá-lo CMOS com múltiplas tensões de limiares (MTCMOS - "Multi- Threshold CMOS" $[11,12])$, transistor MOS com tensão de limiar dinamicamente variável (DTMOS "Dynamic Threshold MOS" [13,14]) ou de transistor MOS com várias tensões de limiares (VTCMOS - "Varied-Threshold MOS" [15]. Esse dispositivo é mais conhecido como DTMOS e está representado na Figura 1.2. 
(A) a

\begin{tabular}{|c|c|c|}
\hline FONTE & DRENO & $b^{\prime}$ \\
\hline $\mathrm{N}+$ & $\mathrm{N}+$ & $\mathrm{P}+$ \\
\hline & & $\begin{array}{l}\text { Contato } \\
\text { Substrato }\end{array}$ \\
\hline
\end{tabular}

b

(B)

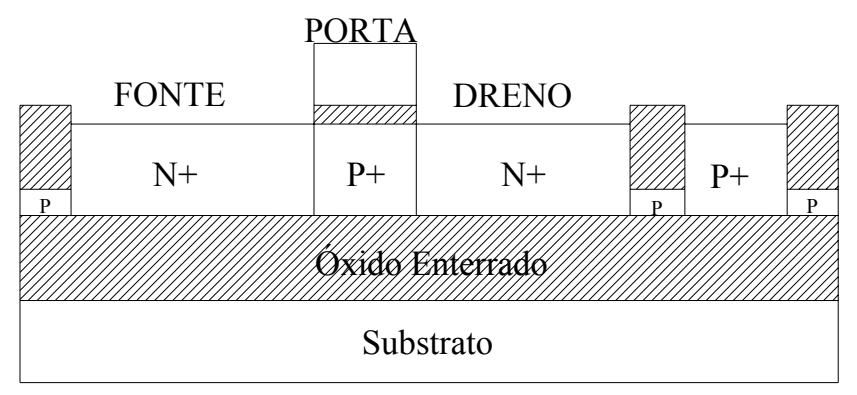

(C)

PORTA
Substrato
P+

Figura 1.2: Desenho esquemático da estrutura do SOI DTMOS com vista superior (A) e seção transversal (B e C).

Devido ao curto-circuito entre o corpo e a porta do dispositivo SOI pelo contato de corpo, pode-se melhorar alguns parâmetros do PDSOI. A inclinação de sublimiar tornou-se próximo do valor teórico ideal $(60 \mathrm{mV} / \mathrm{dec})$, há redução dos efeitos de canal curto, um aumento da corrente de dreno e as características tornam-se ótimas para trabalhar com aplicações em altas freqüências [16] e altas temperaturas [17]. Através deste contato, podemos controlar as cargas na região de depleção. O DTMOS tem sido muito utilizado em aplicações com baixas tensões $(<0,6 \mathrm{~V})[18,19]$. Este dispositivo não pode operar com tensões acima de $0,6 \mathrm{~V}$, pois pode ocorrer a junção direta do diodo formado pela junção fonte/canal. Neste trabalho, é explorada a melhora dos parâmetros 
analógicos quando se trabalha com o DTMOS em comparação com SOI parcialmente depletado.

\subsection{Objetivos do Trabalho}

O presente trabalho tem como objetivo o estudo dos parâmetros analógicos do DTMOS em comparação com o SOI convencional ou parcialmente depletado, dadas as vantagens deste dispositivo para aplicação em circuitos analógicos. O estudo visa a avaliar o desempenho analógico da estrutura DTMOS através do ganho intrínseco DC em malha aberta $\left(A_{V}\right)$ e da freqüência de ganho unitário $\left(f_{T}\right)$.

O estudo será realizado através de simulações numéricas bidimensionais com o simulador ATLAS e, de resultados experimentais, para várias dimensões do dispositivo. No estudo comparativo entre as simulações numéricas bidimensionais e resultados experimentais, serão analisadas as principais características elétricas dos dispositivos, tais como a inclinação de sublimiar $(\mathrm{S})$, tensão de limiar $\left(\mathrm{V}_{\mathrm{TH}}\right)$, transcondutância $\left(\mathrm{g}_{\mathrm{m}}\right)$, tensão Early $\left(\mathrm{V}_{\mathrm{EA}}\right)$, condutância de saída $\left(\mathrm{g}_{\mathrm{D}}\right)$, relação de $\mathrm{g}_{\mathrm{m}} / \mathrm{I}_{\mathrm{DS}}$ em função do fator geométrico (W/L, onde W e L são a largura e o comprimento de canal, respectivamente), o ganho intrínseco $\mathrm{DC}\left(\mathrm{A}_{\mathrm{V}}\right)$ e a freqüência de ganho unitário $\left(\mathrm{f}_{\mathrm{T}}\right)$.

\subsection{Estrutura do Trabalho}

Este trabalho está dividido em 5 capítulos, da seguinte forma:

O capítulo 1 é composto pela introdução e método de trabalho. O capítulo 2 abrange os conceitos básicos teóricos da estrutura SOI convencional, para então poder correlacionar os mesmos com o dispositivo SOI DTMOS. Neste capítulo, são descritos e exemplificados os tipos de estruturas SOI, os regimes de operação e os parâmetros elétricos. Outro ponto importante abordado neste capítulo é o controle do transistor bipolar parasitário inerente à estrutura do dispositivo, uma vez que ele afeta diretamente o funcionamento do DTMOS.

O Capítulo 3 apresenta uma breve introdução ao simulador ATLAS que foi usado para simulações numéricas bidimensionais. Em seguida, são apresentados e analisados os resultados das simulações numéricas. Os parâmetros discutidos neste capítulo são a curva da corrente de dreno $\left(\mathrm{I}_{\mathrm{DS}}\right)$ em função da tensão aplicada na porta 
$\left(\mathrm{V}_{\mathrm{GS}}\right)$ considerando as tensões de dreno fixas em $25 \mathrm{mV}$ e $1 \mathrm{~V}$. Em seguida, obteve-se a tensão de limiar, a inclinação de sublimiar e a transcondutância. Discute-se também a curva da corrente de dreno ( $\left.\mathrm{I}_{\mathrm{DS}}\right)$ em função da tensão de dreno $\left(\mathrm{V}_{\mathrm{DS}}\right)$, a tensão Early $\left(\mathrm{V}_{\mathrm{EA}}\right)$, a condutância de saída $\left(\mathrm{g}_{\mathrm{D}}\right)$, a relação $\mathrm{g}_{\mathrm{m}} / \mathrm{I}_{\mathrm{DS}}$, o ganho intrínseco $\mathrm{DC}\left(\mathrm{A}_{\mathrm{V}}\right)$ e a freqüência de ganho unitário $\left(\mathrm{f}_{\mathrm{T}}\right)$.

O capítulo 4 apresenta na primeira etapa os resultados experimentais nos dispositivos PDSOI e DTMOS para comparação com os resultados obtidos através das simulações numéricas bidimensionais. Em seguida, são apresentados os resultados experimentais realizados na segunda etapa do estudo, onde foi considerado um valor fixo de comprimento de canal $(10 \mu \mathrm{m})$ e variou-se a largura do dispositivo para estudar se ela influencia nos resultados obtidos anteriormente.

E, finalizando, no capítulo 5, são apresentadas as principais conclusões. Também são incorporados neste capítulo, sugestões para a continuidade dos estudos. 


\section{Conceitos Fundamentais}

Neste capítulo, serão apresentados os conceitos básicos do dispositivo SOI MOSFET convencional e do dispositivo SOI DTMOS, juntamente com uma revisão bibliográfica dos parâmetros elétricos fundamentais que estão sendo estudados neste trabalho.

\subsection{Características dos Transistores SOI MOSFET}

O dispositivo SOI MOSFET caracteriza-se por uma camada de silício (região ativa) isolada do substrato por uma camada espessa de óxido enterrado. Desta forma, as capacitâncias de fonte e dreno são substancialmente menores, o que viabilizou a fabricação de circuitos integrados pequenos, densos e rápidos quando comparados a tecnologias anteriores. A seguir, será descrito os tipos de estruturas SOI.

\subsubsection{Estruturas dos dispositivos SOI MOSFET}

O comportamento elétrico do transistor SOI MOSFET depende fortemente da espessura da camada de silício $\left(t_{\mathrm{Si}}\right)$ e da concentração de dopantes do canal. $\mathrm{O}$ dispositivo que possui uma camada espessa de silício que nunca fica totalmente depletada é conhecido como "dispositivo parcialmente depletado" (PD - "Partially Depleted") e o dispositivo que possui uma camada fina de silício, que fica totalmente depletada quando se aplica na porta a tensão de limiar como "totalmente depletado" (FD - "Fully Depleted"). Há ainda uma terceira estrutura que possui uma camada de silício com espessura intermediária que, dependendo das polarizações aplicadas na porta e no substrato, pode trabalhar tanto parcialmente depletada quanto totalmente depletada, que pode ser chamado de quase totalmente depletada (NFD - "Near Fully Depleated") $[20,21]$.

Em dispositivos MOS convencionais, na interface entre $\mathrm{Si}_{-} \mathrm{SiO}_{2}$, tem-se o crescimento da região de depleção até um ponto máximo $\left(\mathrm{x}_{\mathrm{dmax}}\right)$, que pode ser calculada através das equações (2.1 e 2.2): 


$$
\begin{gathered}
x_{d \max }=\sqrt{\frac{2 \varepsilon_{S i} \cdot 2 \phi_{F}}{q \cdot N_{a f}}} \\
\phi_{F}=\frac{k T}{q} \cdot \ln \left(\frac{N_{a f}}{n i}\right)
\end{gathered}
$$

onde $\varepsilon_{\mathrm{Si}}$ é a permissividade do Silício, q é a carga elementar do elétron, $\mathrm{N}_{\mathrm{af}}$ é a concentração de portadores na camada de silício, k é a constante de Boltzmann, T é a temperatura absoluta, ni é a concentração intrínseca de portadores e $\phi_{\mathrm{F}}$ é o potencial de Fermi.

O transistor SOI parcialmente depletado tem a espessura da camada de silício $\left(\mathrm{t}_{\mathrm{Si}}\right)$ maior que o dobro da máxima largura da região de depleção. Desta forma, não existe uma interação entre a região de depleção proveniente da primeira interface e da segunda interface do dispositivo. O espaço entre as duas regiões de depleção é chamado de região neutra ou corpo flutuante. Se nesse corpo flutuante existir um contato elétrico aterrado, o transistor passa a operar de forma semelhante ao dispositivo MOSFET convencional. Se o contato de corpo não estiver aterrado, o dispositivo SOI parcialmente depletado começa a sofrer alguns efeitos parasitários decorrente dos efeitos do corpo flutuante, como a elevação abrupta da corrente - o efeito kink [22, 23] - e a ocorrência de elétrons quentes, além da influência do transistor bipolar parasitário inerente à estrutura [22].

Já nos dispositivos totalmente depletado, a camada de silício $\left(t_{\mathrm{Si}}\right)$ é inferior à máxima largura da região de depleção. Dessa forma, a camada de silício fica totalmente depletada quando a tensão na porta atinge a tensão de limiar, independentemente da polarização da segunda interface. Esse dispositivo é totalmente livre dos efeitos parasitários provenientes do corpo flutuante. Se permitíssemos que a segunda interface fique também depletada, podemos ter mais algumas vantagens, como baixo campo elétrico, alta transcondutância $\left(g_{m}\right)$, menor inclinação de sublimiar e menor efeitos de canal curto [20].

Já o dispositivo com espessura de silício intermediária pode se comportar como parcialmente depletado ou totalmente depletado, dependendo da polarização aplicada no substrato $\mathrm{V}_{\mathrm{GB}}$. Neste caso $\mathrm{x}_{\mathrm{dmax}}<\mathrm{t}_{\mathrm{Si}}<2 \mathrm{x}_{\mathrm{dmax}}$. Se a segunda interface estiver em acumulação, não há interações entre as regiões de depleção da primeira e da segunda 
interface, fazendo com que o dispositivo opere de forma parcialmente depletada. Entretanto, se as regiões de depleção da primeira e da segunda interface se sobrepulhem, devido à polarização do substrato, o dispositivo passa a operar como um dispositivo totalmente depletado [21].

O diagrama de bandas de energia que é exibido na Figura 2.1 mostra as diferenças entre o dispositivo nMOSFET convencional (A), SOI parcialmente depletado (B) e totalmente depletado (C).

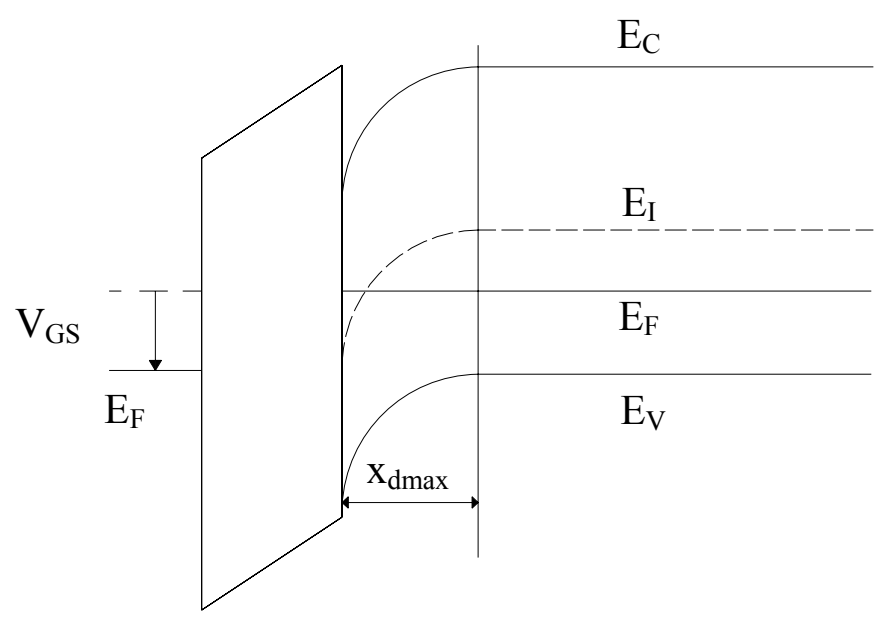

(A)

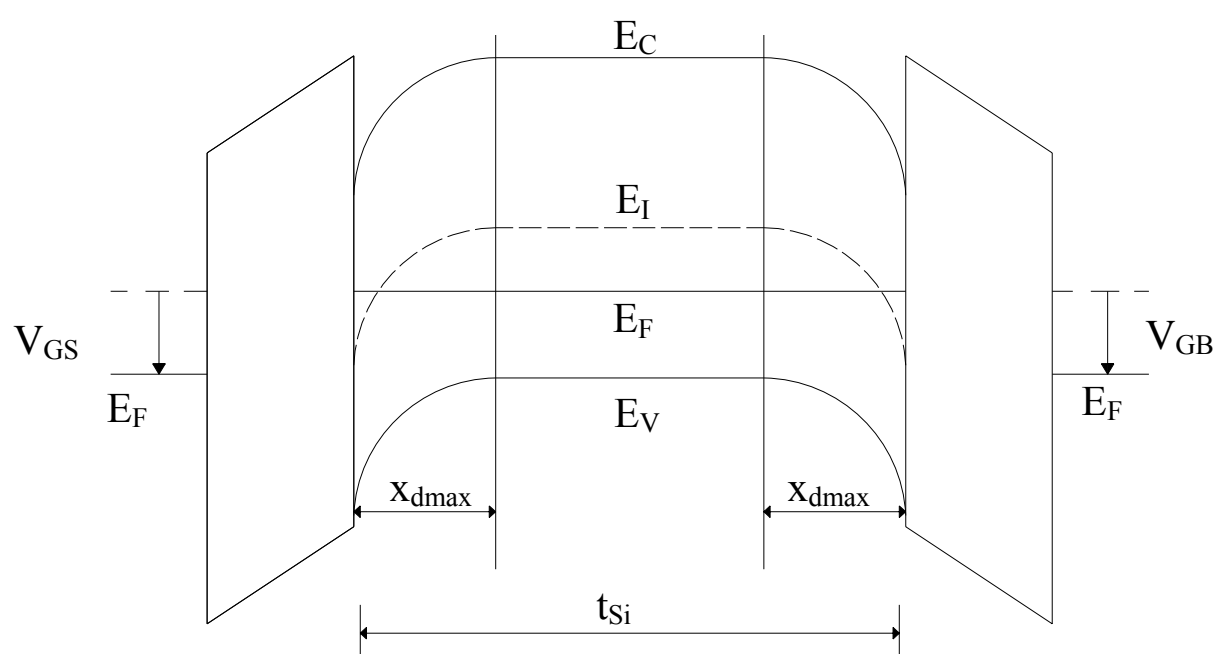

(B) 


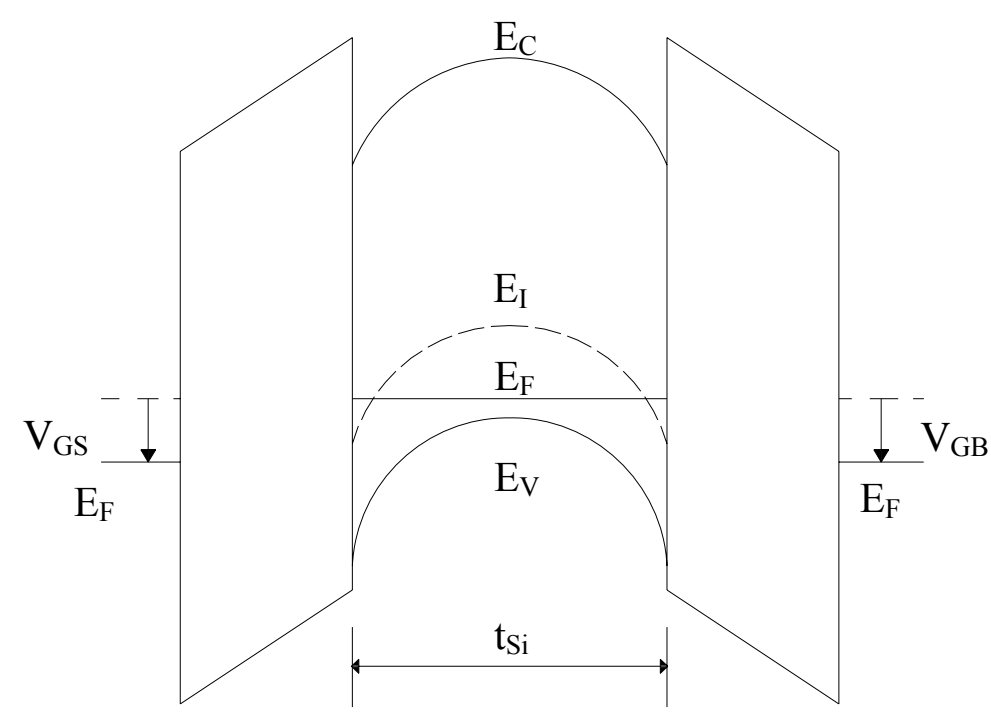

(C)

Figura 2.1: Diagrama de Bandas de Energia de dispositivos MOS convencional (A), SOI de camada espessa (B) e SOI de camada fina (C).

Onde $\mathrm{E}_{\mathrm{C}}$ é o nível energético do extremo inferior da Faixa de Condução, $\mathrm{E}_{\mathrm{F}}$ é o nível de Fermi da camada de silício, $\mathrm{E}_{\mathrm{i}}$ é o nível intrínseco, $\mathrm{E}_{\mathrm{v}}$ é o nível energético do extremo superior da Faixa de Valência e $t_{\mathrm{Si}}$ é a espessura da camada de silício.

Considerando as polarizações aplicadas na porta $\left(\mathrm{V}_{\mathrm{GS}}\right)$ e no substrato $\left(\mathrm{V}_{\mathrm{GB}}\right)$, as condições da primeira e da segunda interface podem estar em acumulação, depleção ou inversão. Existem, portanto, nove modos de operações para o transistor totalmente depletado, como exemplificado na Figura 2.2. A região hachurada representa as operações mais comuns. 


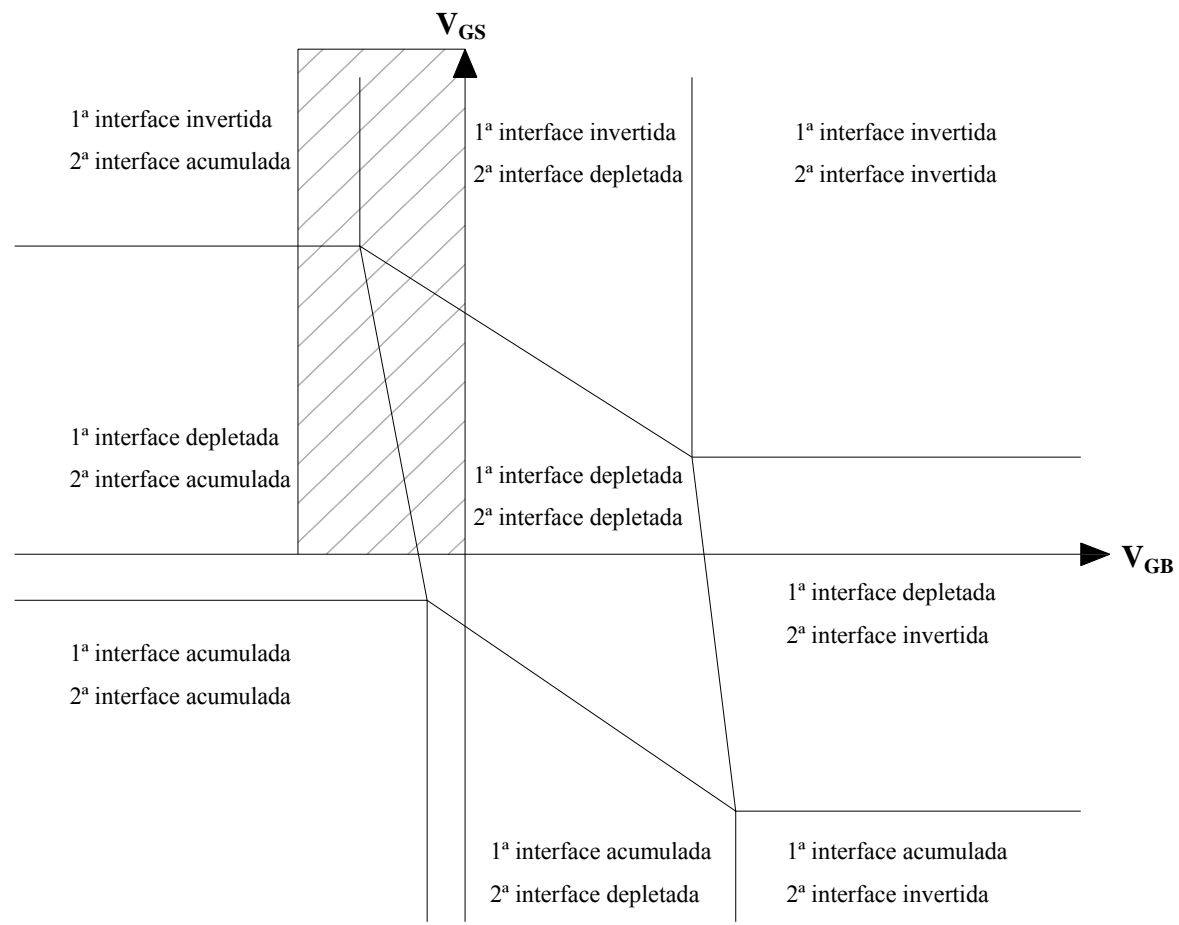

Figura 2.2: Modos de operação do transistor SOI nMOSFET considerando as tensões aplicadas em $\mathrm{V}_{\mathrm{GS}}$ e $\mathrm{V}_{\mathrm{GB}}$, com baixa tensão no dreno. A região hachurada representa os modos de operação mais comum [20].

\subsection{Transistores SOI Parcialmente Depletado}

A partir daqui é dada ênfase aos transistores SOI parcialmente depletados, pois este trabalho tem como foco principal comparar os parâmetros analógicos do DTMOS com os do SOI com o corpo aterrado. O DTMOS é um dispositivo SOI parcialmente depletado que possui um contato de corpo que está curto-circuitado com a porta do dispositivo. 


\subsubsection{Tensão de Limiar}

A tensão de limiar $\left(\mathrm{V}_{\mathrm{TH}}\right)$ de um transistor nMOSFET convencional é dada pela equação (2.3):

$$
V_{T H}=\phi_{M S}-\frac{Q_{o x}}{C_{o x}}+2 \cdot \phi_{F}+\frac{q \cdot N_{A} \cdot x_{d \max }}{C_{o x}}
$$

onde, $\phi_{\mathrm{MS}}$ é a diferença de função trabalho entre o metal e o semicondutor, $\mathrm{Q}_{\mathrm{ox}}$ é a carga efetiva no óxido de porta, $\mathrm{C}_{\mathrm{ox}}$ é a capacitância do óxido por unidade de área, $\Phi_{\mathrm{F}}$ é o potencial de Fermi, q é a carga elementar do elétron, $\mathrm{N}_{\mathrm{A}}$ é a concentração do substrato, $\mathrm{x}_{\mathrm{dmax}}$ é a largura máxima de depleção e $\varepsilon_{\mathrm{si}}$ é a permissividade do silício.

A tensão de limiar em transistor MOSFET pode ser determinada experimentalmente através da curva $\mathrm{I}_{\mathrm{DS}} \mathrm{x} \mathrm{V}_{\mathrm{GS}}$. Se consideramos a região de triodo, temos a seguinte equação (2.4) [24]:

$$
I_{D S}=\beta_{N} \cdot\left[\left(V_{G S}-V_{T H}\right) V_{D S}-\frac{V_{D S}^{2}}{2}\right]
$$

Matematicamente, se colocarmos o termo $\mathrm{V}_{\mathrm{DS}}$ em evidência, temos:

$$
I_{D S}=\beta_{N} \cdot V_{D S}\left[\left(V_{G S}-V_{T H}\right)-\frac{V_{D S}}{2}\right]
$$

Desta forma, a curva característica de $\mathrm{I}_{\mathrm{DS}} \mathrm{x} \mathrm{V}_{\mathrm{GS}}$ terá um coeficiente angular $\beta_{\mathrm{N}} \cdot \mathrm{V}_{\mathrm{DS}}$ na região linear (triodo) que interceptará o eixo $\mathrm{V}_{\mathrm{GS}}$ quando a corrente $\mathrm{I}_{\mathrm{DS}}=0$, como segue:

$$
\begin{gathered}
\beta_{N} \cdot V_{D S}\left[\left(V_{G S}-V_{T H}\right)-\frac{V_{D S}}{2}\right]=0 \\
V_{G S}=V_{T H}+\frac{V_{D S}}{2}
\end{gathered}
$$


Isolando-se $\mathrm{V}_{\mathrm{TH}}$, temos a equação (2.8)

$$
V_{T H}=V_{G S}-\frac{V_{D S}}{2}
$$

Outra forma de calcularmos o $\mathrm{V}_{\mathrm{TH}}$ eficientemente é através do pico máximo da segunda derivada da curva da corrente de dreno $\left(\mathrm{I}_{\mathrm{DS}}\right)$ na região de saturação em função de $\mathrm{V}_{\mathrm{GS}}$, considerando baixos valores para $\mathrm{V}_{\mathrm{DS}}(<100 \mathrm{mV})$ [25].

Em dispositivo SOI parcialmente depletado, como não há interação entre as zonas de depleção, porque $t_{\mathrm{Si}}>\left(2 \cdot \mathrm{x}_{\mathrm{dmax}}\right)$, a tensão de limiar pode ser dada pela mesma equação do transistor MOS convencional.

\subsubsection{Efeito de Canal Curto}

Com a redução dos dispositivos, é necessário reduzir o comprimento de canal (L) e, quando isso é feito, surgem diversos efeitos indesejáveis nas características elétricas dos dispositivos que são conhecidos como efeito de canal curto [1]. A redução do canal causa a perda do controle das cargas na região de depleção ( $\left.Q_{D P L}\right)$ que ficam abaixo da porta. Se considerarmos a equação da tensão de limiar $\left(\mathrm{V}_{\mathrm{TH}}\right)$ (ver seção 2.2.1), não é possível observar este efeito. Isto ocorre porque o efeito de canal curto interfere de forma indireta na carga efetiva total (QDPLef) [20].

Como efeito de canal curto, pode-se observar uma degradação na inclinação de sublimiar e redução da tensão de limiar, entre outros efeitos. Isso ocorre devido a uma invasão das linhas de campo elétrico que vêm do dreno na região do canal, que competem pela carga de depleção disponível [20].

Em dispositivos com comprimentos de canal longo, a carga de depleção (QDEPL) no canal é formada por uma região de forma trapezoidal, onde a base menor e a base maior são praticamente do mesmo comprimento do canal, como representado na Figura 2.3 A. Já em dispositivos de canal curto, a base maior é idêntica ao comprimento do canal, porém a base menor praticamente desaparece, passando a ter a forma de um triângulo, conforme ilustrado na Figura 2.3 B [20]. Conforme há a diminuição do comprimento do canal, tem-se a redução do controle das cargas com a polarização da 
porta. Desta forma, temos que, $\mathrm{Q}_{\mathrm{DPLef}}<\mathrm{Q}_{\mathrm{DPL}}$, implicando que $\mathrm{V}_{\mathrm{TH}}\left(\mathrm{Q}_{\mathrm{DPLef}}\right)<\mathrm{V}_{\mathrm{TH}}$ $\left(\mathrm{Q}_{\mathrm{DPL}}\right)[20]$.

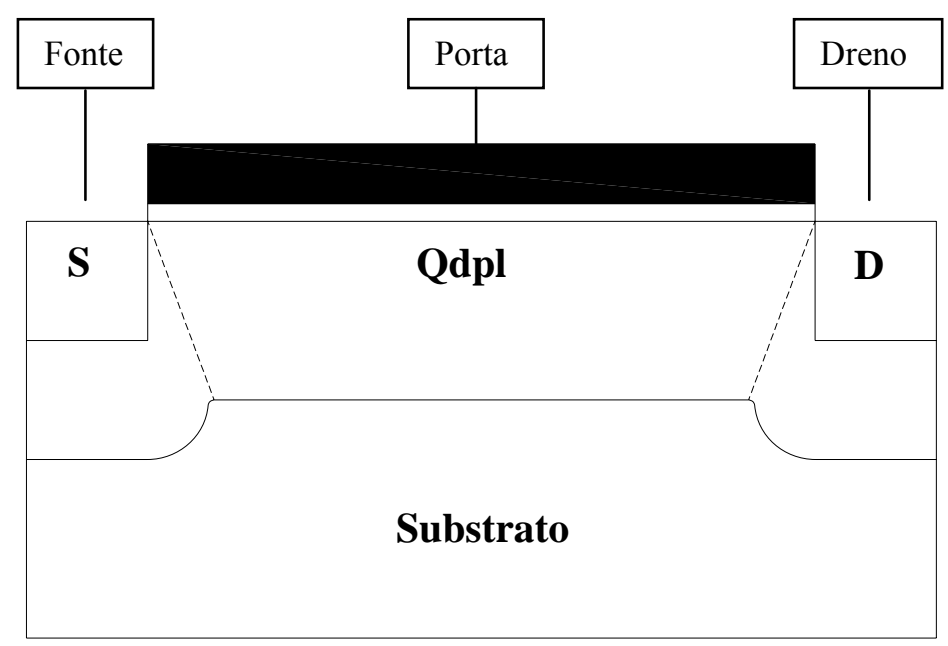

(A)

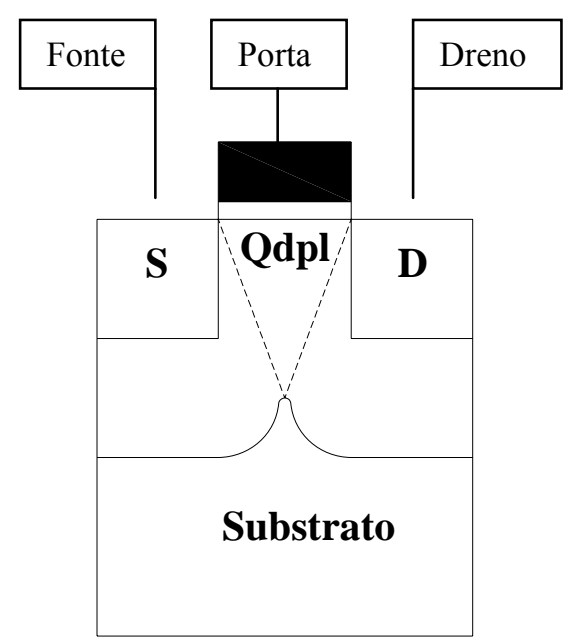

(B)

Figura 2.3: Distribuição das cargas de depleção em dispositivos MOSFET convencionais de canal longo (A) e de canal curto (B) [20].

A carga de depleção em canal longo é dada pela equação (2.9).

$$
Q_{D P L}=q N_{A} x_{d \max }
$$

Em dispositivos MOS parcialmente depletado de canal curto, podemos aproximar o valor de QDPLef através da equação (2.10), onde $r_{j}$ é a profundidade da junção de fonte e dreno.

$$
Q_{\text {DPLef }}=Q_{D P L}\left(1-\frac{r_{j}}{L}\left(\sqrt{1+\frac{2 \cdot x_{d \max }}{r_{j}}}-1\right)\right)
$$


No transistor SOI MOSFET convencional, o efeito de canal curto é semelhante ao observado no dispositivo MOS convencional, uma vez que o mesmo possui uma camada de silício $\left(\mathrm{t}_{\mathrm{Si}}\right)$ superior a $2 \cdot \mathrm{x}_{\mathrm{dmax}}[20]$.

\subsubsection{Efeito de Corpo}

O efeito de corpo no transistor MOS convencional é caracterizado pela dependência da tensão de limiar com a polarização do substrato [( $\left.\mathrm{V}_{\mathrm{TH}}\left(\mathrm{V}_{\mathrm{BS}}\right)\right]$ [24]. No dispositivo SOI MOS, o efeito de corpo pode ser definido como a dependência da tensão de limiar com a polarização da segunda interface $\mathrm{Si}_{-} \mathrm{SiO}_{2}[20]$.

Como descrito anteriormente, o SOI parcialmente depletado funciona da mesma forma que o transistor MOSFET convencional. Sendo assim, reapresentando a equação (2.3) já considerando a profundidade da região de depleção $\left(\mathrm{x}_{\mathrm{dmax}}\right)$ como função da polarização do substrato $\left(\mathrm{V}_{\mathrm{BS}}\right)$, tem-se:

$$
V_{T H}=\phi_{M S}-\frac{Q_{o x}}{C_{o x}}+2 . \phi_{F}+\frac{\sqrt{2 \cdot \varepsilon_{s i} \cdot q \cdot N_{A}\left(2 \phi_{F}-V_{B S}\right)}}{C_{o x}}
$$

Colocando em evidência o termo constante, obtemos o $\gamma$, como descrito abaixo:

$$
\gamma=\frac{\sqrt{2 \cdot \varepsilon_{s i} \cdot q \cdot N_{A}}}{C_{o x}}
$$

Reescrevendo a equação, obtemos a equação (2.13):

$$
V_{T H}=\phi_{M S}-\frac{Q_{o x}}{C_{o x}}+2 . \phi_{F}+\gamma \sqrt{2 \phi_{F}}+\gamma\left(\sqrt{\left(2 \phi_{F}-V_{B S}\right)}-\sqrt{\left(2 \phi_{F}\right)}\right.
$$

Escrevendo a equação de outra forma, considerando a polarização do substrato, temos:

$$
V_{T H}\left(V_{B S}\right)=V_{T H 0}+\gamma\left(\sqrt{2 \cdot \phi_{F}-V_{B S}}-\sqrt{2 \cdot \phi_{F}}\right)
$$


Se este contato de corpo do SOI convencional estiver aterrado, o dispositivo se comportará da mesma forma que o MOSFET convencional. Na condição em que o corpo esteja flutuante, o potencial de corpo é determinado pela corrente da junção PN entre fonte/canal e dreno/canal, bem como pelos efeitos capacitivos. Isso faz com que o dispositivo SOI parcialmente depletado comece a sofrer os efeitos de corpo flutuante, como a elevação abrupta da corrente de dreno, também chamado de "kink effect" [22], que é apresentado no item 2.2.6. Se aplicarmos somente a polarização reversa no substrato, sem que o corpo esteja aterrado, a tensão de limiar não varia porque não há acoplamento entre a região de depleção da segunda interface com a primeira [20].

\subsubsection{Inclinação de sublimiar}

A inclinação de sublimiar (S) é dada pelo inverso da variação do log da corrente $\mathrm{I}_{\mathrm{DS}}$ em função da tensão aplicada na porta $\left(\mathrm{V}_{\mathrm{GS}}\right)$. A corrente de sublimiar é independente da tensão aplicado no dreno porque, nessa condição, a corrente $\mathrm{I}_{\mathrm{DS}}$ depende exponencialmente da tensão aplicada à porta $\left(\mathrm{V}_{\mathrm{GS}}\right)$. Considerando o gráfico mono logarítmico da corrente $\left(\mathrm{I}_{\mathrm{DS}}\right)$ em função da tensão aplicada na porta $\left(\mathrm{V}_{\mathrm{GS}}\right)$ mostrado na Figura 2.4, obtemos o valor da inclinação de sublimiar (S) através do inverso do coeficiente angular [24], como mostrado na equação (2.15).

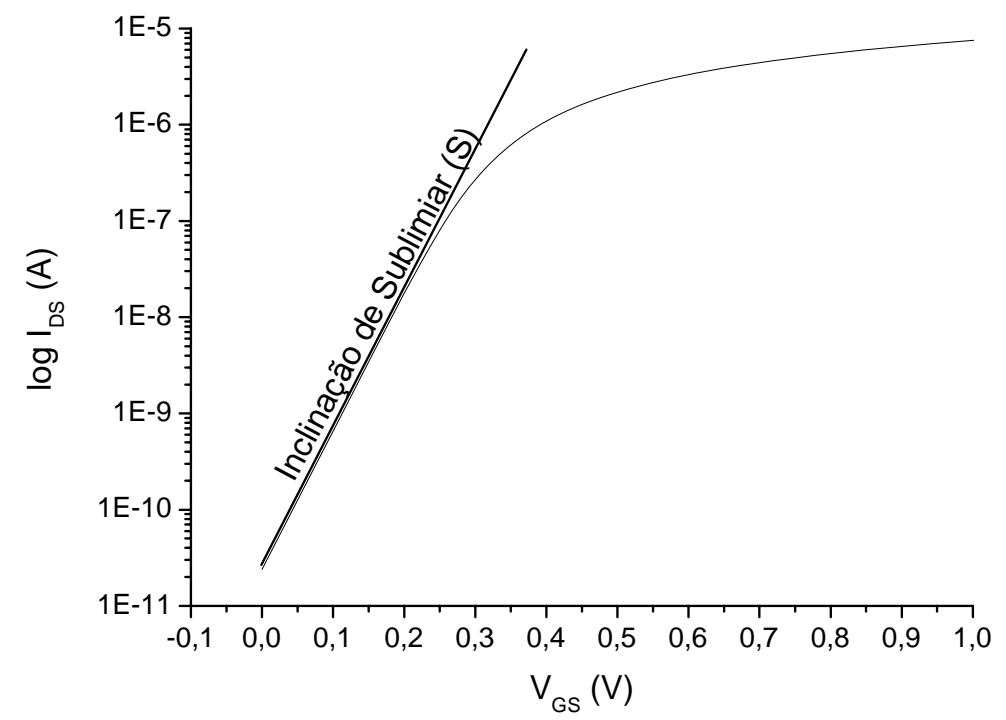

Figura 2.4: Gráfico mono logaritmo da corrente $\mathrm{I}_{\mathrm{DS}} \mathrm{x} \mathrm{V}_{\mathrm{GS}}$, indicando a inclinação de sublmiar (S). 


$$
S=\frac{\partial V_{G S}}{\partial\left(\log I_{D S}\right)}(m V / d e c)
$$

No caso do dispositivo SOI parcialmente depletado, tal como no transistor MOS convencional, se utilizarmos a equação da corrente na região de sublimiar, com algumas simplificações obtemos que a inclinação de sublimiar (S) [20] é igual à:

$$
S=\frac{k T}{q} \cdot \ln (10)\left(1+\frac{C_{D}+C_{i t}}{C_{O X}}\right)
$$

Onde, $C_{D}$ é a capacitância da região de depleção e $C_{i t}$ é a capacitância das armadilhas de interface, $\mathrm{k}$ é a constante de Boltzman, q é a carga elementar do elétron e $\mathrm{T}$ é a temperatura. Se desconsiderarmos as armadilhas de interface, reescrevemos a equação (2.16) [24] como segue:

$$
S=\frac{k T}{q} \cdot \ln (10)\left(1+\frac{C_{D}}{C_{O X}}\right)
$$

\subsubsection{Transcondutância de um nMOSFET}

A transcondutância $\left(\mathrm{g}_{\mathrm{m}}\right)$ é a medida da eficácia do controle da corrente de dreno pela tensão na porta $\left(\mathrm{V}_{\mathrm{GS}}\right)$. Considerando a curva característica $\mathrm{I}_{\mathrm{DS}}$ versus $\mathrm{V}_{\mathrm{GS}}$ para valores de $V_{D S}$ baixo, no mesmo molde para a obtenção de $V_{T H}$, conseguimos extrair $g_{m}$ através da derivada da equação de corrente na região de triodo descrito na equação (2.18) em função de $\mathrm{V}_{\mathrm{GS}}$ :

$$
I_{D S}=\mu_{n} \cdot C_{o x} \cdot \frac{W}{L} \cdot\left[\left(V_{G S}-V_{T H}\right) V_{D S}-\frac{V_{D S}^{2}}{2}\right]
$$

Obtendo assim a equação (2.19):

$$
g_{m}=\mu_{n} \cdot C_{o x} \cdot V_{D S} \cdot \frac{W}{L}
$$


Para saber o valor máximo de transcondutância $\left(g_{m \text { max }}\right)$, isolamos $\mu_{\mathrm{n}}$ para obter a equação (2.20):

$$
\mu_{n}=\frac{g_{m}}{C_{o x} \cdot V_{D S}} \cdot \frac{L}{W}
$$

Então, através da equação (2.20), podemos estabelecer uma relação linear entre a mobilidade e a transcondutância. Considerando que a tensão aplicada no dreno é pequena, do mesmo modo que $\mathrm{V}_{\mathrm{GS}}$ na região linear, o valor da mobilidade terá uma independência dos efeitos do campo elétrico tanto vertical quanto horizontal, e atingirá o seu valor máximo que é o mesmo valor da transcondutância máxima $\left(g_{m_{\max }}\right)$ [24]. A Figura 2.5 mostra a curva de transcondutância $\left(g_{m}\right)$ em função da tensão aplicada na porta $\left(\mathrm{V}_{\mathrm{GS}}\right)$

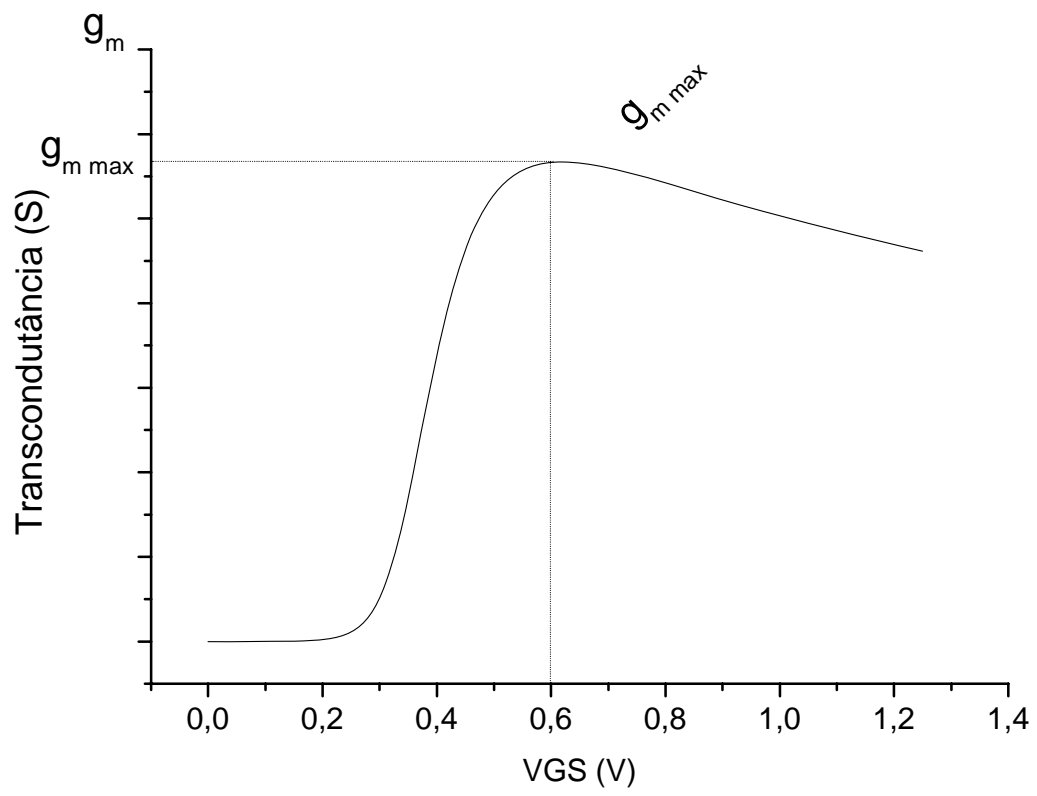

Figura 2.5: Curva de transcondutância $\left(\mathrm{g}_{\mathrm{m}}\right)$ em função da tensão aplicada na porta $\left(\mathrm{V}_{\mathrm{GS}}\right)$ com baixo valor de $\mathrm{V}_{\mathrm{DS}}[24]$. 
Em dispositivos MOS convencional e em dispositivos SOI parcialmente depletados, a transcondutância na região de triodo é obtida da mesma forma. Porém, na região de saturação, temos que $\mathrm{V}_{\mathrm{DS}}>\mathrm{V}_{\mathrm{GS}}-\mathrm{V}_{\mathrm{TH}}$. Como a camada de inversão é menor que a extensão entre fonte/dreno e o campo elétrico horizontal é extremamente grande, os portadores minoritários que são lançados para o dreno através do alto potencial, atingem sua velocidade limite e a corrente passa a ser constante [20]. Portanto, se considerarmos a equação da corrente na região de saturação (2.21) e realizarmos a derivada da mesma em função da tensão aplicada na porta (2.22), obtêm-se a equação (2.23):

$$
\begin{gathered}
I_{D S}=\mu_{n} \cdot C_{o x} \cdot \frac{W}{L} \cdot\left[\left(V_{G S}-V_{T H}\right)^{2}\right] \\
g_{m}=\frac{\partial I_{D s a t}}{\partial V_{G S}}
\end{gathered}
$$

Fazendo as devidas operações matemáticas, e já considerando a relação de capacitâncias, obtemos a equação 2.23 :

$$
g_{m}=\frac{\mu_{n} \cdot C_{o x}}{(1+\alpha)} \cdot \frac{W}{L} \cdot\left(V_{G S}-V_{T H}\right)
$$

$$
\text { Onde } \alpha=\frac{\varepsilon_{s i}}{x_{d \max } \cdot C_{o x}}
$$

Se analisarmos a região de saturação em dispositivos SOI totalmente depletado, $o \alpha$ é a relação $C_{B} / C_{o x}$, sendo $C_{B}$ a capacitância entre a primeira interface e o contato do substrato que está aterrado, e $\mathrm{C}_{\mathrm{ox}}$, a capacitância do óxido de porta. Já nos dispositivos MOSFET e SOI parcialmente depletado, desde que o mesmo esteja com o substrato aterrado, $C_{B}$ é a mesma capacitância da região de depleção $\left(C_{D}\right)$ descrita na equação (2.25) [20]: 


$$
C_{D}=\frac{\varepsilon_{s i}}{x_{d \max }}
$$

\subsubsection{Efeito de Elevação Abrupta da Corrente de Dreno}

Alguns dos efeitos parasitários que ocorrem em transistores SOI convencional são devidos à ionização por impacto e ao alto campo elétrico próximo a região do dreno [26]. Entre eles, podemos destacar o efeito de elevação abrupta da corrente de dreno (kink effect) [22]. Existem também outros efeitos como a degradação da mobilidade por portadores (elétrons) quentes (hot-electrons) [23].

O efeito de elevação abrupta da corrente de dreno, que está representado na Figura 2.6 é o salto na corrente de dreno do SOI. Este efeito é usualmente observado em transistores com canal tipo $\mathrm{N}$, e não em transistores que possuem canal tipo P. Este efeito também não é observado em MOSFET, à temperatura ambiente, desde que o contato de substrato esteja aterrado. Porém este efeito pode ser observado em MOSFET quando está operando em baixas temperaturas [27].

Quando a tensão aplicada no dreno é suficientemente alta, os elétrons do canal podem adquirir energia suficiente, devido ao alto campo elétrico próximo à região de dreno, criando assim pares elétrons-lacunas, devido à ionização por impacto. Os elétrons gerados movem-se em direção ao dreno, enquanto as lacunas migram para a região de menor potencial (o corpo). A injeção dessas lacunas no corpo flutuante faz com que aumente o potencial de corpo, diminuindo a tensão de limiar e conseqüentemente causando o aumento da corrente de dreno em função da tensão aplicada ao dreno. Este fenômeno é chamado de "kink effect" [22]. 


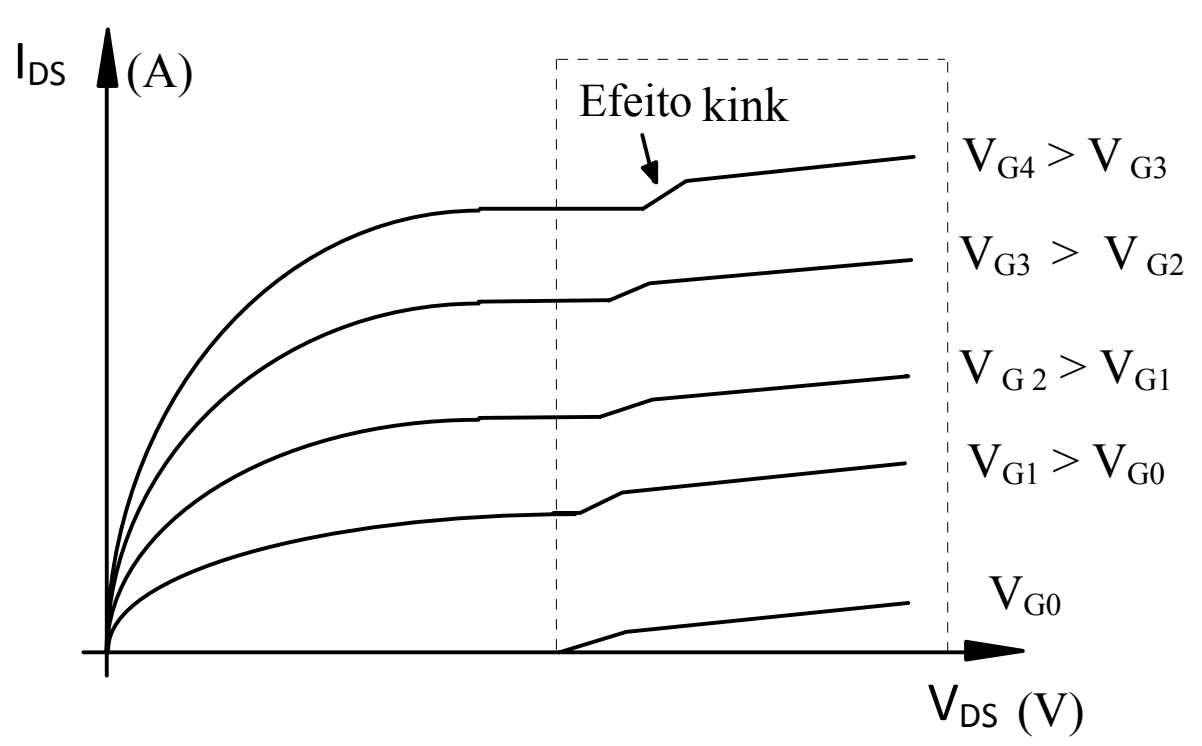

Figura 2.6: Elevação abrupta da corrente de dreno "kink effect" na característica de saída do transistor SOI nMOSFET [20].

Este efeito pode ser calculado a partir da equação (2.26):

$$
I_{l a c}=I_{S a t}\left[\exp \left(\frac{q \cdot V_{B S}}{n \cdot k \cdot T}\right)-1\right]
$$

Onde, $\mathrm{I}_{\text {lac }}$ é a corrente de lacunas geradas próximo ao dreno, $\mathrm{I}_{\text {Sat }}$ é a corrente de saturação do diodo formado na junção P-N entre a fonte e o substrato, $\mathrm{V}_{\mathrm{BS}}$ é o potencial de substrato e $\mathrm{n}$ é o fator de idealidade do diodo. Como a solução desta equação exige uma configuração complexa de outras equações e não é o foco deste trabalho, a mesma não será discutida [28].

Se considerarmos que os portadores tenham um tempo de vida relativamente alto, o salto na corrente de dreno pode ser reforçado pelo ganho do transistor bipolar parasitário inerente à estrutura. Este fenômeno também pode ser chamado de "second kink". Em transistores FDSOI, este fenômeno não é observado porque a camada de silício já está totalmente depletada, resultando em uma menor formação de pares elétrons-lacunas [29]. 


\subsubsection{Transistor Bipolar Parasitário}

Outro importante efeito parasitário pode ocorrer quando temos uma baixa tensão aplicada à porta do dispositivo e um alto campo elétrico na junção do dreno, ocasionado pela alta tensão aplicada no mesmo. Se isso ocorrer, poderemos ter a ionização por impacto na região de sublimiar [10]. Como este fenômeno de ionização gera pares elétrons-lacuna, o potencial de corpo aumenta, reduzindo dessa forma a tensão de limiar. Como descrito no item 2.2.6, se o tempo de vida dos portadores minoritários (elétrons) for suficientemente alto, o transistor bipolar parasitário presente na estrutura NPN pode amplificar a corrente de base que é dada pela equação (2.27):

$$
I_{\text {corpo }}=(M-1) \cdot I_{D s a t}=(M-1) \cdot I_{\text {canal }}
$$

onde, $I_{\text {canal }}$ é a corrente de canal devido ao transistor MOS, $\mathrm{I}_{\text {corpo }}$ é a corrente de corpo do transistor bipolar parasitário, $M$ é o fator de multiplicação, e o resultado do aumento da corrente de dreno $\left(\Delta \mathrm{I}_{\mathrm{d}}\right)$ é dado pela equação (2.28):

$$
\Delta I_{d}=\beta_{F} \cdot I_{\text {corpo }}=\beta_{F} \cdot(M-1) \cdot I_{\text {canal }}
$$

Onde $\beta_{\mathrm{F}}$ é o ganho de corrente do emissor comum do BJT. A Figura 2.7 A e 2.7 B mostra o esquema do BJT parasitário inerente na estrutura e o fluxo de corrente do corpo (ou corrente de canal) respectivamente. Como conseqüência, a corrente de dreno aumenta de forma considerável, fazendo com que a inclinação de sublimiar chegue a próximo do zero. Esse efeito é conhecido como "single-transistor-latchup". Este efeito também pode ocorrer em transistor SOI totalmente depletado (FD SOI), porém, com efeito, bastante reduzido [26,30]. 


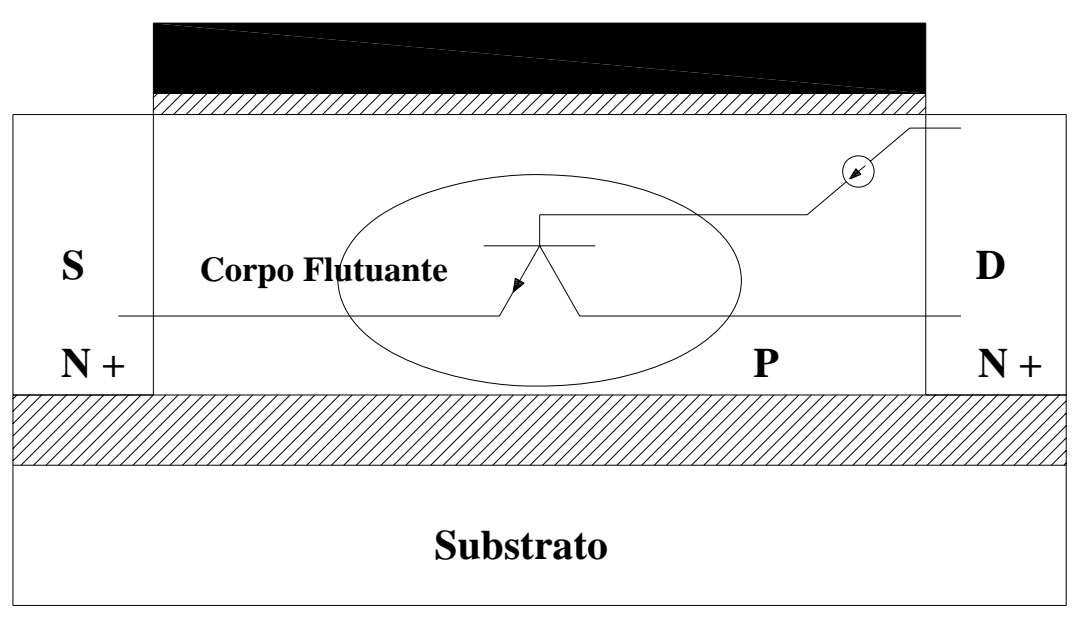

(A)

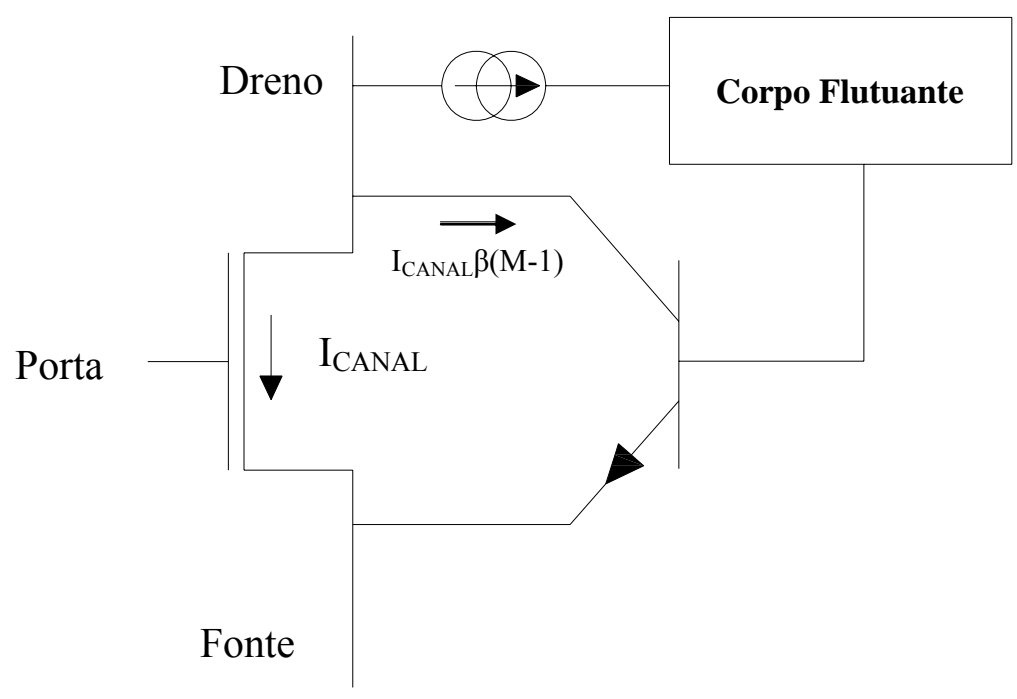

(B)

Figura 2.7: Transistor Bipolar Parasitário (BJT) (A) e o fluxo da corrente de corpo do transistor bipolar parasitário do dispositivo SOI MOSFET parcialmente depletado (B) $[10]$.

Desta forma, para minimizar e até mesmo eliminar alguns desses efeitos parasitários temos como solução usar um contato de corpo, curto-circuitando o mesmo com a porta do dispositivo, formando assim o DTMOS [6]. Com essa polarização podemos controlar a corrente do bipolar parasitário, fazendo com que o mesmo trabalhe a favor do dispositivo. 


\subsubsection{Condutância de Saída $\left(\mathrm{g}_{\mathrm{D}}\right)$ e Tensão Early $\left(\mathrm{V}_{\mathrm{EA}}\right)$}

Quando temos um valor fixo de tensão aplicado à porta e aumentamos a tensão do dreno, verificamos através da característica da curva $\mathrm{I}_{\mathrm{DS}}$ em função de $\mathrm{V}_{\mathrm{DS}}$ uma reta, que apresenta uma leve inclinação. Se extrapolarmos essas retas, onde cada uma possui um valor fixo de $\mathrm{V}_{\mathrm{GS}}$, as mesmas se encontram próximas de um ponto no eixo negativo de $V_{D S}$. Este ponto no eixo $V_{D S}=-V_{E A}$. Esse valor $\left(V_{E A}\right)$ é conhecido como tensão Early e é mostrado na Figura 2.8.

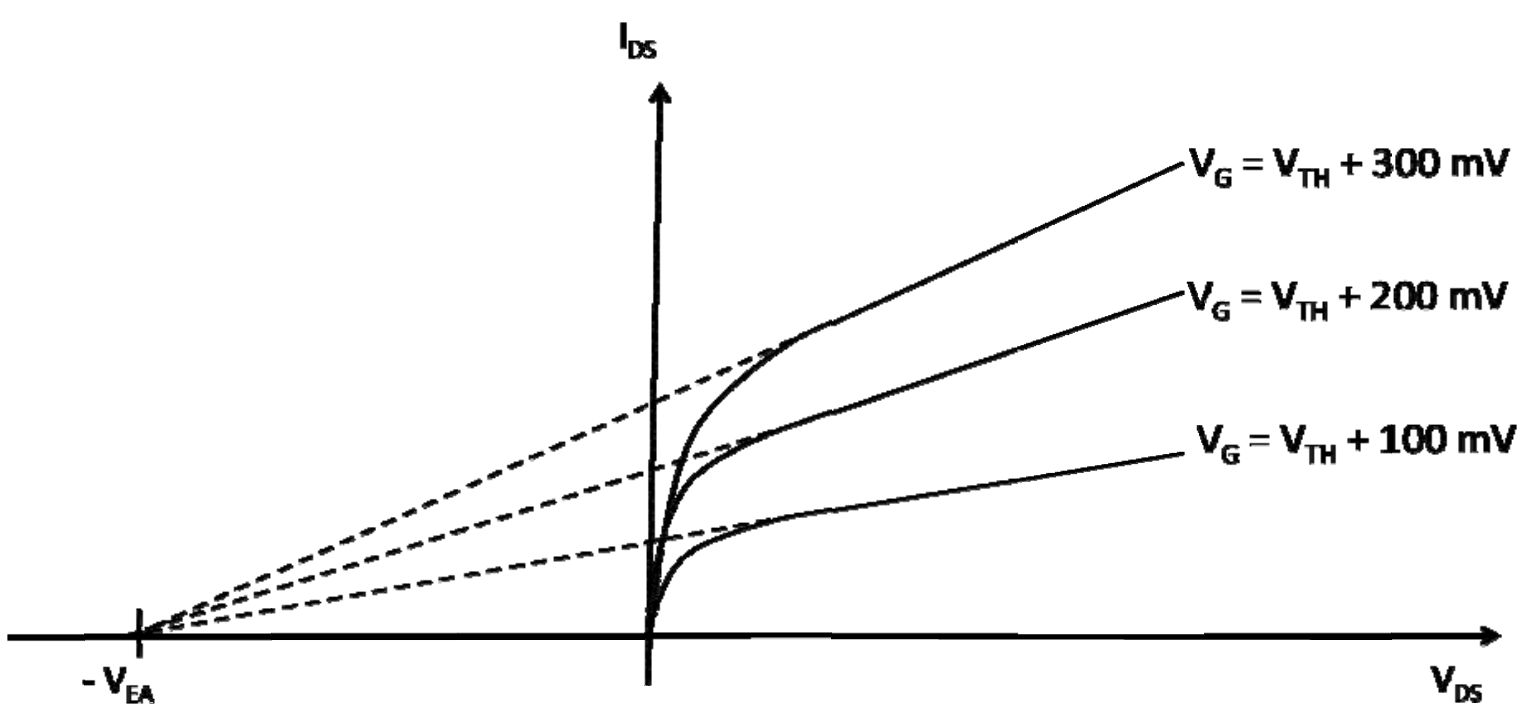

Figura 2.8: Obtenção da tensão Early através da curva de corrente de dreno em função da tensão aplicada no dreno.

Se aumentarmos a tensão de dreno, aumentamos a tensão de polarização reversa, e conseqüentemente aumenta-se a região de depleção da junção canal/dreno, diminuindo assim o comprimento efetivo do canal. A tensão Early está diretamente relacionada com a corrente de dreno ( $\left.\mathrm{I}_{\mathrm{DS}}\right)$ em função da tensão aplicada ao dreno $\left(\mathrm{V}_{\mathrm{DS}}\right)$, considerando a operação do dispositivo na região de saturação. Este parâmetro também pode ser aproximado pela razão $\mathrm{I}_{\mathrm{DS}} / \mathrm{g}_{\mathrm{D}}$, onde $\mathrm{g}_{\mathrm{D}}$ é a condutância de saída, que é dada pela equação (2.29) [20].

$$
g_{D} \approx \frac{\partial I_{D S}}{\partial V_{D S}}
$$


Como pode ser observado na equação (2.29), a condutância de saída ( $\mathrm{g}_{\mathrm{D}}$ ) é a derivada da corrente de dreno ( $\left.\mathrm{I}_{\mathrm{DS}}\right)$ em função da tensão aplicada entre dreno e fonte $\left(\mathrm{V}_{\mathrm{DS}}\right)$, enquanto a tensão entre porta e fonte $\left(\mathrm{V}_{\mathrm{GS}}\right)$ se mantém constante. A condutância de saída é um parâmetro importante para as aplicações analógicas.

\subsubsection{Razão da transcondutância pela corrente de dreno $-\mathrm{g}_{\mathrm{m}} / \mathrm{I}_{\mathrm{DS}}$}

A razão $g_{m} / I_{D S}$ é a medida direta da eficiência do transistor [20]. Em transistores MOSFETs, o valor máximo de $\mathrm{g}_{\mathrm{m}} / \mathrm{I}_{\mathrm{DS}}$ ocorre quando o dispositivo está em inversão fraca e é dado pela equação (2.30). A Figura 2.9 mostra $\mathrm{g}_{\mathrm{m}} / \mathrm{I}_{\mathrm{DS}}$ em função da corrente normalizada:

$$
\frac{g_{m}}{I_{D S}}=\frac{\partial I_{D S}}{I_{D S} \partial V_{G}}=\frac{\delta \ln I_{D S}}{\delta V_{G}}=\frac{\ln (10) \cdot \partial \log I_{D S}}{\partial V_{G}}=\frac{\ln (10)}{S}
$$

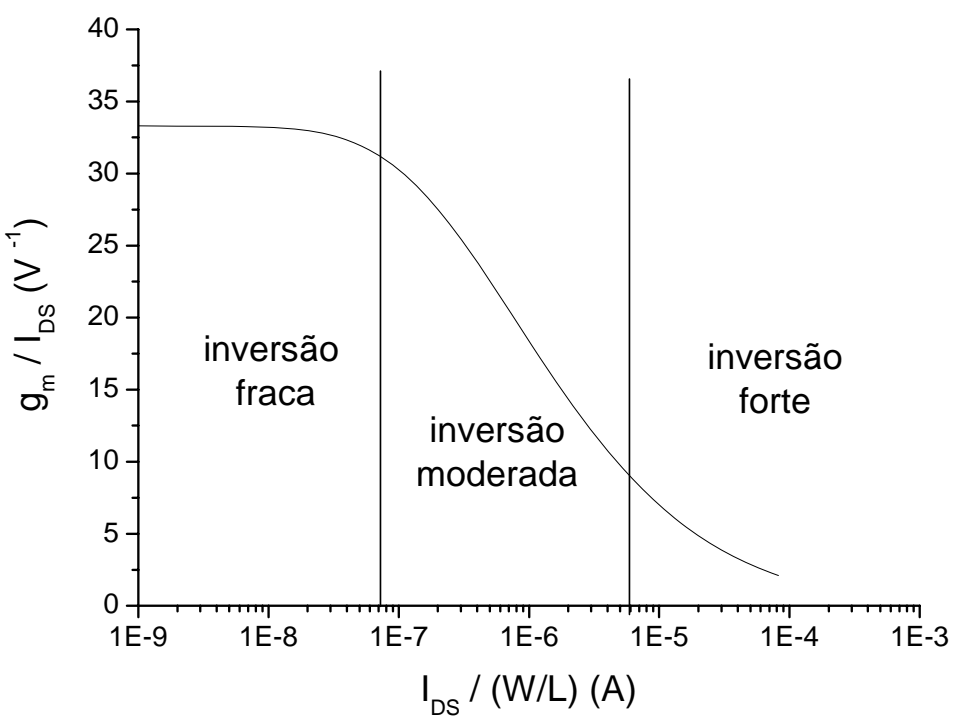

Figura 2.9: Curva característica da relação da transcondutância em função da corrente normalizada $\left(\mathrm{I}_{\mathrm{DS}} /(\mathrm{W} / \mathrm{L})\right)$ de um dispositivo SOI convencional. 
À medida que o dispositivo começa a operar em região de inversão moderada, a razão $g_{m} / I_{D S}$ diminui com o aumento da corrente do dreno. Essa curva característica é em função da corrente $\mathrm{I}_{\mathrm{DS}} /(\mathrm{W} / \mathrm{L})$ normalizada [31] porque a mesma não depende das dimensões dos dispositivos. Como essa curva não depende das dimensões do comprimento e da largura do canal, geralmente utiliza-se a mesma para projetos de circuitos integrados analógicos.

\subsubsection{Ganho Intrínseco DC $\left(\mathrm{A}_{\mathrm{V}}\right)$}

O ganho intrínseco DC de transistores é dado pela equação (2.31) [20], como descrito abaixo:

$$
A_{V}=\frac{\Delta V_{0}}{\Delta V_{I}}=\frac{\Delta V_{D S}}{\Delta V_{G S}}=r_{D S} \Delta I_{D S} \frac{1}{\Delta V_{G S}}=\frac{1}{g_{D}} g_{m} \cong\left(\frac{g_{m}}{I_{D S}}\right) \cdot V_{E A}
$$

Essa equação é válida para o estudo realizado na região de saturação, sendo que para este caso, os dispositivos serão considerados como amplificador de um único transistor, alimentado por uma fonte de corrente $\left(\mathrm{I}_{\mathrm{B}}\right)$. A fonte de corrente é responsável pela polarização do transistor como detalhado na Figura 2.10. O esquema abaixo representado tem como objetivo amplificar a parcela alternada $\left(\mathrm{v}_{\mathrm{gs}}\right)$ do sinal aplicada à porta do transistor, para o sinal de saída. Esse sinal de saída também possui uma parcela contínua $\left(\mathrm{V}_{\mathrm{DS}}\right)$ e uma alternada $\left(\mathrm{v}_{\mathrm{ds}}\right)$. Neste caso também está sendo representada uma carga capacitiva $\left(\mathrm{C}_{\mathrm{L}}\right)$ associada à saída.

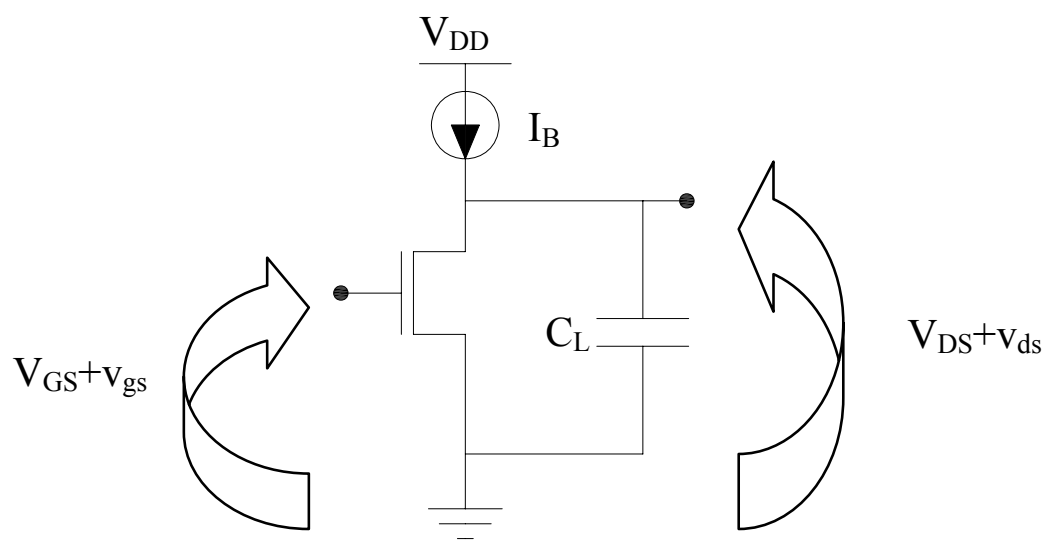

Figura 2.10: Bloco amplificador formado por um único transistor nMOSFET. 
Através da equação 2.30 , podemos observar que quanto maior for a relação $\mathrm{g}_{\mathrm{m}} / \mathrm{I}_{\mathrm{DS}}$ e a tensão Early $\left(\mathrm{V}_{\mathrm{EA}}\right)$, mais altos serão os valores do ganho intrínseco $\left(\mathrm{A}_{\mathrm{V}}\right)$ do dispositivo.

2.2.11 Freqüência de ganho unitário $\left(\mathrm{f}_{\mathrm{T}}\right)$

A Figura 2.11 mostra a resposta em freqüência de um dispositivo, considerando que o mesmo esteja com um capacitor $\left(C_{L}\right)$ conectado na sua saída. A freqüência de corte $\left(\mathrm{f}_{0}\right)$ corresponde à freqüência na qual a potência na saída de um sistema (circuito eletrônico, linha de transmissão, amplificador, ou filtro eletrônico) cai para metade da potência máxima. Em termos de amplitude, essa redução corresponde a uma diminuição de $3 \mathrm{~dB}[32]$.

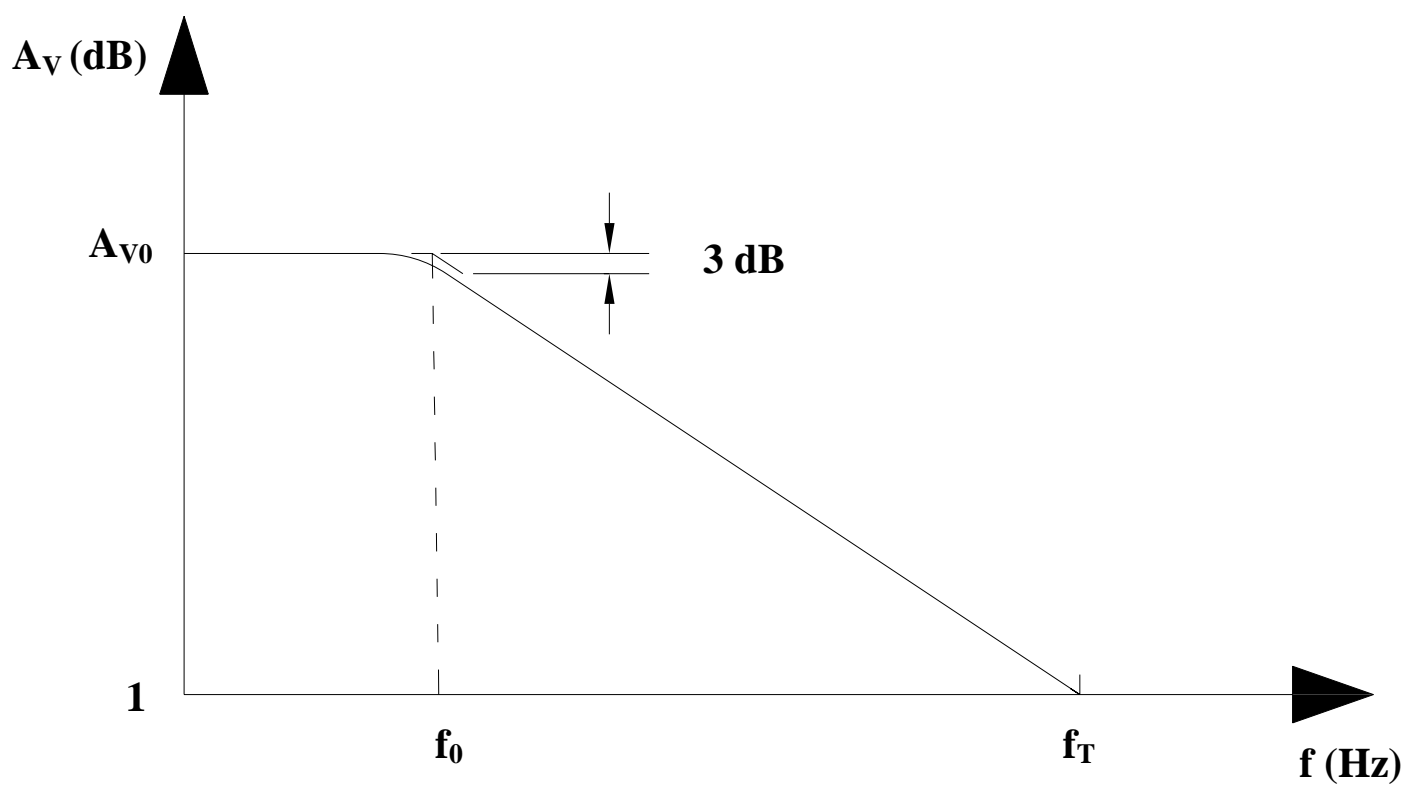

Figura 2.11: Curva de Bode representando a resposta em freqüência de um transistor $[32]$.

A freqüência de ganho de tensão unitário $\left(\mathrm{f}_{\mathrm{T}}\right)$ representa a freqüência, onde o ganho de tensão do circuito torna-se unitário e é dada pela equação (2.32).

$$
f_{T}=\left(\frac{g_{m}}{I_{D S}}\right) \cdot \frac{I_{D S}}{2 \cdot \pi \cdot C_{L}}
$$


onde $\mathrm{f}_{0}$ é a freqüência de corte. Como $\mathrm{f}_{\mathrm{T}}$ é diretamente proporcional à transcondutância e inversamente proporcional a $\mathrm{C}_{\mathrm{L}}$, temos que quanto maior for a transcondutância, maior será a $\mathrm{f}_{\mathrm{T}}$, e, conseqüentemente, o dispositivo terá melhores características para trabalhar em circuitos analógicos e amplificadores com características de alta resposta em freqüência.

\subsection{O Dispositivo SOI DTMOS}

Para aplicações em circuitos analógicos, temos alguns parâmetros que são fundamentais, que são a relação $\mathrm{g}_{\mathrm{m}} / \mathrm{I}_{\mathrm{D}}$, a tensão Early $\left(\mathrm{V}_{\mathrm{EA}}\right)$, o ganho intrínseco $\mathrm{DC}$ $\left(A_{V}\right)$ e a freqüência de ganho de tensão unitário $\left(f_{T}\right)$ do dispositivo. Por ser um dispositivo robusto, existem alguns estudos sobre o comportamento do SOI DTMOS quando operado em altas temperaturas [17]. Todos esses parâmetros têm sido pouco explorados no DTMOS, fato que originou a essência desse trabalho [33].

A fabricação do DTMOS representado na figura 2.12, foi realizada pela primeira vez em 1987 por Colinge, como descrito na referência [6]. Esse dispositivo tem sido reportado na literatura como promissor para aplicações em dispositivo "Low-PowerLow-Voltage". À medida que aplicamos uma tensão na porta, o contato de corpo também recebe a mesma tensão, pelo fato de o mesmo estar curto-circuitado com a porta. Desta forma, passamos a controlar a corrente do transistor bipolar parasitário inerente na estrutura e o potencial de corpo. Como há o controle dessa corrente, conseguimos eliminar os efeitos de corpo flutuante, fazendo com que o dispositivo possua características ideais na inclinação de sublimiar (S), uma redução do efeito de corpo e alta corrente. Essa corrente total resulta da combinação da corrente do transistor principal e da corrente do BJT parasitário inerente na estrutura do DTMOS [7]. 
Figura 2.12: Dispositivo SOI DTMOS. O contato de corpo está curto-circuitado com a porta.

\subsubsection{Estrutura do Dispositivo SOI DTMOS}

O processo de fabricação do dispositivo DTMOS é o mesmo utilizado na fabricação do SOI convencional. A diferença é que se fabrica um quarto terminal em uma extensão do canal (base) independente dos contatos de fonte, dreno e porta, fazendo com que o dispositivo possa operar no modo padrão, onde o corpo está aterrado, ou flutuando, ou no modo DTMOS quando se conecta o terminal de corpo com a porta.

Se o contato de corpo estiver aterrado, podemos eliminar alguns efeitos parasitários, como o "efeito kink", e os efeitos provenientes do transistor bipolar parasitário. $\mathrm{O}$ mais tradicional consiste na difusão tipo $\mathrm{P}^{+}$de um contato no substrato do silício embaixo da porta( Figura 2.13 A). Este contato também pode ser usado para servir como a base do transistor bipolar lateral, enquanto que a fonte e o dreno são usados como emissor e coletor, respectivamente [20].

Outro tipo de contato é encontrado em portas do tipo T (Figura 2.13 B), que é simplesmente uma derivação do mesmo contato descrito acima, porém em dispositivos que possuem porta muito larga, este simples contato não costuma ser eficiente para evitar o "efeito kink" ou o efeito do transistor bipolar parasitário [20]. 
Quando a porta tipo H (Figura 2.13 C) é usada, é possível resolver este tipo de problema, desde que seja feito um contato de corpo em ambos os lados do canal. Este tipo de contato ainda apresenta mais uma vantagem, que é o de evitar a corrente de fuga entre fonte e dreno [20].

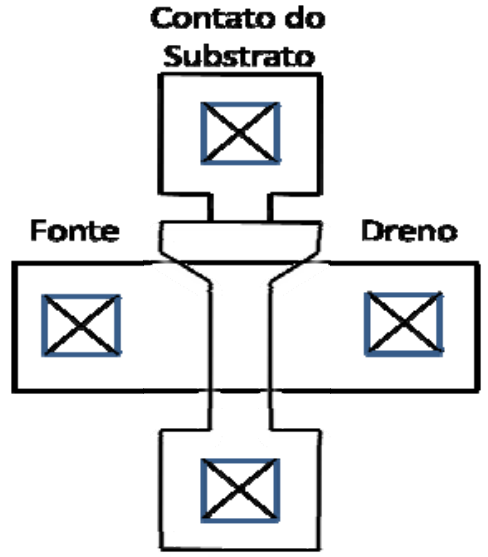

Porta

(A)

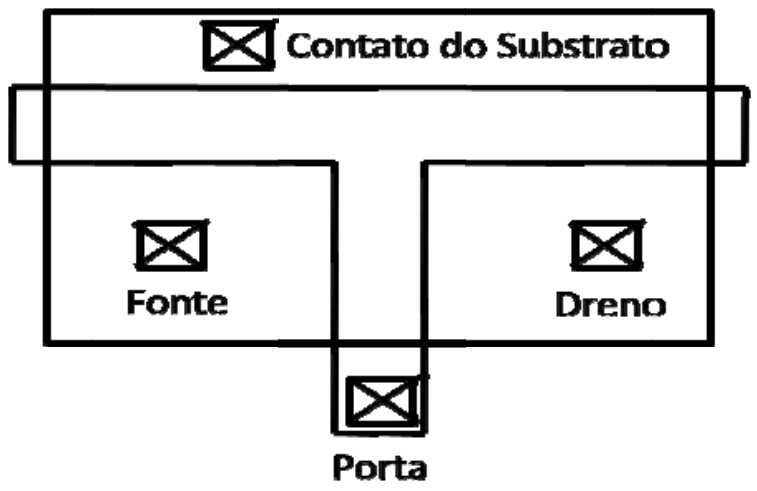

(B) 


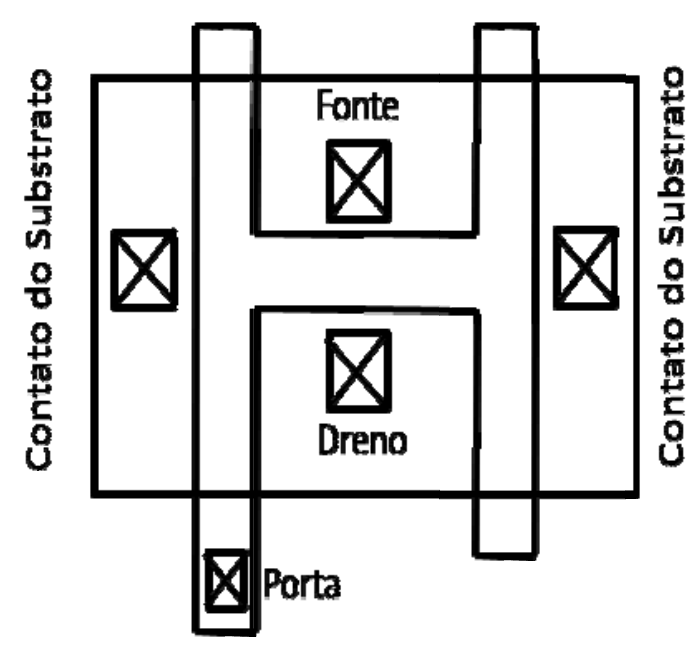

(C)

Figura 2.13: Esquema do contato de corpo em formato de porta tipo I (A); dispositivo com porta tipo $\mathrm{H}$ (B), dispositivo com porta tipo $\mathrm{T}$ (C) [20].

\subsubsection{Tensão de Limiar}

O dispositivo DTMOS possui diversas vantagens devido ao contato de corpo estar curto-circuitado com a porta do transistor, que lhe confere superioridade quando comparado com o SOI convencional de mesmas dimensões e condições de polarização. Como exposto no item 2.2.1, quanto menor o comprimento do canal, mais presentes estão os efeitos de canal curto e, conseqüentemente, maiores são os efeitos parasitários, que degradam os parâmetros da inclinação de sublimiar $(\mathrm{S})$, transcondutância $\left(\mathrm{g}_{\mathrm{m}}\right)$ e a tensão de limiar $\left(\mathrm{V}_{\mathrm{TH}}\right)$ [20].

A diminuição do comprimento do canal proporciona os efeitos parasitários de canal curto. A tensão de limiar está diretamente relacionada com o comprimento do canal do dispositivo. Como o DTMOS possui o contato de corpo curto-circuitado com a porta, pode se controlar as cargas da região de depleção, minimizando os efeitos de canal curto, como a diminuição da corrente de fuga [20].

Considerando que a tensão de limiar é baixa o suficiente, a corrente do BJT parasitário inerente a estrutura é desprezível quando comparado com a corrente do dispositivo DTMOS. A corrente do transistor DTMOS é modulada somente pela tensão aplicada na porta do dispositivo [20]. Conforme descrito no item 2.2.2, o efeito de corpo é idêntico ao de dispositivo MOS convencional e a tensão de limiar é obtida da mesma 
forma, porém na parcela que antes era usado a tensão de substrato, utiliza-se a mesma tensão aplicada na porta, como indicado na equação 2.33 :

$$
V_{T H 1}=V_{T H 0}-\frac{\sqrt{2 q \varepsilon_{s i} N_{A}}}{C_{o x}}\left(\sqrt{2 \phi_{F}}-\sqrt{2 \phi_{F}-V_{G S}}\right)
$$

onde $\mathrm{V}_{\mathrm{TH} 1}$ é a tensão de limiar do SOI DTMOS e $\mathrm{V}_{\mathrm{TH} 0}$ é a tensão de limiar considerando $\mathrm{V}_{\mathrm{GB}}=0$.

\subsubsection{Transcondutância}

Um parâmetro importante no DTMOS é a transcondutância $\left(\mathrm{g}_{\mathrm{m}}\right)$, dada pela derivada da corrente de dreno ( $\left.\mathrm{I}_{\mathrm{DS}}\right)$ em função da tensão aplicada na porta $\left(\mathrm{V}_{\mathrm{GS}}\right)$, que aumenta em relação ao SOI parcialmente depletado convencional. Essa melhora ocorre porque a corrente do transistor principal sobrepõem-se a corrente de base do BJT, aumentando dessa forma a corrente total do dispositivo. Porém, não é possível observar a degradação da mesma. Isso ocorre porque com o aumento de $\mathrm{V}_{\mathrm{GS}}$, aumenta-se também o potencial de corpo e a corrente de dreno. Quando a tensão aplicada à porta ultrapassa $700 \mathrm{mV}$, perde-se o controle das cargas na região de depleção devido à polarização direta da junção fonte / canal [33].

\subsubsection{Inclinação de Sublimiar}

Outro parâmetro importante é a inclinação de sublimiar $\left(\mathrm{S}=\partial \mathrm{V}_{\mathrm{GS}} / \partial \log \left(\mathrm{I}_{\mathrm{DS}}\right)\right)$ do DTMOS. Esses dispositivos mostram valores da inclinação de sublimiar ideais próximo ao valor teórico (60 mV/dec), que é dada pela equação (2.34) [20].

$$
S=\ln (10) \cdot \frac{k T}{q}
$$




\section{Resultados de Simulações Numéricas e Análises.}

Neste capítulo, é apresentada uma introdução do simulador ATLAS que foi utilizado para realizar as simulações de $\mathrm{I}_{\mathrm{DS}}$ em função de $\mathrm{V}_{\mathrm{GS}}$ e $\mathrm{V}_{\mathrm{DS}}$. Após essa etapa será apresentado os modelos físicos utilizados nas simulações e os resultados obtidos.

\subsection{Simulador Atlas}

O simulador ATLAS, desenvolvido pela SILVACO [34], é capaz de simular as características elétricas dos mais diversos dispositivos. Neste simulador, as simulações numéricas podem ser bidimensionais ou tridimensionais.

\subsubsection{Modelos Físicos Utilizados no Simulador ATLAS}

Para o simulador poder produzir os resultados experimentais, é necessário incluir alguns modelos físicos e modificar alguns valores "default" dos parâmetros nos modelos. São vários os modelos presentes no simulador que vão desde a concentração de dopantes até modelos específicos como degradação da mobilidade e ionização por impacto. Em seguida, serão descritos brevemente cada modelo utilizado nas simulações do DTMOS e SOI convencional.

$>\quad$ SHI (Shirahata): modelo de mobilidade geral proposto para introduzir os efeitos da camada de inversão e a dependência do campo elétrico perpendicular do óxido de porta.

SRH: especifica a recombinação Shockley-Head-Hall, utilizando tempo de vida dos portadores fixos.

$>$ KLA (Klaassen): modelo de mobilidade proposto, que inclui dependência com concentração de portadores, concentração intrínseca de portadores e temperatura absoluta. Aplica diferentes mobilidades para portadores majoritários e minoritários. Este modelo é recomendado para transistores da tecnologia SOI. 
BGN (Bandgap Narrowing): importante em regiões altamente dopadas, este modelo diz respeito ao estreitamento da faixa proibida e é necessário para a correta modelagem do ganho do transistor bipolar parasita intrínseco ao transistor SOI. Deve ser utilizado junto com o modelo KLA.

CONSRH (Concentration Dependent Lifetime SRH): modelo de recombinação onde o tempo de vida dos portadores depende da concentração. Recomendado para estruturas de silício.

$>\quad$ AUGER: modelo de recombinação através da transição direta de três partículas, onde um portador é capturado ou emitido. Importante em altas densidades de corrente.

$>\quad$ FLDMOB (Parallel Electric Field Dependence): modelo de degradação da mobilidade dependente do efeito de campo lateral, utilizado para estruturas de silício e arseneto de gálio. Necessário para a modelagem de qualquer efeito relacionado à velocidade de saturação dos portadores.

SELB (Selberherr): embora não seja definido juntamente com os demais (definido em uma linha à parte após o comando IMPACT), este modelo de ionização por impacto é dependente do campo elétrico horizontal. Inclui parâmetros dependentes da temperatura.

\subsection{Resultados Gerados Através das Simulações}

Os dispositivos PDSOI e DTMOS estudados através de simulações numéricas utilizam parâmetros da tecnologia SOI CMOS de 0,13 $\mu \mathrm{m}$. As espessuras do óxido de porta, do filme de silício e do óxido enterrado são de 2,5 nm, $100 \mathrm{~nm}$ e $400 \mathrm{~nm}$, respectivamente. A concentração do corpo é de $5,5 \times 10^{17} \mathrm{~cm}^{-3}$ e as concentrações de fonte e dreno é de $1 \times 10^{20} \mathrm{~cm}^{-3}$. Os dispositivos simulados tiveram quatro medidas de comprimento de canal, sendo respectivamente $(1 ; 0,5 ; 0,20$ e $0,15 \mu \mathrm{m})$. Todos os resultados foram obtidos por unidade de largura (W), visto que as simulações numéricas utilizadas são bidimensionais. 
As análises e discussões dos resultados simulados obtidos são baseadas na comparação entre o DTMOS e o SOI parcialmente depletado. A estrutura dos dispositivos são as mesmas descritas acima, exceto pela conexão existente entre a porta e o contato de corpo no caso do DTMOS (ANEXO A).

\subsubsection{Potencial elétrico}

A Figura 3.1 mostra o potencial elétrico em função da espessura do filme de silício $\left(\mathrm{t}_{\mathrm{Si}}\right)$ do dispositivo SOI convencional. O estudo é necessário, porque o contato de corpo necessita ser colocado na região neutra do canal, para que o mesmo não interfira na região de depleção quando for aplicada tensão na porta.

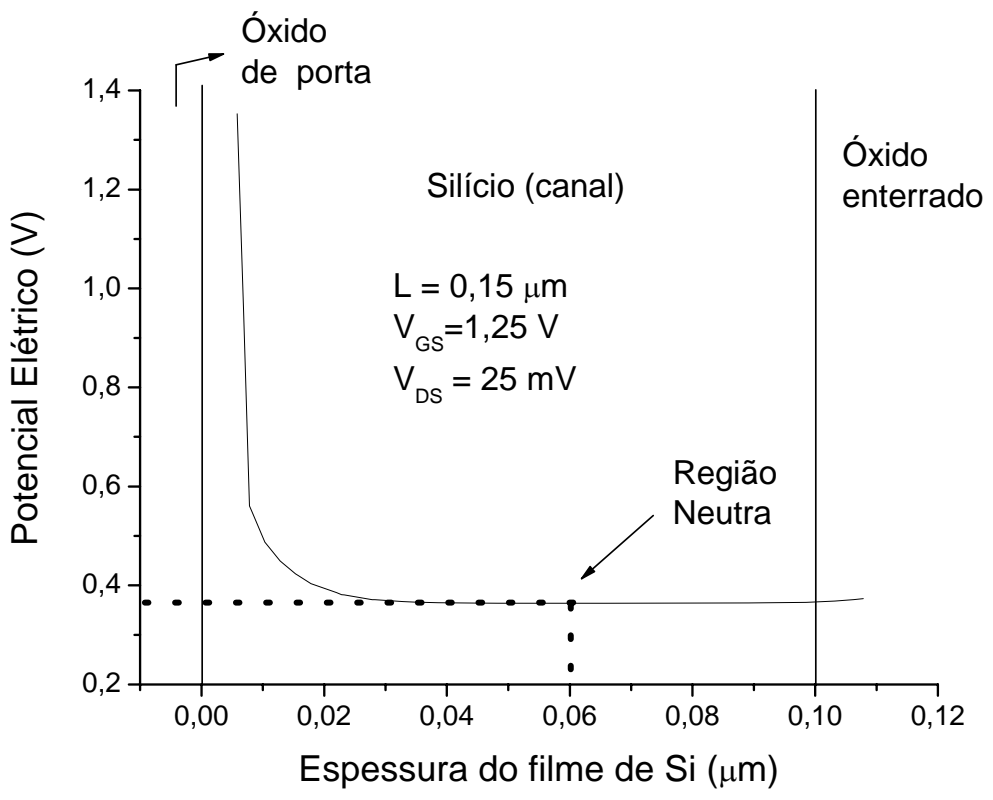

Figura 3.1: Curva do potencial elétrico em função da espessura do filme de silício do SOI convencional.

É possível observar na figura que há uma queda do potencial elétrico até aproximadamente $60 \mathrm{~nm}$ da camada silício. Após isso, o potencial torna-se constante, fato que demonstra que a partir dessa profundidade, a região do canal está neutra. Então, baseado nesta informação, foi definido o contato de corpo em uma profundidade de 80 $\mathrm{nm}$ com espessura de $1 \mathrm{~nm}$. 


\subsubsection{Curva $\mathrm{I}_{\mathrm{DS}} \mathrm{x} \mathrm{V}_{\mathrm{GS}}$}

Extraiu-se a curva característica da corrente de dreno $\left(\mathrm{I}_{\mathrm{DS}}\right) / \mathrm{W}$ em função da tensão aplicada na porta $\left(\mathrm{V}_{\mathrm{GS}}\right)$, aplicando-se uma tensão de $25 \mathrm{mV}$ no dreno dos dispositivos. Esta análise foi feita tanto para transistores SOI convencional como para o DTMOS, de acordo com os comprimentos de canal mencionados anteriormente, como mostrado na Figura 3.2.

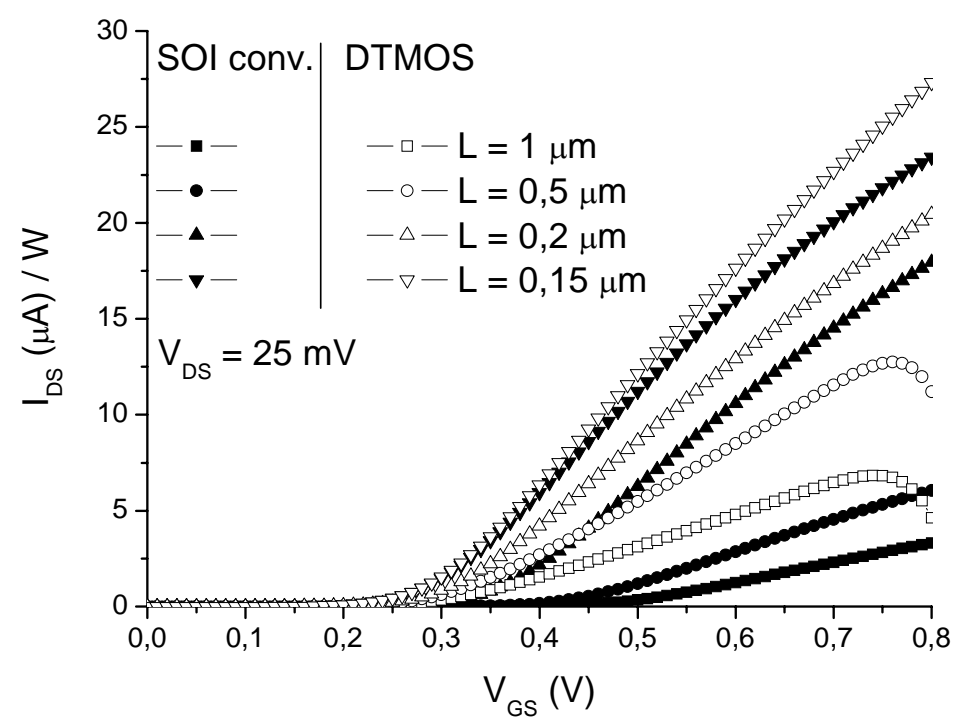

(A) 


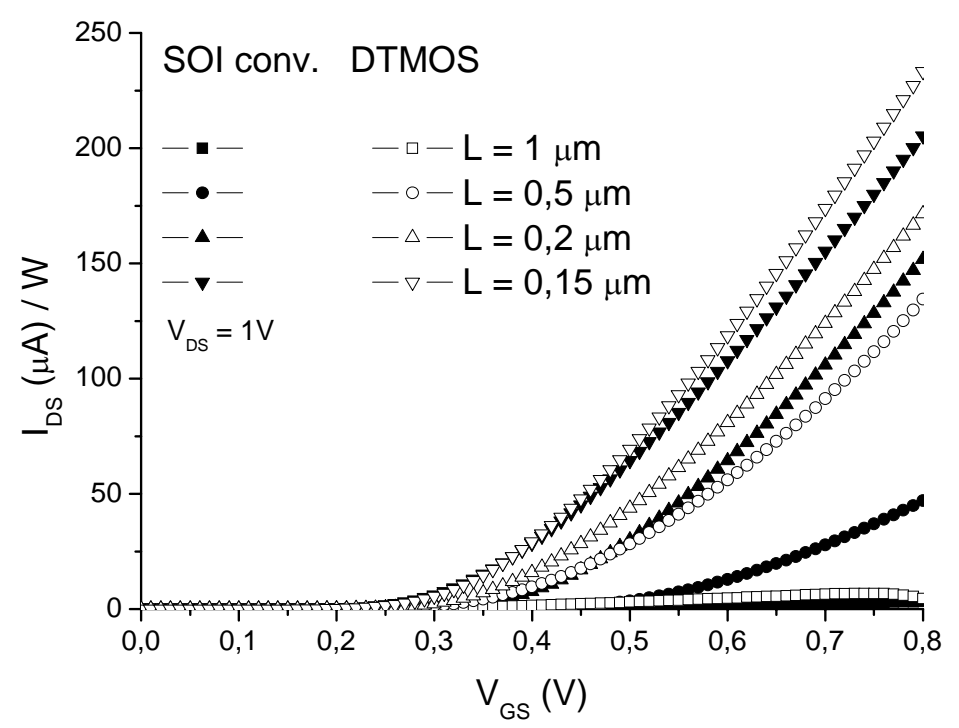

(B)

Figura 3.2: Curva $\mathrm{I}_{\mathrm{DS}}$ em função da tensão de porta $\mathrm{V}_{\mathrm{GS}}$ para diferentes comprimentos de canais do dispositivo SOI convencional e DTMOS considerando $\mathrm{V}_{\mathrm{DS}}=25 \mathrm{mV}$ (A) e $\mathrm{V}_{\mathrm{DS}}=1 \mathrm{~V}(\mathrm{~B})$.

É possível observar que a corrente do dispositivo DTMOS é maior em todos os comprimentos de canal analisados como mostrado na tabela 3.1. Isso ocorre porque a corrente total do dispositivo é composta de duas parcelas, sendo a primeira composta pela corrente do transistor principal e a segunda parcela composta pela corrente do transistor bipolar parasitário (BJT), inerente à estrutura. O DTMOS não pode ter uma polarização aplicada na porta acima de $700 \mathrm{mV}$. Isso se deve porque a partir desse valor a junção canal / fonte é polarizada diretamente. Se isso ocorrer, perde-se o controle das cargas na região do canal do dispositivo [33]. 
Tabela 3.1: Valores da corrente de dreno do SOI convencional e do DTMOS por considerando $\mathrm{V}_{\mathrm{GT}}=50 \mathrm{mV}$ e $\mathrm{V}_{\mathrm{DS}}=25 \mathrm{mV}$.

\begin{tabular}{|c|c|c|c|}
\hline $\mathbf{I}_{\mathbf{D S}}(\boldsymbol{\mu A} \mathbf{)}$ & SOI Convencional & DTMOS & \% de ganho \\
\hline $\mathrm{L}=1 \mu \mathrm{m}$ & 0,571 & 0,862 & 50 \\
\hline $\mathrm{L}=0,5 \mu \mathrm{m}$ & 0,908 & 1,31 & 44 \\
\hline $\mathrm{L}=0,2 \mu \mathrm{m}$ & 2,518 & 3,372 & 34 \\
\hline $\mathrm{L}=0,15 \mu \mathrm{m}$ & 2,980 & 3,642 & 22 \\
\hline
\end{tabular}

\subsubsection{Transcondutância $\left(g_{m}\right)$}

A Figura 3.3 mostra a transcondutância em função da tensão aplicada na porta $\left(\mathrm{V}_{\mathrm{GS}}\right)$ do dispositivo SOI parcialmente depletado convencional e do DTMOS. Pode-se notar que para todos os comprimentos de canal avaliados, a transcondutância é maior quando comparada com o dispositivo SOI convencional. No DTMOS, quando se atinge valores de tensões superiores a $0,7 \mathrm{~V}$, perde-se o controle das cargas na região do canal, até o momento que acontece a degradação do dispositivo.

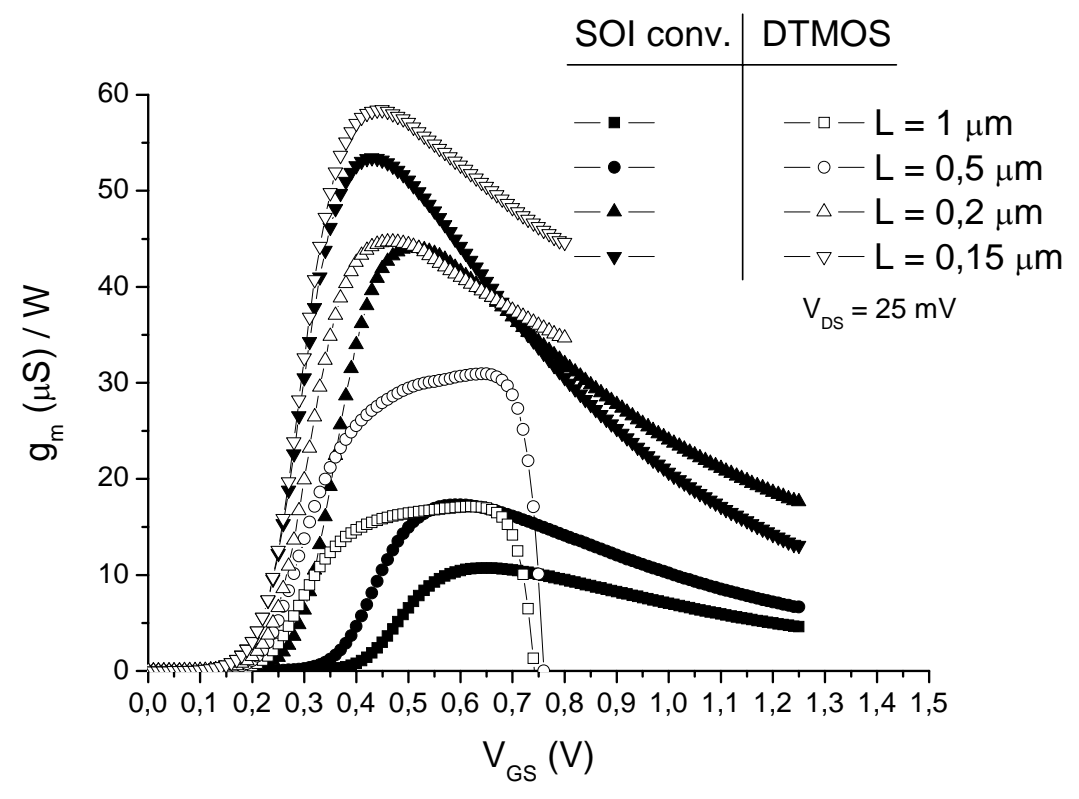

Figura 3.3: Curva de Transcondutância em função da tensão aplicada à porta para diferentes comprimentos de canais do SOI convencional e DTMOS. 
Este aumento contínuo na corrente de dreno, também pode ser visto como a contínua elevação da transcondutância, até que a tensão aplicada na porta seja suficientemente elevada $(>700 \mathrm{mV})$, para polarizar diretamente a junção canal / fonte. Na tabela 3.2 é apresentado o valor da transcondutância máxima em comparação do SOI convencional com o DTMOS.

Tabela 3.2: Valores da transcondutância máxima do dispositivo SOI convencional e DTMOS considerando $\mathrm{V}_{\mathrm{DS}}=25 \mathrm{mV}$.

\begin{tabular}{|c|c|c|c|}
\hline $\mathbf{g}_{\mathbf{m m a x}}(\boldsymbol{\mu S})$ & SOI Convencional & DTMOS & \% de ganho \\
\hline $\mathrm{L}=1 \mu \mathrm{m}$ & 10,716 & 17,119 & 59,75 \\
\hline $\mathrm{L}=0,5 \mu \mathrm{m}$ & 17,310 & 30,910 & 78,74 \\
\hline $\mathrm{L}=0,2 \mu \mathrm{m}$ & 44,084 & 46,250 & 5,01 \\
\hline $\mathrm{L}=0,15 \mu \mathrm{m}$ & 53,431 & 58,456 & 10 \\
\hline
\end{tabular}

\subsubsection{Tensão de Limiar $\left(\mathrm{V}_{\mathrm{TH}}\right)$}

Para a extração da tensão de limiar dos dispositivos, foi usado o método da segunda derivada da corrente do dreno em função da tensão aplicada à porta [25].

A Figura 3.4 A mostra a segunda derivada da corrente de dreno $\left(\mathrm{I}_{\mathrm{DS}}\right)$ em função de $\mathrm{V}_{\mathrm{GS}}$ para dispositivos SOI parcialmente depletados e a Figura 3.4 B para DTMOS. A partir destas figuras, é possível observar que com a diminuição do comprimento do canal, a tensão de limiar $\left(\mathrm{V}_{\mathrm{TH}}\right)$ do SOI convencional também diminui. Pode-se também observar que os valores da tensão de limiar obtidos são praticamente constante para os dispositivos DTMOS, independente do comprimento de canal, para a faixa analisada. 


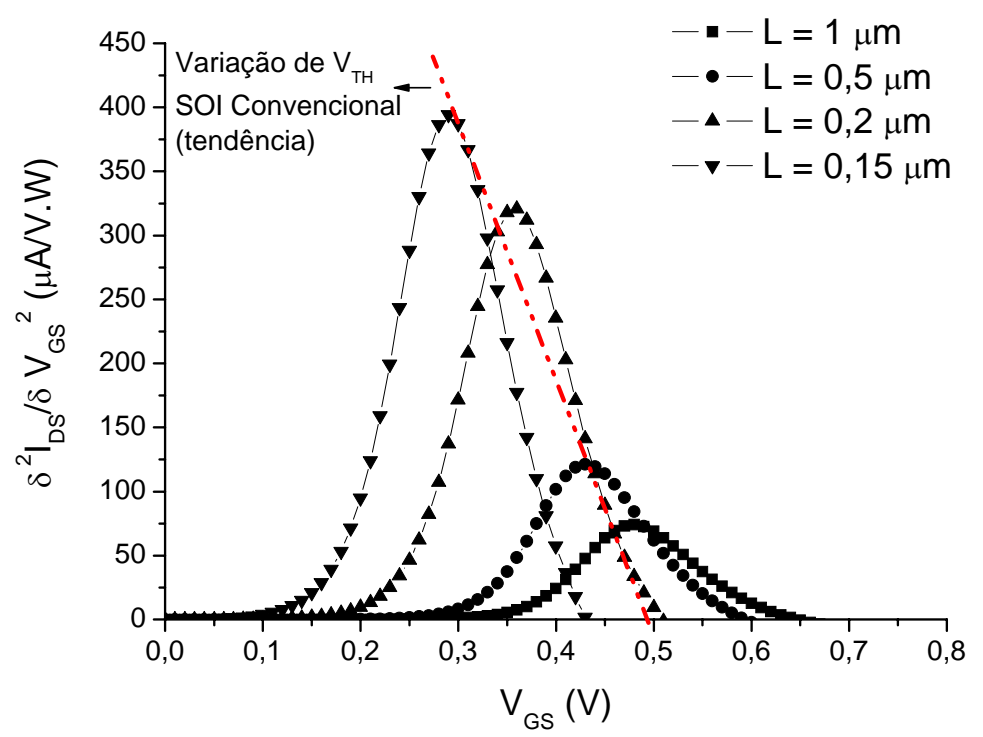

(A)

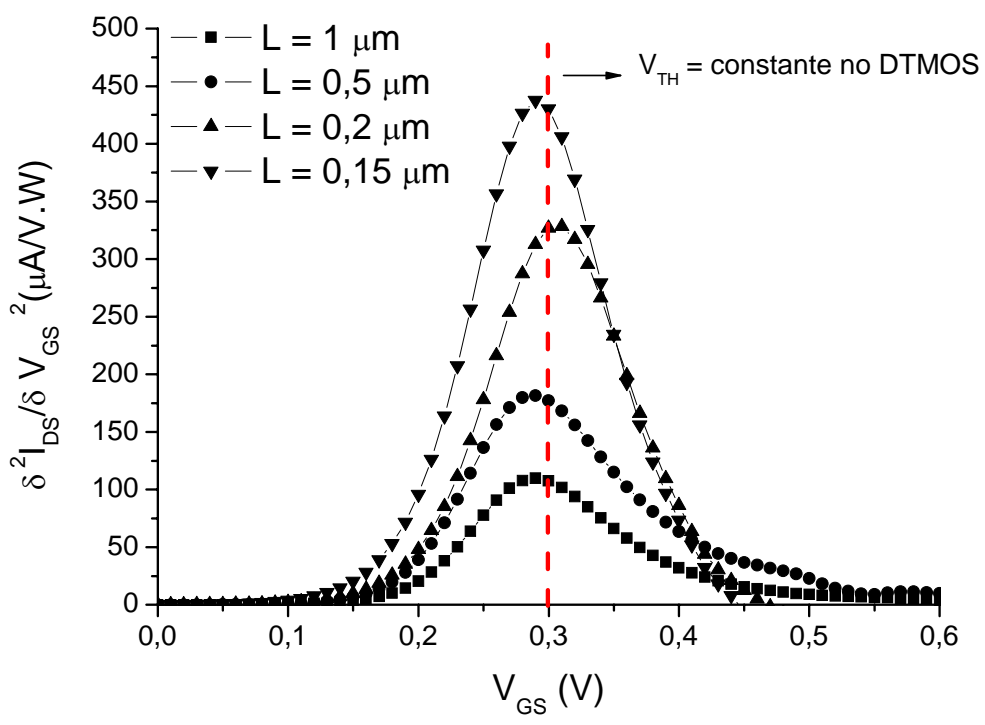

(B)

Figura 3.4: Curva da segunda derivada da corrente em função da tensão aplicada na porta do transistor SOI parcialmente depletado (A) e DTMOS (B) para diversos valores de comprimento de canal (L). 
Este comportamento se deve aos dispositivos SOI convencionais serem mais susceptíveis aos efeitos de canal curto que o transistor DTMOS, uma vez que a região de depleção entre fonte/canal e dreno/canal do DTMOS é menor devido ao aumento do potencial de corpo. O resultado da tensão de limiar para cada dispositivo está representado na tabela 3.1 e na Figura 3.5. A partir de comprimentos menores que 0,15 $\mu \mathrm{m}$, o DTMOS também passa a sofrer dos efeitos de canal curto.

Tabela 3.3: Tensão de limiar obtida a partir da figura 3.5 para todos os dispositivos.

\begin{tabular}{|c|c|c|}
\hline $\mathbf{V}_{\mathbf{T H}}(\mathbf{V})$ & DTMOS & SOI Convencional \\
\hline $\mathrm{L}=1 \mu \mathrm{m}$ & 0,29 & 0,48 \\
\hline $\mathrm{L}=0,5 \mu \mathrm{m}$ & 0,29 & 0,43 \\
\hline $\mathrm{L}=0,2 \mu \mathrm{m}$ & 0,30 & 0,36 \\
\hline $\mathrm{L}=0,15 \mu \mathrm{m}$ & 0,29 & 0,29 \\
\hline
\end{tabular}

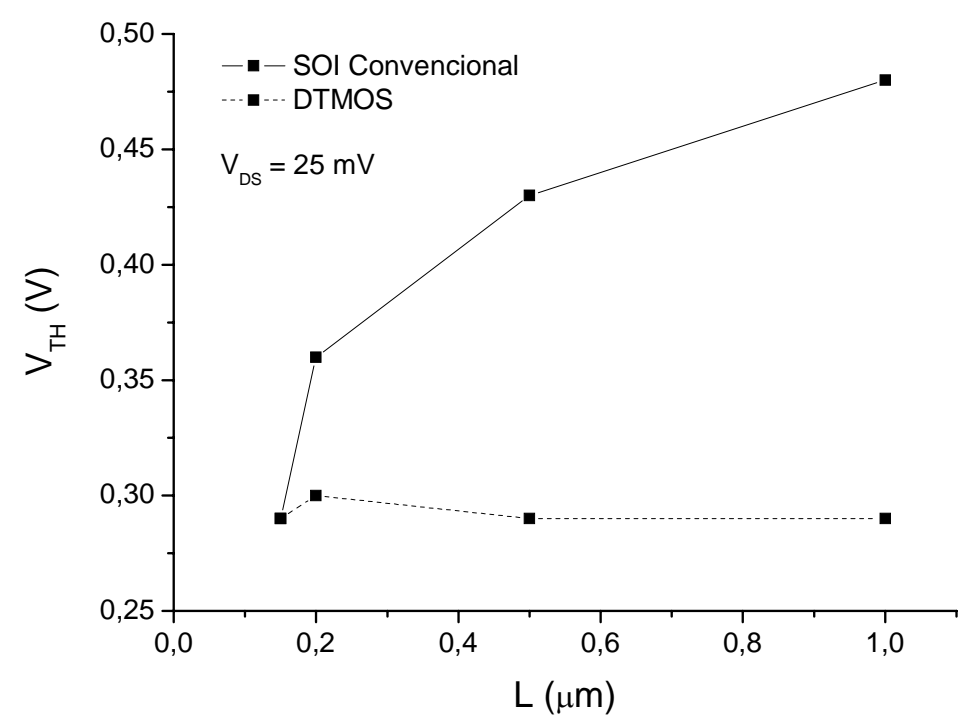

Figura 3.5: Variação da Tensão de limiar em função do comprimento do canal para o SOI convencional e DTMOS. 


\subsubsection{Inclinação de Sublimiar (Slope)}

A Figura 3.6 apresenta a inclinação de sublimiar para ambos os dispositivos.

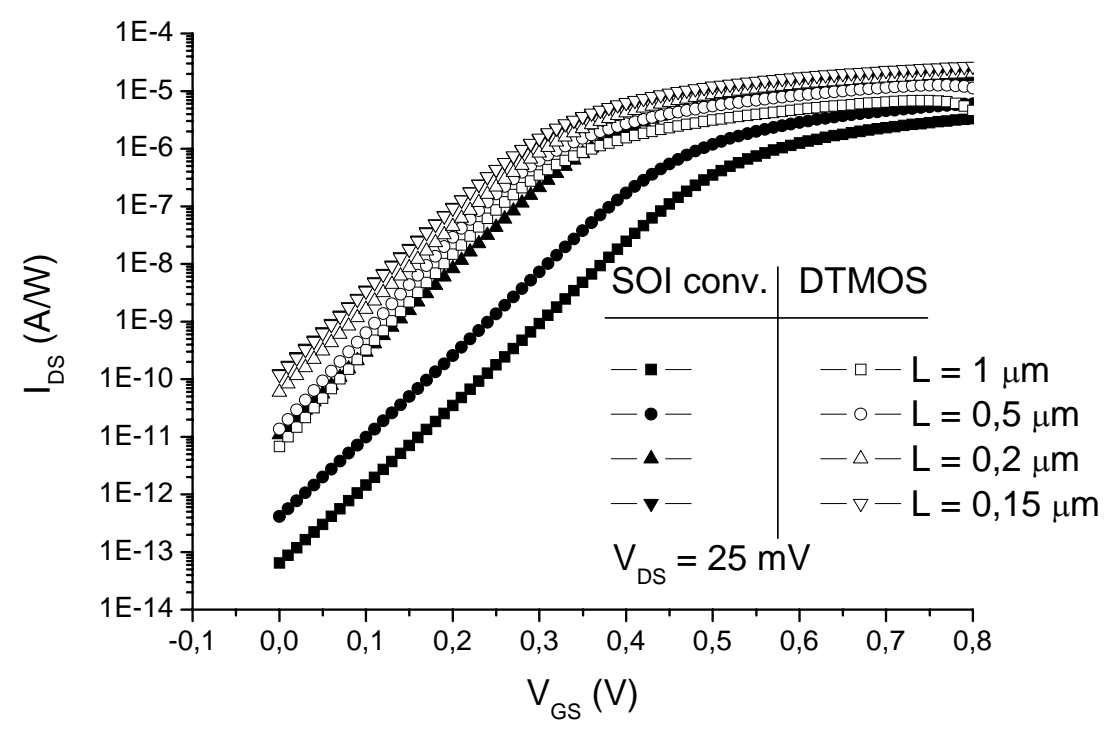

Figura 3.6: Corrente de dreno para ambos os dispositivos considerando vários comprimentos de canais.

A Tabela 3.4 mostra os valores da inclinação de sublimiar (S) para diferentes comprimentos de canal $(1 \mu \mathrm{m} \leq \mathrm{L} \leq 0,15 \mu \mathrm{m})$ e a Figura 3.7 mostra o gráfico comparativo. Observa-se que o valor da inclinação de sublimiar para comprimento de canal longo $(1 \mu \mathrm{m})$ é próximo do valor ideal $(60 \mathrm{mV} / \mathrm{dec})$, enquanto no SOI convencional esse valor é de $70 \mathrm{mV} /$ dec. Essa melhora é devido à diminuição de $\mathrm{V}_{\mathrm{TH}}$ com o aumento de $\mathrm{V}_{\mathrm{GS}}$ [20]. Através dessa tabela, é possível verificar novamente que os efeitos de canal curto influenciam menos os parâmateros do DTMOS que os do SOI convencional. 
Tabela 3.4: Valores da inclinação de sublimiar para vários comprimentos de canal.

\begin{tabular}{|c|c|c|c|}
\hline $\mathbf{S}(\mathbf{m V} / \mathbf{d e c})$ & DTMOS & SOI Convencional & \% de Melhora \\
\hline $\mathrm{L}=1 \mu \mathrm{m}$ & 60 & 70 & 16,00 \\
\hline $\mathrm{L}=0,5 \mu \mathrm{m}$ & 60 & 70 & 16,00 \\
\hline $\mathrm{L}=0,2 \mu \mathrm{m}$ & 61 & 71 & 16,50 \\
\hline $\mathrm{L}=0,15 \mu \mathrm{m}$ & 63 & 76 & 20,63 \\
\hline
\end{tabular}

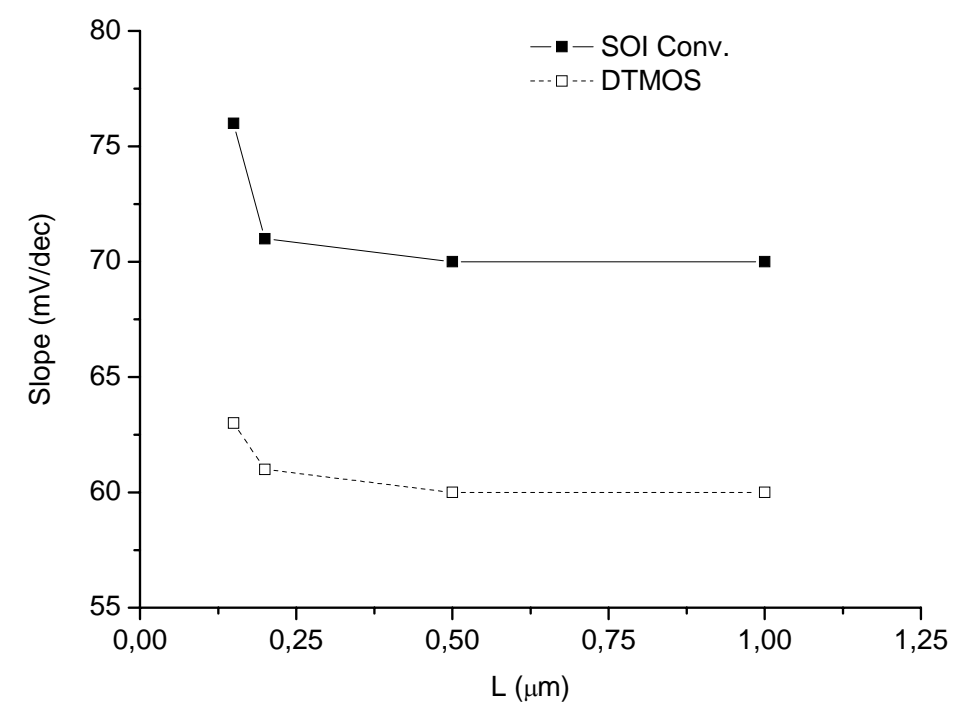

Figura 3.7: Curva da inclinação de sublimiar (S) comparativa entre os resultados obtidos através da simulação para diferentes comprimentos de canais do PDSOI e do DTMOS.

\subsubsection{Tensão Early $\left(\mathrm{V}_{\mathrm{EA}}\right)$ e Condutância de Saída $\left(\mathrm{g}_{\mathrm{D}}\right)$}

A Figura 3.8 mostra a corrente de dreno ( $\left.\mathrm{I}_{\mathrm{DS}}\right)$ em função da tensão aplicada no dreno $\left(\mathrm{V}_{\mathrm{DS}}\right)$ para ambos os dispositivos (PDSOI e DTMOS), com comprimento de canal de $1 \mu \mathrm{m}$. Como o DTMOS apresenta uma curva na região de saturação mais paralelo ao eixo das tensões de dreno que o SOI convencional, consegue-se obter maiores valores da tensão Early, conforme pode ser observado na Tabela 3.5. 
Tabela 3.5: Valores da tensão Early $\left(\mathrm{V}_{\mathrm{EA}}\right)$ considerando $\mathrm{V}_{\mathrm{GT}}=50 \mathrm{mV}$.

\begin{tabular}{|c|c|c|c|}
\hline \multirow{2}{*}{$\mathbf{L}(\boldsymbol{\mu m})$} & \multicolumn{2}{|c|}{$\mathbf{V}_{\mathrm{EA}}(\mathbf{V})$} & $\%$ \\
\cline { 1 - 3 } & SOI Convencional & DTMOS & Melhora \\
\hline 1 & 12,32 & 23,45 & 90,34 \\
\hline 0,5 & 3,94 & 5,68 & 44,16 \\
\hline 0,2 & 2,56 & 4,93 & 92,58 \\
\hline 0,15 & 1,89 & 3,38 & 78,83 \\
\hline
\end{tabular}

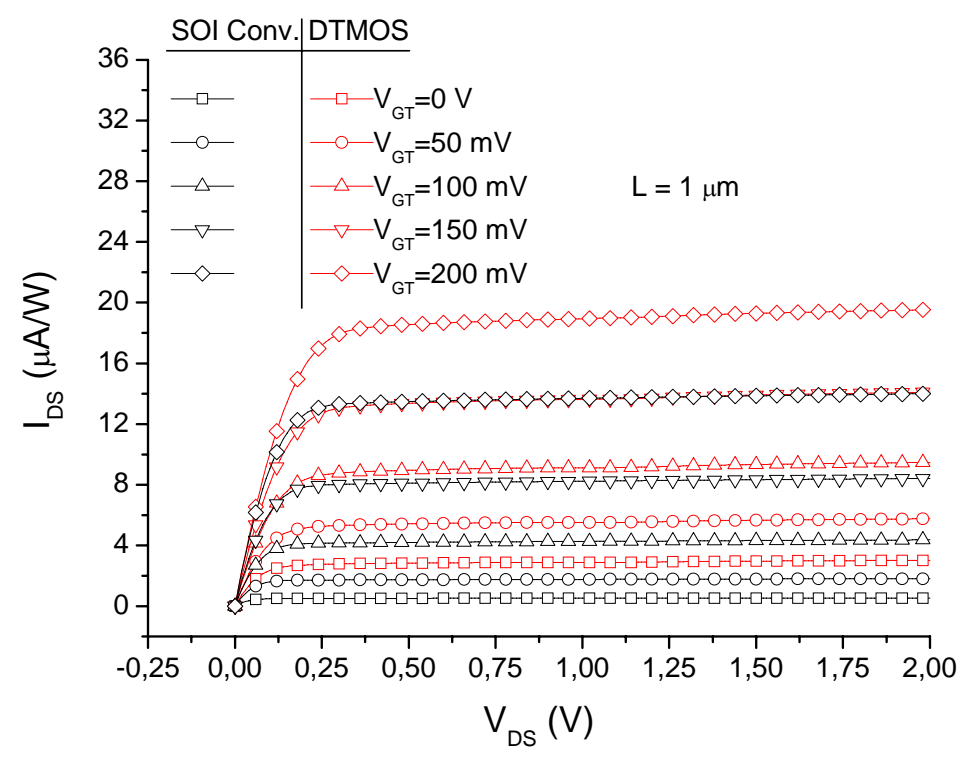

Figura 3.8: Curva da corrente de dreno em função da tensão aplicada na porta para comprimento de canal de $1 \mu \mathrm{m}$

Essa análise foi feita para vários comprimentos de canais e, independentemente do comprimento, obteve-se os mesmos resultados mostrados na Figura 3.8 e já explicados anteriormente.

Na Figura 3.9, podemos observar que o DTMOS possui condutância de saída de dreno menor que o SOI convencional, onde este apresenta um leve efeito "kink". Essa característica da curva de dreno é boa para aplicação em circuitos analógicos por causa dos altos valores da tensão de Early e menores valores da condutância de saída. 


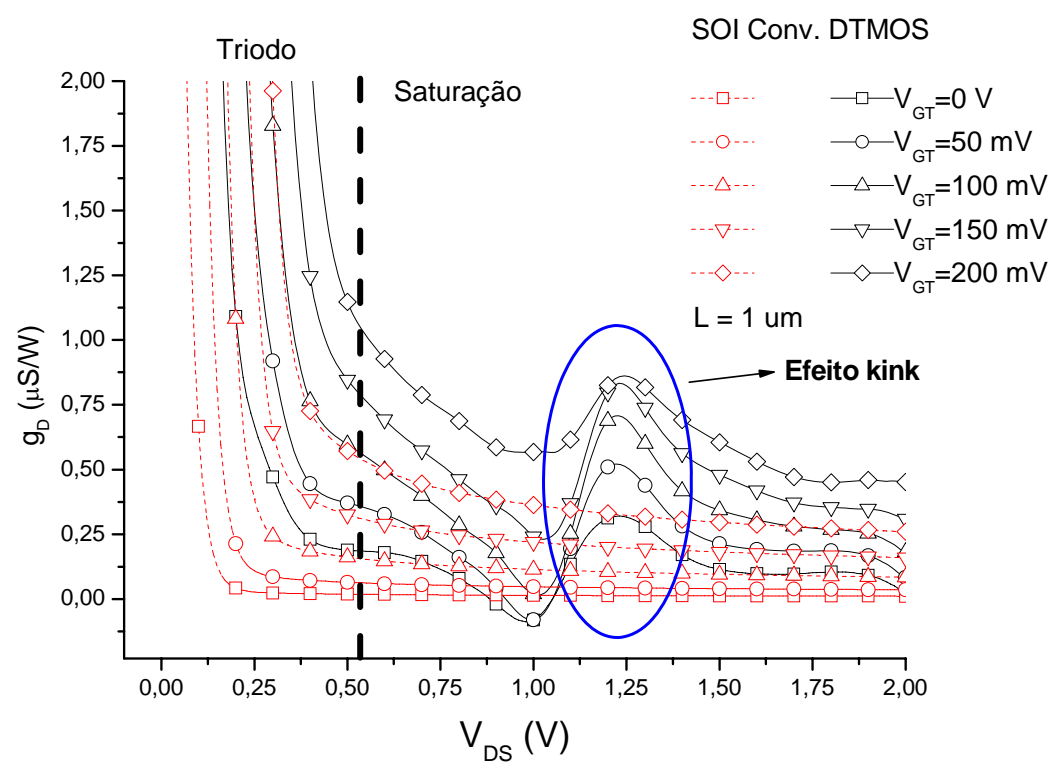

Figura 3.9: Curva da corrente de dreno em função da tensão aplicada na porta para comprimento de canal de $1 \mu \mathrm{m}$.

\subsubsection{Razão $g_{m} / I_{D S}$}

A razão $g_{m} / I_{D S}$ em função da corrente normalizada $I_{D S}$ é mostrado na Figura 3.10 e a mesma foi calculada através das curvas de $\left(\mathrm{g}_{\mathrm{m}}\right)$ e $\left(\mathrm{I}_{\mathrm{DS}}\right)$ considerando a tensão no dreno $\left(\mathrm{V}_{\mathrm{DS}}\right)$ de $1 \mathrm{~V}$. É possível observar que a razão $\mathrm{g}_{\mathrm{m}} / \mathrm{I}_{\mathrm{DS}}$ pode atingir valores de 40 $\mathrm{V}^{-1}$ para o dispositivo DTMOS, enquanto o valor máximo obtido para a SOI convencional é de $33 \mathrm{~V}^{-1}$, ambas na região de inversão fraca. Esse aumento se deve ao fato de o DTMOS possuir a transcondutância e corrente de dreno maior. Esse aumento de corrente é descrito no item 2.2.9 e na Tabela 3.6 pode-se observar a relação de melhora quando comparamos o SOI convencional com o DTMOS. 


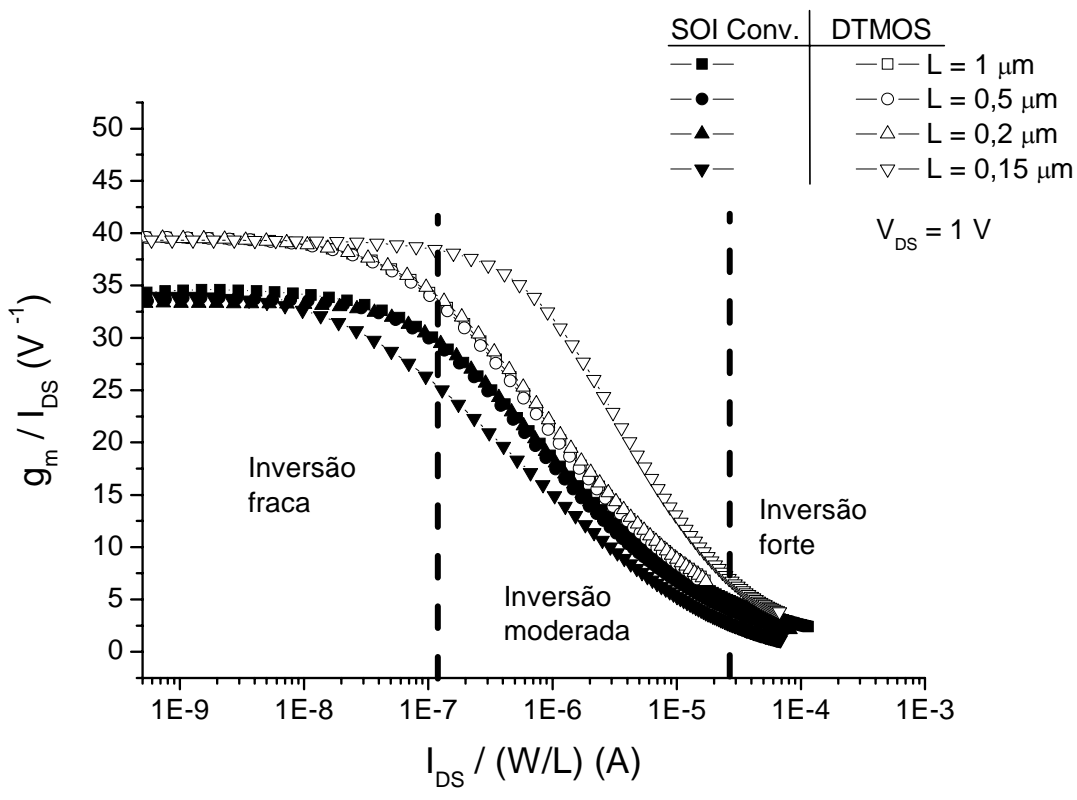

Figura 3.10: Curva de $g_{m}$ em função da corrente normalizada $I_{D S}$ parra os dispositivo SOI convencional e DTMOS para diversos valores de comprimento e canal.

Tabela 3.6: Valores da relação da transcondutância $g_{m}$ em função da corrente normalizada $\mathrm{I}_{\mathrm{DS}} / \mathrm{W}$ considerando o $\mathrm{V}_{\mathrm{GT}}$ de $50 \mathrm{mV}$.

\begin{tabular}{|c|c|c|c|}
\hline $\mathbf{L}(\boldsymbol{\mu m})$ & \multicolumn{2}{|c|}{$\mathbf{g}_{\mathbf{m}} / \mathbf{I}_{\mathbf{D S}}\left(\mathbf{V}^{\mathbf{- 1}}\right)$} & $\begin{array}{c}\% \\
\text { Melhora }\end{array}$ \\
\hline 1 & SOI Convencional & DTMOS & 10 \\
\hline 0,5 & 18,68 & 20,71 & 45 \\
\hline 0,2 & 19,04 & 27,66 & 55 \\
\hline 0,15 & 17,45 & 27,03 & 50 \\
\hline
\end{tabular}

3.2.8 Ganho de Tensão Intrínseco $\left(\mathrm{A}_{\mathrm{V}}\right)$ e freqüência de ganho unitário $\left(\mathrm{f}_{\mathrm{T}}\right)$

A Figura 3.11 (A) mostra o ganho DC versus a corrente normalizada $I_{D S}$ nas regiões de inversão fraca, moderada e forte. Através dos resultados obtidos anteriormente $\left(\mathrm{g}_{\mathrm{m}} / \mathrm{I}_{\mathrm{DS}}\right.$ e $\left.\mathrm{V}_{\mathrm{EA}}\right)$, é perceptível que o dispositivo DTMOS apresenta um ganho de tensão DC mais elevado quando comparado com o SOI convencional. É 
possível observar que o ganho de tensão para a região de inversão fraca do DTMOS atingiu valores próximos a $55 \mathrm{~dB}$, enquanto o SOI convencional atingiu valores próximos de $48 \mathrm{~dB}$, considerando o comprimento de canal de $1 \mu \mathrm{m}$ e próximo de $46 \mathrm{~dB}$ contra $32 \mathrm{~dB}$ considerando o comprimento de canal de $0,2 \mu \mathrm{m}$.

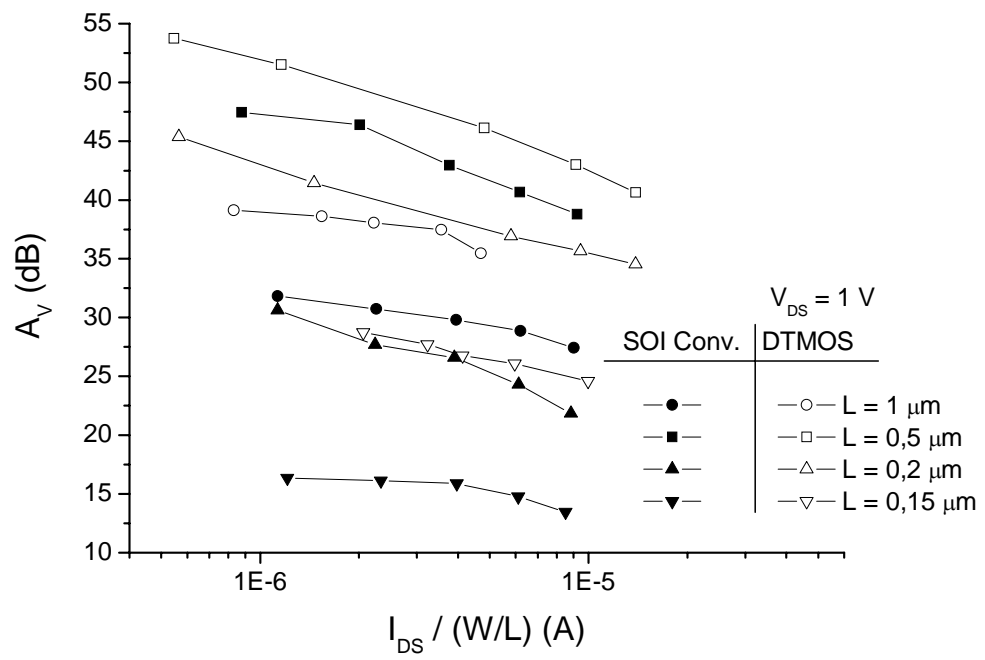

(A) 


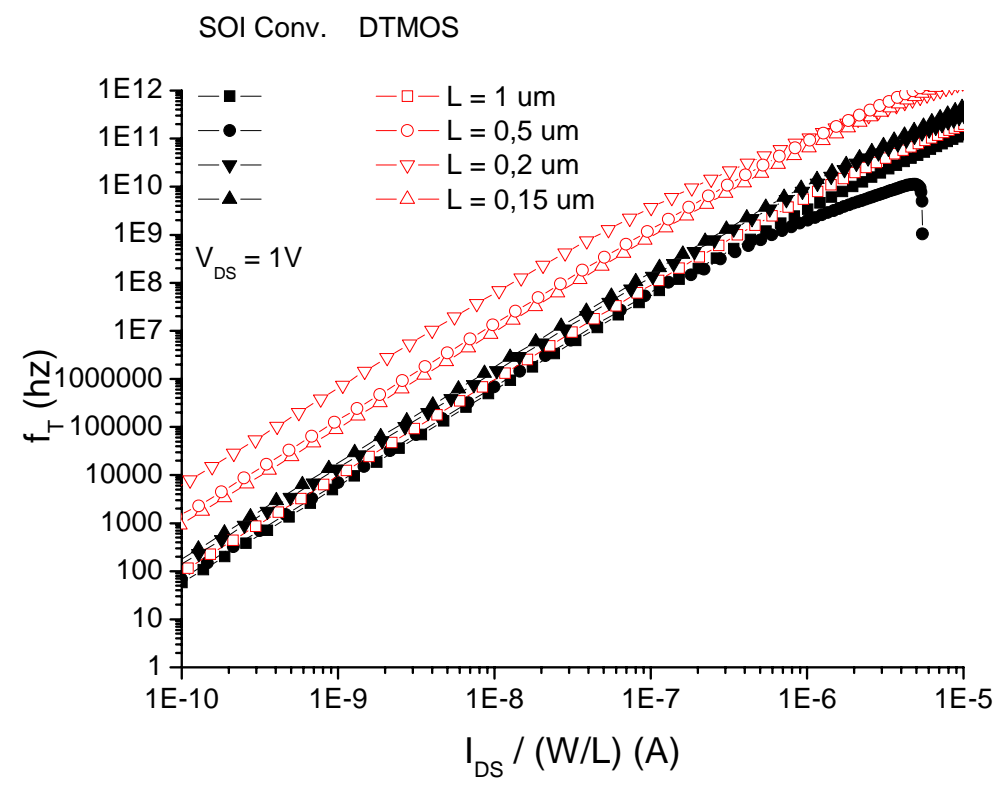

(B)

Figura 3.11: Curva do ganho de tensão DC em função da corrente normalizada $\mathrm{I}_{\mathrm{DS}} /(\mathrm{W} / \mathrm{L})(\mathrm{A})$ e, da freqüência de ganho unitário $\left(\mathrm{f}_{\mathrm{T}}\right)$ com uma capacitância de carga de $14 \mathrm{pF}(\mathrm{B})$ para diferentes comprimentos de canais do PDSOI e do DTMOS.

A figura $3.11 \mathrm{~B}$ mostra o ganho intrínseco da freqüência de ganho unitário $\left(\mathrm{f}_{\mathrm{T}}\right)$ dependente da corrente de dreno normalizada. Os valores do dispositivo DTMOS são superiores quando comparados com o SOI convencional devido ao melhor comportamento da curva $\mathrm{g}_{\mathrm{m}} / \mathrm{I}_{\mathrm{DS}}$ (vide equação 2.29), como mostra a figura 3.9. 


\section{Resultados Experimentais}

Este capítulo está dividido em duas partes. Na primeira parte são apresentados todos os resultados obtidos experimentalmente do dispositivo DTMOS do tipo I (Figura 2.3 A), e do SOI convencional considerando a variação do comprimento de canal. Na segunda parte são apresentados os resultados experimentais, considerando a variação da largura (W) em ambos os dispositivos.

Os dispositivos que foram utilizados experimentalmente foram fabricados no IMEC (Interuniversity Microelectronics Centre) que fica em Leuven, Bélgica. Na tabela 4.1, estão descritas as características físicas do dispositivo. Para a caracterização elétrica dos mesmos, foi utilizado o analisador de parâmetros "Agilent 4156".

Tabela 4.1: Características físicas do dispositivo utilizado para obtenção dos resultados experimentais.

\begin{tabular}{|l|l|}
\hline Tecnologia & $0,13 \mu \mathrm{m}$ \\
\hline $\mathrm{t}_{\mathrm{oxf}}$ & $2,5 \mathrm{~nm}$ \\
\hline $\mathrm{t}_{\mathrm{Si}}$ & $100 \mathrm{~nm}$ \\
\hline Variação do comprimento do canal (L) & 10 a $0,15 \mu \mathrm{m}$ \\
\hline Variação da largura $(\mathrm{W})$ & 10 a $0,8 \mu \mathrm{m}$ \\
\hline Concentração do canal $\left(\mathrm{N}_{\mathrm{A}}\right)$ & $5,5 \times 10^{17} \mathrm{~cm}^{-3}$ \\
\hline
\end{tabular}

Através das curvas características obtidas de $\mathrm{I}_{\mathrm{DS}} \times \mathrm{V}_{\mathrm{GS}}$ e $\mathrm{I}_{\mathrm{DS}} \times \mathrm{V}_{\mathrm{DS}}$, tanto para a variação do comprimento do canal (L) quanto para a variação da largura (W), foi extraído a tensão de limiar, transcondutância, inclinação de sublimiar, condutância de saída, tensão Early, relação da transcondutância pela corrente $\mathrm{I}_{\mathrm{DS}}$, ganho intrínseco DC e freqüência de ganho unitário. 


\subsection{Resultados considerando a variação do comprimento de canal (L)}

\subsubsection{Curva característica $\mathrm{I}_{\mathrm{DS}} \mathrm{x} \mathrm{V}_{\mathrm{GS}}$}

Como foi discutido no item 3.2.2, é possível verificar experimentalmente na Figura 4.1 (A) que a corrente do dispositivo SOI DTMOS é maior quando comparado com o SOI parcialmente depletado. Esse aumento de corrente faz com que o dispositivo tenha uma transcondutância máxima maior que o SOI parcialmente depletado. A Figura 4.1 (B) mostra a mesma curva, porém com uma tensão no dreno de 1V. As medidas experimentais foram realizadas até $0,6 \mathrm{~V}$ para evitar polarização direta da junção canal/fonte.

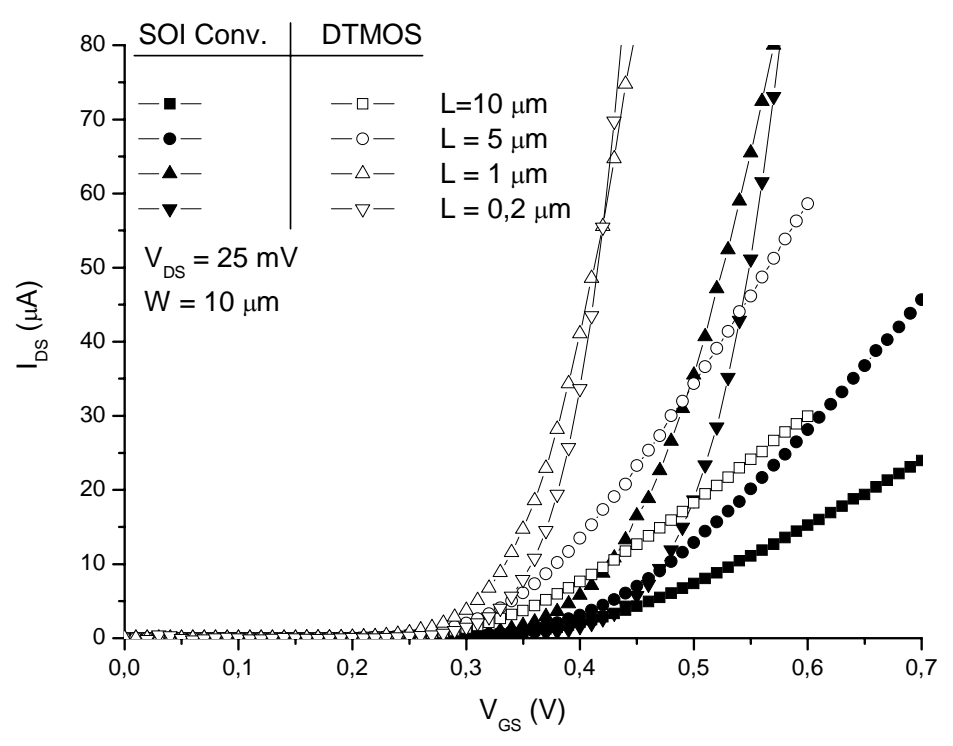

(A) 


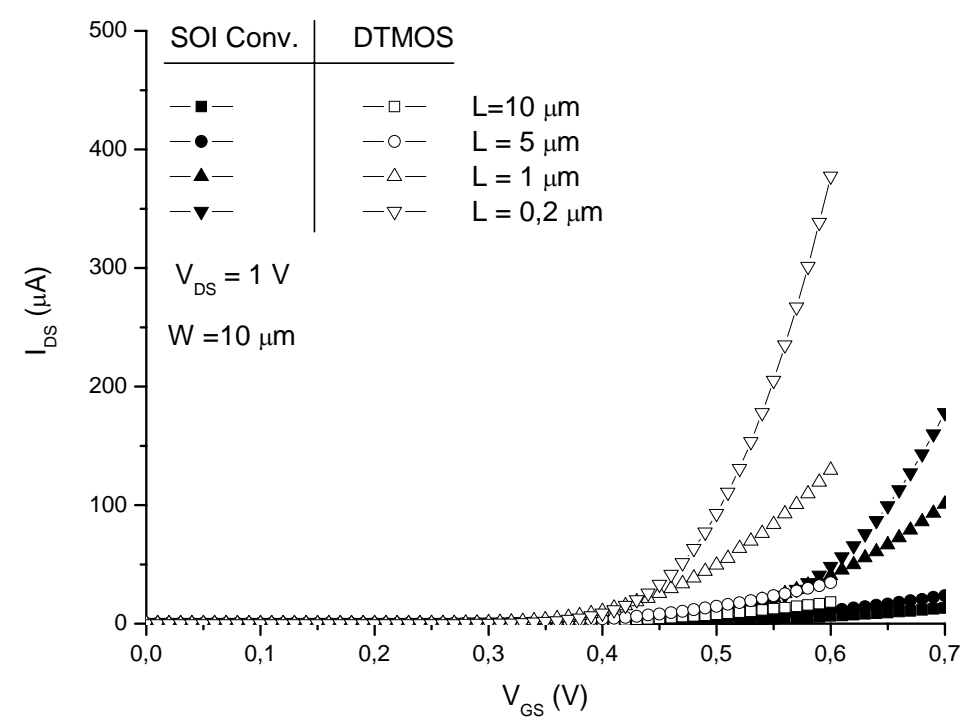

(B)

Figura 4.1: Curva de $\mathrm{I}_{\mathrm{DS}}$ em função da tensão aplicada na porta $\mathrm{V}_{\mathrm{GS}}$ obtidos experimentalmente para diferentes comprimentos de canais do PDSOI e do DTMOS

$$
\text { para } \mathrm{V}_{\mathrm{DS}}=25 \mathrm{mV}(\mathrm{A}) \text { e } \mathrm{V}_{\mathrm{DS}}=1 \mathrm{~V}(\mathrm{~B}) \text {. }
$$

\subsubsection{Transcondutância $\left(\mathrm{g}_{\mathrm{m}}\right)$}

A Figura 4.2 (A) mostra a transcondutância do DTMOS em comparação com o SOI parcialmente depletado. Como dito anteriormente, as curvas obtidas experimentalmente foram realizadas com uma tensão máxima na porta de $600 \mathrm{mV}$. Já a figura 4.2 (B) mostra a transcondutância do dispositivo com tensão no dreno de $1 \mathrm{~V}$. Esse valor mais elevado para o DTMOS se deve ao aumento da corrente que ocorre quando polarizamos o contato de corpo do transistor com a porta e o valor da transcondutância máxima é observado na tabela 4.2 . 
Tabela 4.2: Valores da transcondutância máxima do dispositivo SOI convencional e DTMOS considerando $\mathrm{V}_{\mathrm{DS}}=25 \mathrm{mV}$.

\begin{tabular}{|c|c|c|c|}
\hline $\mathbf{g}_{\mathbf{m m a x}}(\boldsymbol{\mu S})$ & SOI Convencional & DTMOS & \% de ganho \\
\hline $\mathrm{L}=10 \mu \mathrm{m}$ & 9,07 & 12,08 & 33,18 \\
\hline $\mathrm{L}=5 \mu \mathrm{m}$ & 18,12 & 25,01 & 38,02 \\
\hline $\mathrm{L}=0,2 \mu \mathrm{m}$ & 96,87 & 137,23 & 41,66 \\
\hline $\mathrm{L}=0,15 \mu \mathrm{m}$ & 324,00 & 453,00 & 39,81 \\
\hline
\end{tabular}

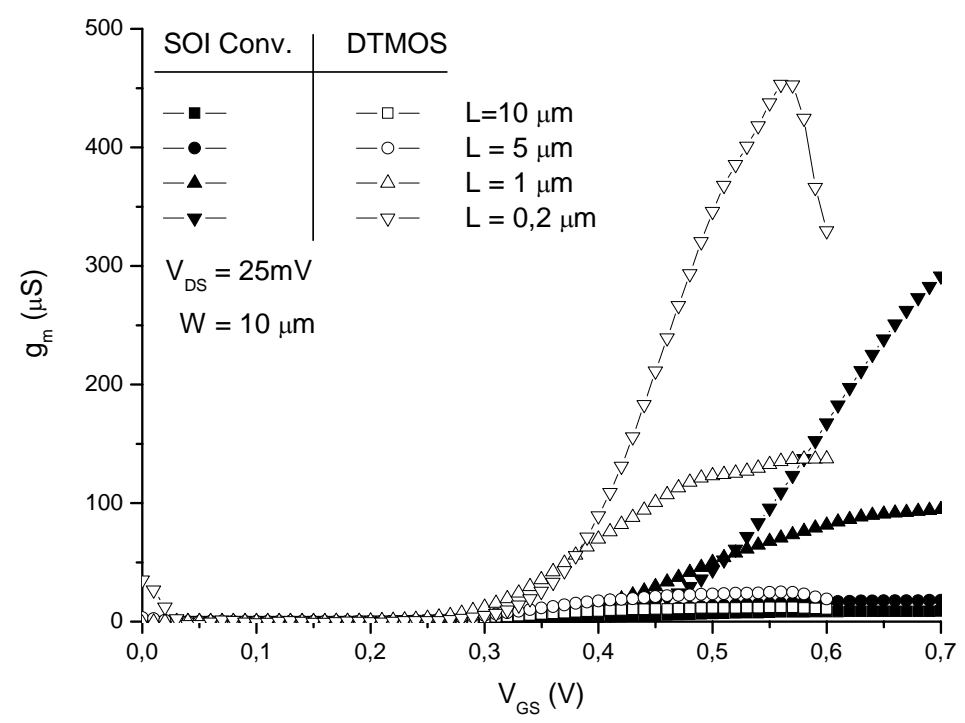

(A) 


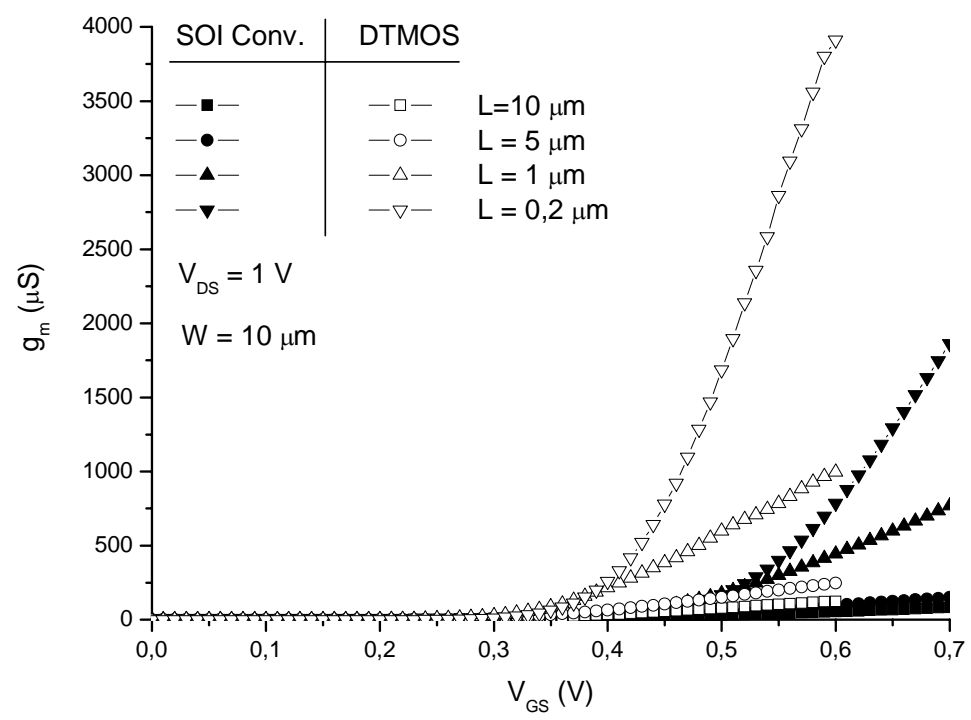

(B)

Figura 4.2: Curvas experimentais da transcondutância em função da tensão aplicada na porta para diferentes comprimentos de canais para o PDSOI e DTMOS considerando

$$
\mathrm{V}_{\mathrm{DS}}=25 \mathrm{mV}(\mathrm{A}) \text { e } \mathrm{V}_{\mathrm{DS}}=1 \mathrm{~V}(\mathrm{~B}) \text {. }
$$

\subsubsection{Inclinação de sublimiar (S)}

Como explicado na seção 3.2.5, a Figura 4.3 (A) mostra que a inclinação de sublimiar do dispositivo DTMOS é melhor quando comparado com o SOI convencional, tendo valores muito próximos do ideal $(60 \mathrm{mV} / \mathrm{dec})$, como pode ser observado na Figura 4.3 (B), mesmo com a redução do comprimento do canal. Foi obtida a inclinação de sublimiar para todos os comprimentos de canal $(10 \mu \mathrm{m} \leq \mathrm{L} \leq$ $0,15 \mu \mathrm{m})$. Pode-se observar que os efeitos de canal curto do transistor DTMOS são menores que o SOI convencional. 


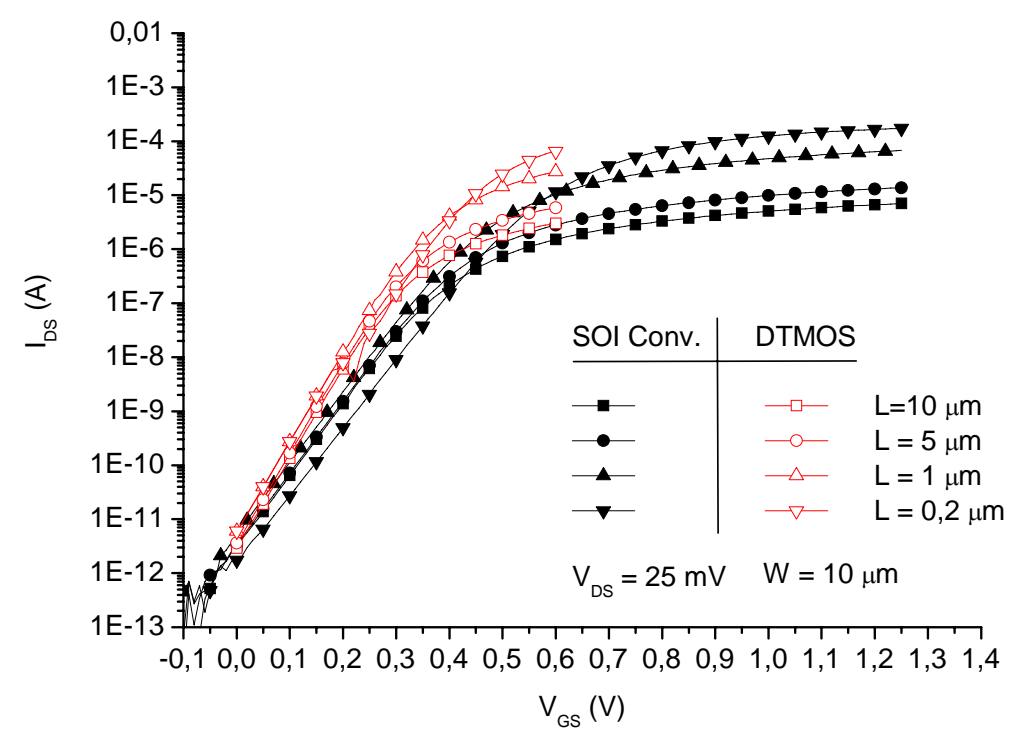

(A)

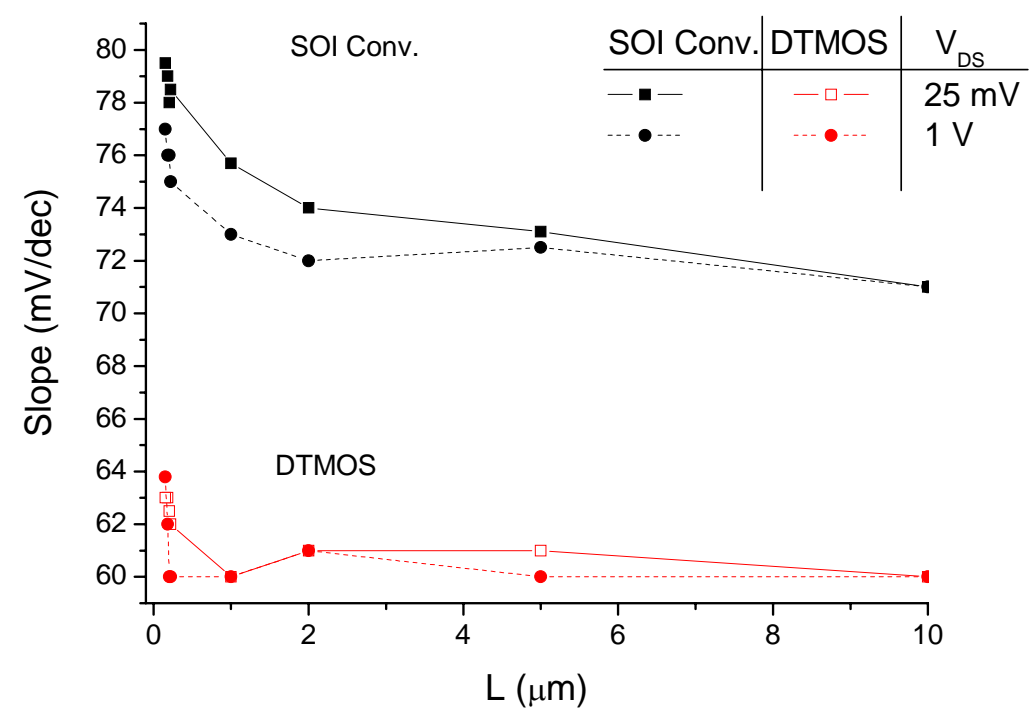

(B)

Figura 4.3: Curvas da corrente de dreno (A) e inclinação de sublimiar (B) obtidas experimentalmente para diferentes comprimentos de canais do PDSOI e do DTMOS. 


\subsubsection{Tensão de Limiar $\left(\mathrm{V}_{\mathrm{TH}}\right)$}

A tensão de limiar foi obtida através da segunda derivada da corrente em função da tensão aplicada na porta, considerando a tensão de dreno em $25 \mathrm{mV}$, e são mostradas na Tabela 4.2 e na Figura 4.4.

Diferentemente dos resultados obtidos através das simulações numéricas bidimensionais, há uma aumento da tensão de limiar do dispositivo SOI convencional quando comparado com o DTMOS. No DTMOS, $\mathrm{V}_{\mathrm{TH}}$ se manteve praticamente constante até $0,5 \mu \mathrm{m}$. Este teve um aumento de aproximadamente $37 \%$ para comprimentos de canal abaixo de $0,22 \mu \mathrm{m}$. Já o dispositivo SOI convencional tem um aumento constante da tensão de limiar tendo uma diferença de $54 \%$. Este fato ocorre porque o dispositivo utilizado experimentalmente possui Halo [35,36]. A implantação do Halo é realizada para reduzir a barreira induzida pelo dreno (DIBL - Drain Induced Barrier Lowering), que provoca um aumento da tensão de limiar e diminuição da mobilidade devido ao aumento médio da concentração do canal.

Tabela 4.3: Valores da tensão de limiar para o dispositivo SOI convencional e DTMOS com $\mathrm{V}_{\mathrm{DS}}=25 \mathrm{mV}$.

\begin{tabular}{|c|c|c|}
\hline \multirow{2}{*}{$\mathrm{L}(\mu \mathrm{m})$} & \multicolumn{2}{|c|}{ Tensão de Limiar $\left(\mathrm{V}_{\mathrm{TH}}\right)(\mathrm{V})$} \\
\cline { 2 - 3 } & SOI Convencional & DTMOS \\
\hline 10 & 0,41 & 0,35 \\
\hline 5 & 0,44 & 0,37 \\
\hline 2 & 0,48 & 0,38 \\
\hline 1 & 0,49 & 0,37 \\
\hline 0,8 & 0,51 & 0,37 \\
\hline 0,6 & 0,52 & 0,38 \\
\hline 0,5 & 0,54 & 0,37 \\
\hline 0,22 & 0,60 & 0,46 \\
\hline 0,20 & 0,61 & 0,46 \\
\hline 0,18 & 0,62 & 0,50 \\
\hline 0,15 & 0,63 & 0,51 \\
\hline
\end{tabular}




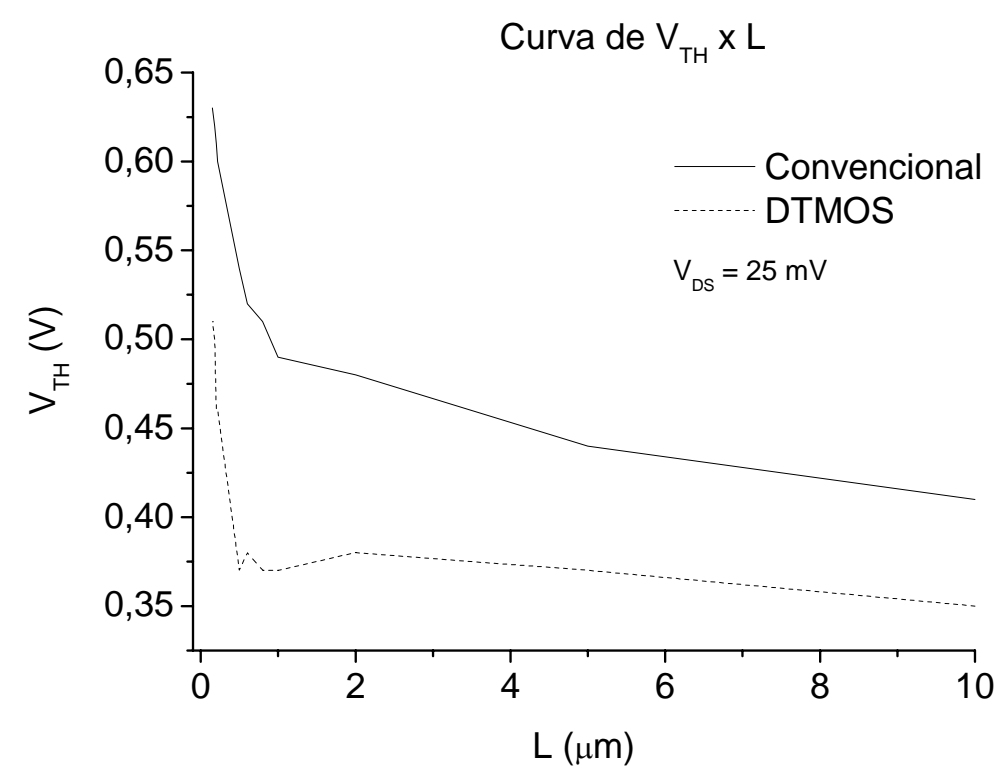

Figura 4.4: Valores da tensão de limiar em função do comprimento de canal (L).

\subsubsection{Tensão Early e condutância de saída}

Através da curva da corrente de dreno em função da tensão aplicada no dreno mostrada na Figura 4.5 (A, B e C), obteve-se a tensão Early que é mostrado na tabela 4.4. Este parâmetro é de extrema importância, pois o mesmo tem uma relação direta com o ganho intrínseco DC como descrito na seção 2.2.10 e foi obtido da mesma forma que na simulação numérica bidimensional. Na Figura $4.5 \mathrm{C}$, pode-se observar claramente a melhora do DTMOS quando comparado com o SOI convencional, pois o mesmo tem uma estabilidade maior na região de saturação, proporcionando assim maiores valores na tensão Early. Em seguida, obteve-se a condutância de saída para ambos os comprimentos de canais que são exibidos também na tabela 4.4. 
Tabela 4.4: Valores da tensão Early $\left(\mathrm{V}_{\mathrm{EA}}\right)$ e $\mathrm{g}_{\mathrm{D}}$ considerando $\mathrm{V}_{\mathrm{GT}}=50 \mathrm{mV}$.

\begin{tabular}{|c|c|c|c|c|c|}
\hline \multirow[t]{2}{*}{$\mathbf{L}(\mu \mathbf{m})$} & \multicolumn{2}{|c|}{ SOI Convencional } & \multicolumn{2}{|c|}{ DTMOS } & \multirow{2}{*}{$\begin{array}{c}\% \\
\text { Melhora V } \\
\text { EA }(V)\end{array}$} \\
\hline & $\mathrm{V}_{\mathrm{EA}}(\mathrm{V})$ & $\mathrm{g}_{\mathrm{D}}(\mu \mathrm{S})$ & $\mathrm{V}_{\mathrm{EA}}(\mathrm{V})$ & $\mathrm{g}_{\mathrm{D}}(\mu \mathrm{S})$ & \\
\hline 10 & 20,01 & 0,124 & 49,75 & 0,012 & 248,00 \\
\hline 5 & 27,43 & 0,151 & 33,02 & 0,020 & 20,37 \\
\hline 1 & 13,05 & 0,136 & 18,60 & 0,032 & 42,52 \\
\hline 0,20 & 12,85 & 0,167 & 16,35 & 0,021 & 27,23 \\
\hline
\end{tabular}

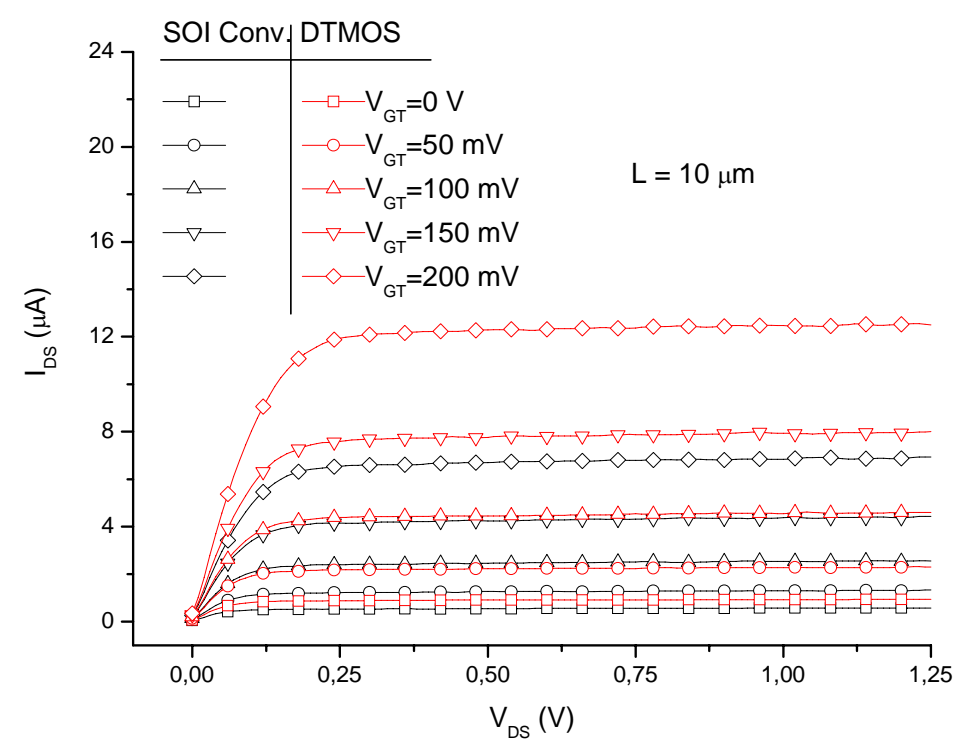

(A) 


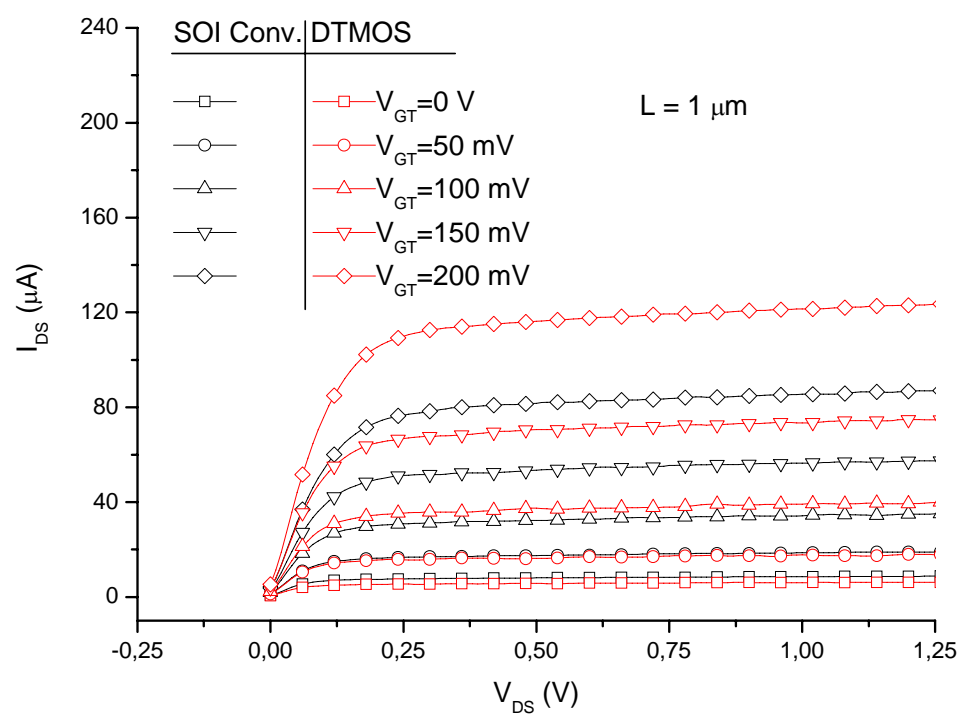

(B)

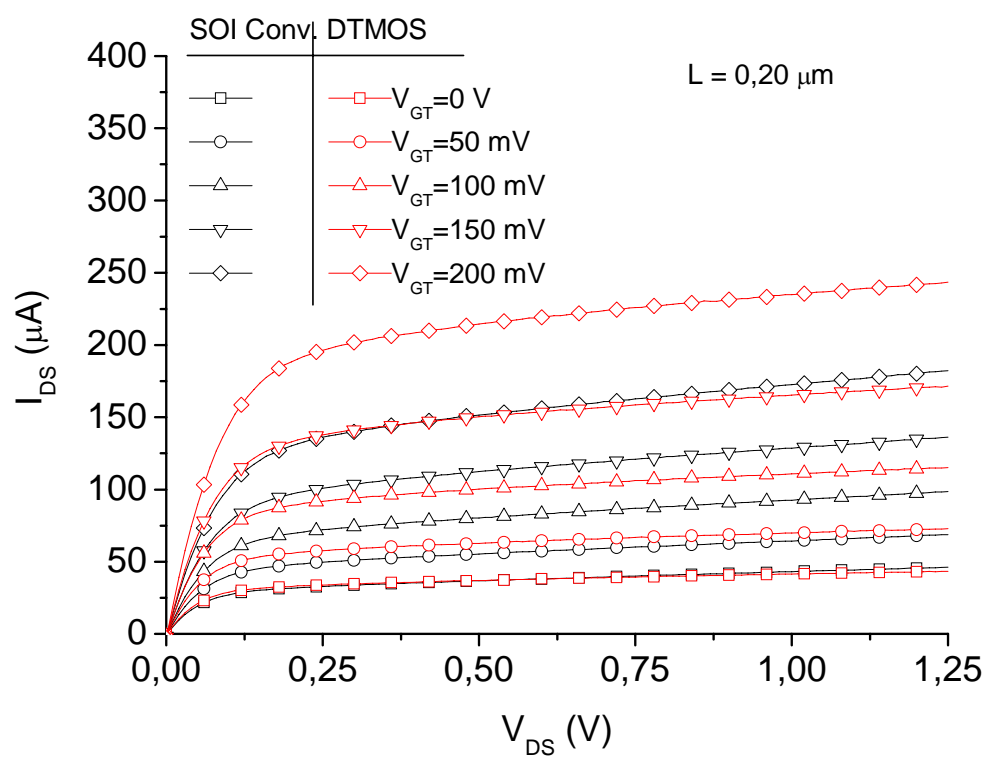

(C)

Figura 4.5: Curva da corrente de dreno em função da tensão aplicada no dreno para comprimento de canal de $10 \mu \mathrm{m}(\mathrm{A}), 1 \mu \mathrm{m}$ (B) e 0,2 $\mu \mathrm{m}$ (C). 


\subsubsection{Relação de $g_{m} / I_{D S}$}

É possível observar na Figura 4.7 que o DTMOS atingiu valores aproximados de $40 \mathrm{~V}^{-1}$ na região de inversão fraca, enquanto que o SOI parcialmente depletado chegou próximo de $35 \mathrm{~V}^{-1}$. Como explicado no capítulo 3, isso ocorre porque o DTMOS possui uma maior transcondutância e maior corrente de dreno. Na tabela 4.5 é possível observar os valores obtidos considerando $\mathrm{V}_{\mathrm{GT}}=50 \mathrm{mV}$.

Tabela 4.5: Valores da relação da transcondutância $g_{m}$ em função da corrente normalizada $\mathrm{I}_{\mathrm{DS}} / \mathrm{W}$ considerando o $\mathrm{V}_{\mathrm{GT}}$ de $50 \mathrm{mV}$.

\begin{tabular}{|c|c|c|c|}
\hline \multirow[t]{2}{*}{$\mathbf{L}(\mu \mathbf{m})$} & \multicolumn{2}{|c|}{$g_{m} / I_{D S}\left(V^{-1}\right)$} & \multirow{2}{*}{$\begin{array}{c}\% \\
\text { Melhora }\end{array}$} \\
\hline & SOI Convencional & DTMOS & \\
\hline 10 & 17,57 & 26,02 & 48,00 \\
\hline 5 & 16,91 & 21,60 & 27,73 \\
\hline 1 & 9,36 & 17,55 & 87,50 \\
\hline 0,20 & 10,81 & 13,87 & 28,31 \\
\hline
\end{tabular}

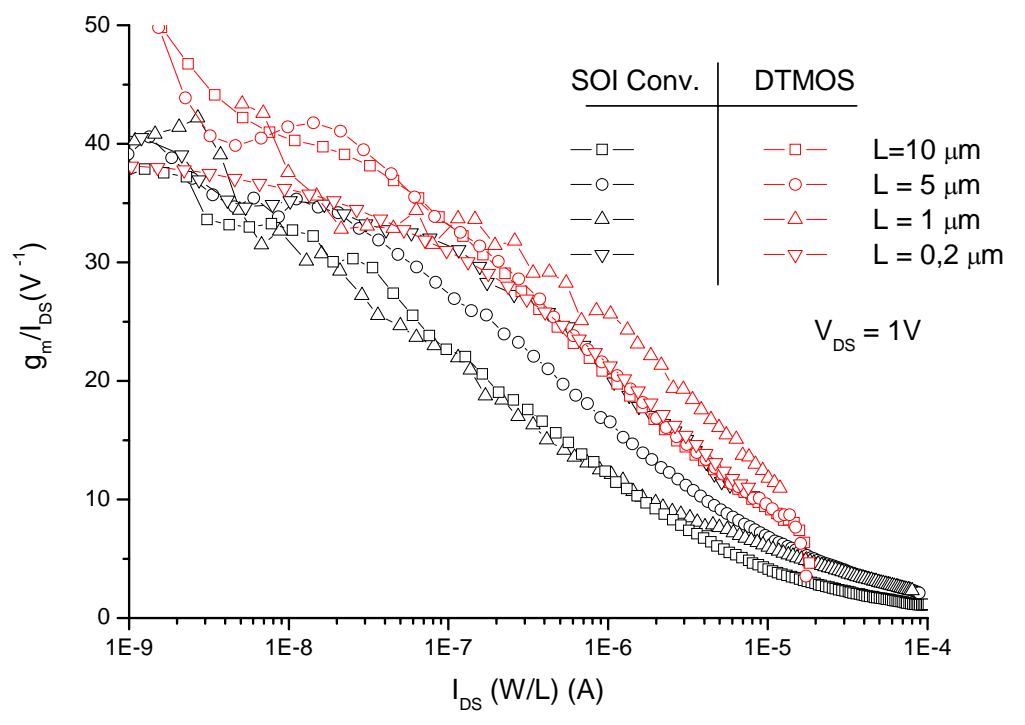

Figura 4.6: Curva de $g_{m} / I_{D S}$ em função da corrente normalizada $\mathrm{I}_{\mathrm{DS}} /(\mathrm{W} / \mathrm{L})$ comparativa dos resultados obtidos através da simulação e experimentalmente para o PDSOI e DTMOS para diferentes comprimentos de canais. 
4.1.7 Ganho intrínseco $\mathrm{DC}\left(\mathrm{A}_{\mathrm{V}}\right)$ e freqüência de ganho unitário $\left(\mathrm{f}_{\mathrm{T}}\right)$

Na Figura 4.8 (A), observa-se o ganho intrínseco DC do SOI convencional em comparação com o DTMOS. Observa-se que o DTMOS possui maiores valores que o SOI convencional. Os resultados simulados não ficaram iguais, mas pode-se verificar a tendência dos resultados. O melhor resultado é observado considerando o comprimento de canal de $0,2 \mu \mathrm{m}$, onde o DTMOS atinge aproximadamente $40 \mathrm{~dB}$, enquanto o SOI parcialmente depletado alcança cerca de $26 \mathrm{~dB}$.

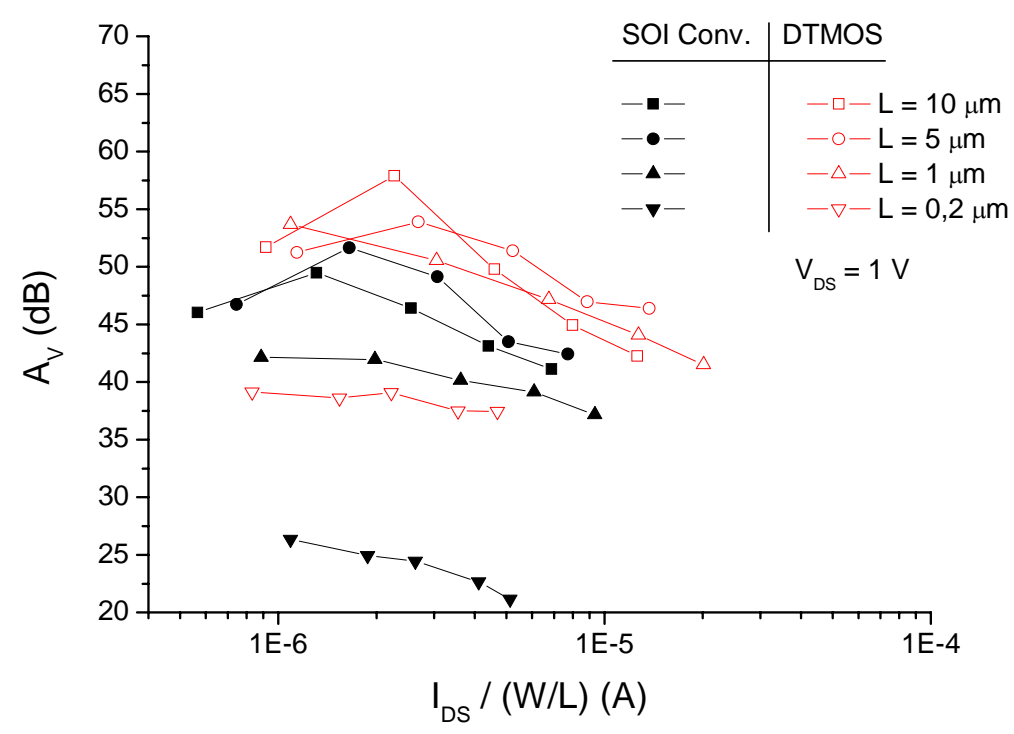

(A) 


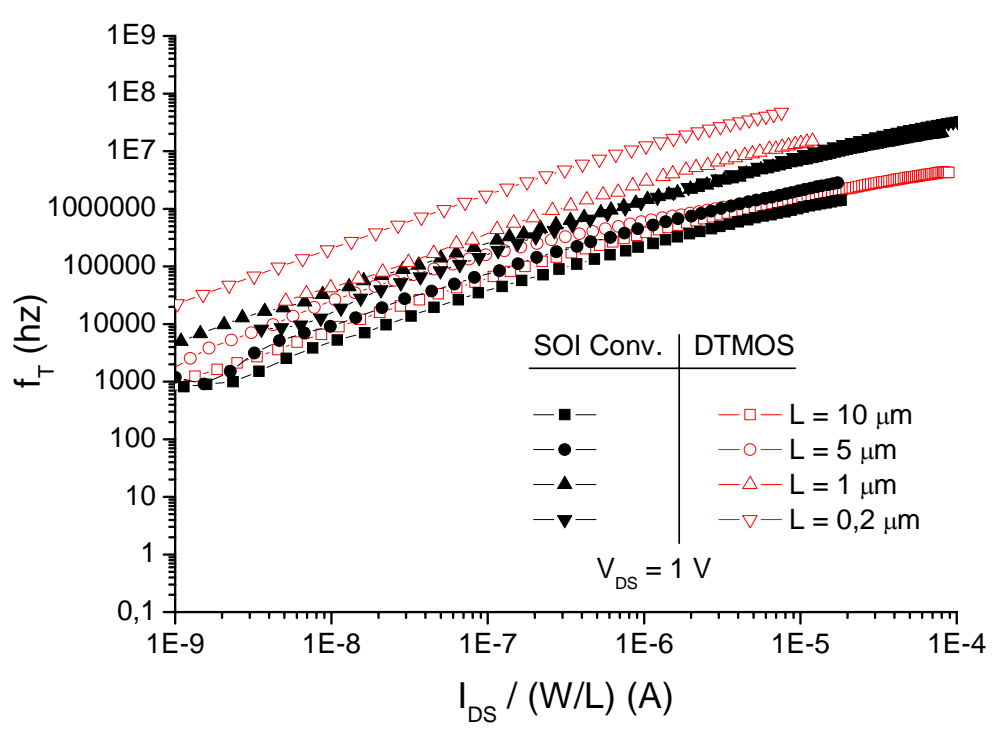

(B)

Figura 4.7: Curva do ganho DC em função da corrente normalizada $\mathrm{I}_{\mathrm{DS}}(\mathrm{A})$ e da freqüência de ganho unitário com uma capacitância de carga de 14 pF (B) obtido experimentalmente para diferentes comprimentos de canais.

Na Figura 4.8 (B) observa-se a freqüência de ganho unitário para vários valores de comprimento de canal. Como já eram esperados, os valores da freqüência de ganho unitário do DTMOS se manteve maior. Isso ocorre porque a mesma tem uma relação direta com a transcondutância, fato que concede o DTMOS apto a trabalhar em circuitos analógicos e aplicações Low-Power-Low-Voltage (LPLV).

\subsection{Resultados obtidos considerando a variação da largura do dispositivo (W)}

Neste tópico comparou-se o comportamento do DTMOS com o SOI parcialmente depletado, quando temos uma variação da largura (W) dos dispositivos. A largura teve uma variação de 10 a $0,8 \mu \mathrm{m}$. Mesmo tendo uma redução na largura, o DTMOS se manteve com as suas características elétricas melhores quando comparado com o PDSOI. A seguir segue os resultados obtidos com a variação de W. 


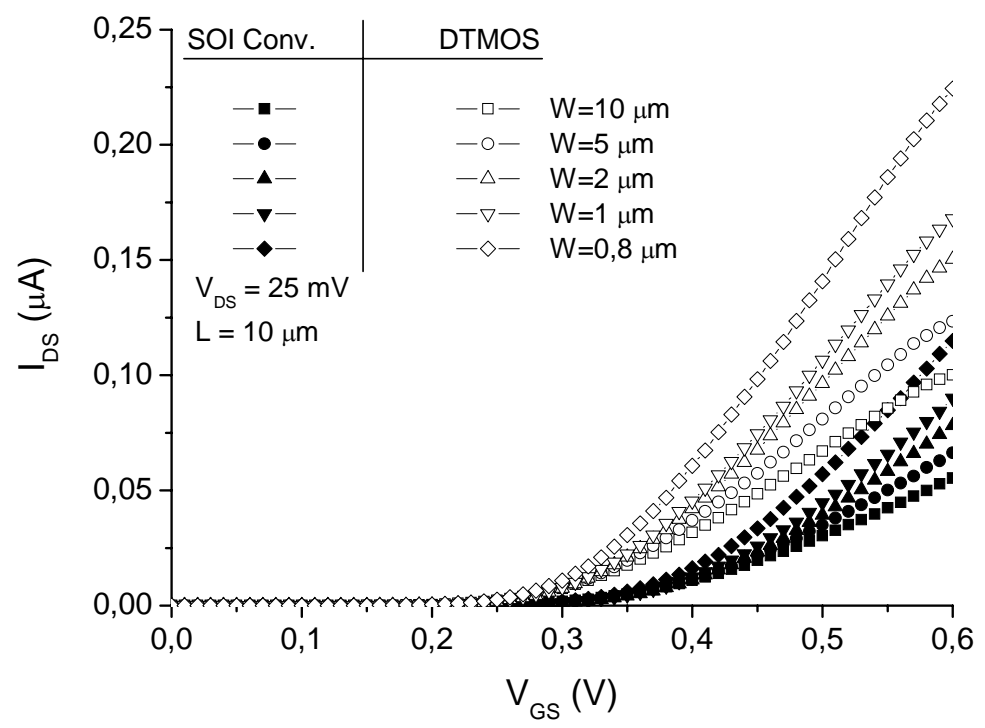

Figura 4.8: Curva da corrente $\mathrm{I}_{\mathrm{DS}}$ em função de $\mathrm{V}_{\mathrm{GS}}$ do dispositivo SOI e DTMOS para várias larguras $\mathrm{W}$.

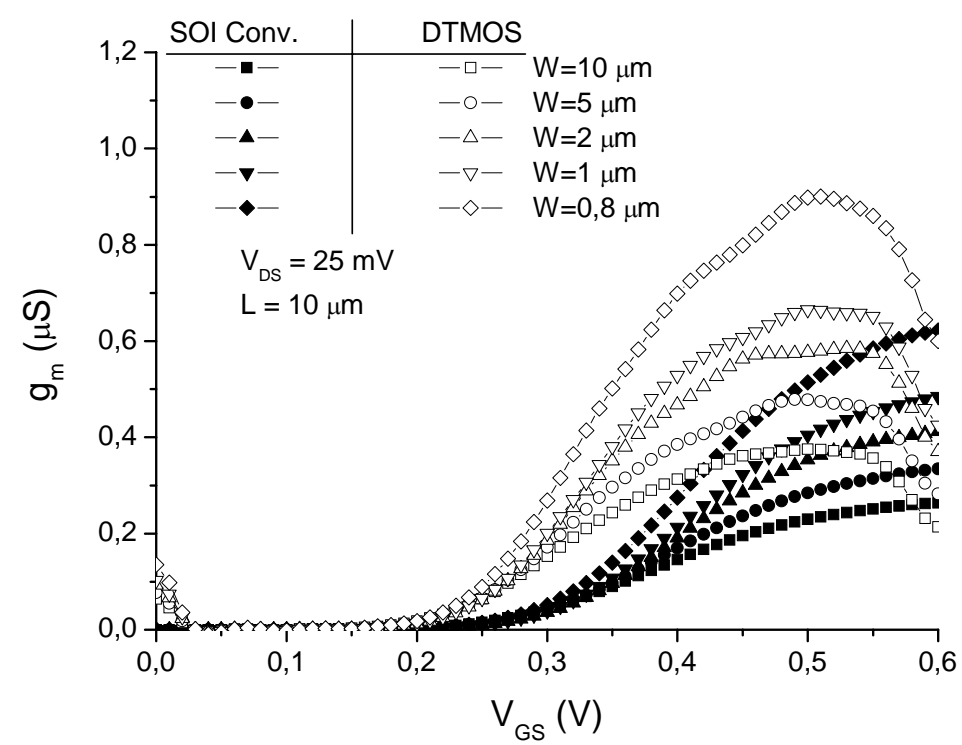

Figura 4.9: Curva da transcondutância em função da tensão aplicada na porta $\mathrm{V}_{\mathrm{GS}}$ para diversas larguras do PDSOI e do DTMOS. 


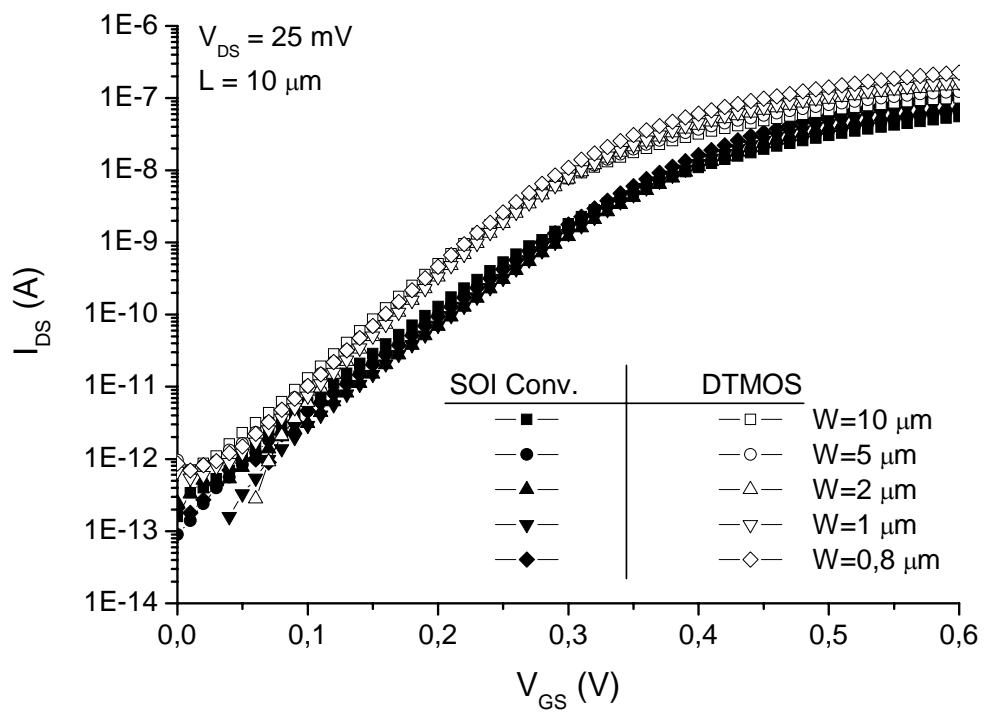

Figura 4.10: Curva da corrente de dreno em função da tensão aplicada na porta $\mathrm{V}_{\mathrm{GS}}$ do PDSOI e do DTMOS para diversas larguras (W).

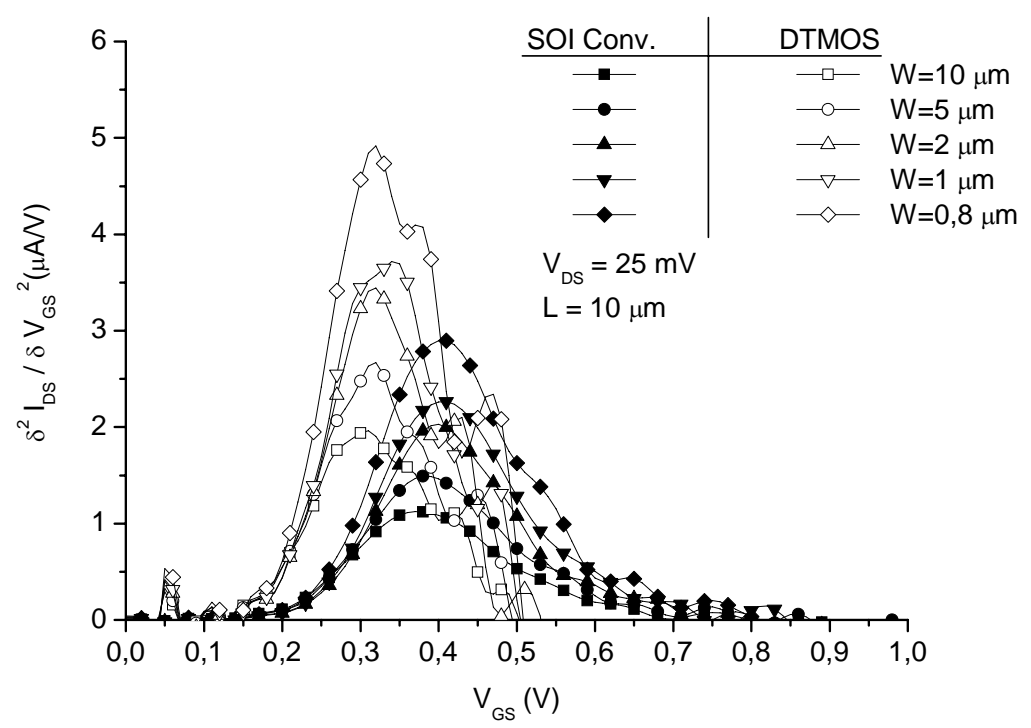

(A) 


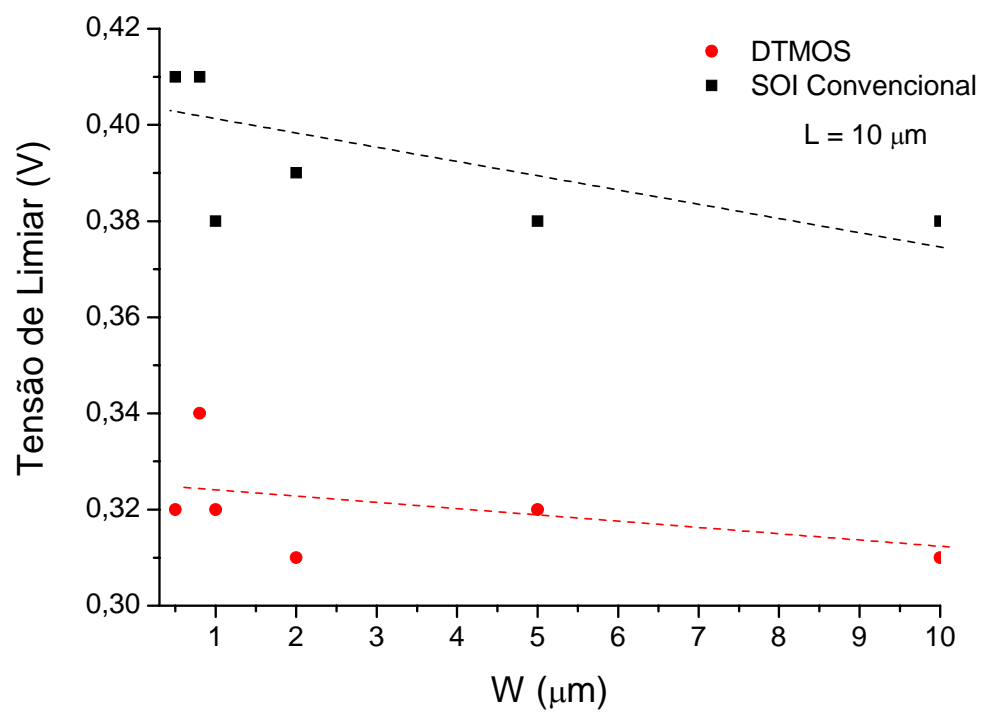

(B)

Figura 4.11: Curva da segunda derivada da corrente em função da tensão aplicada na porta do dispositivo PDSOI e DTMOS para diversas larguras (W) (A) e valores da tensão de limiar em função de W (B). 


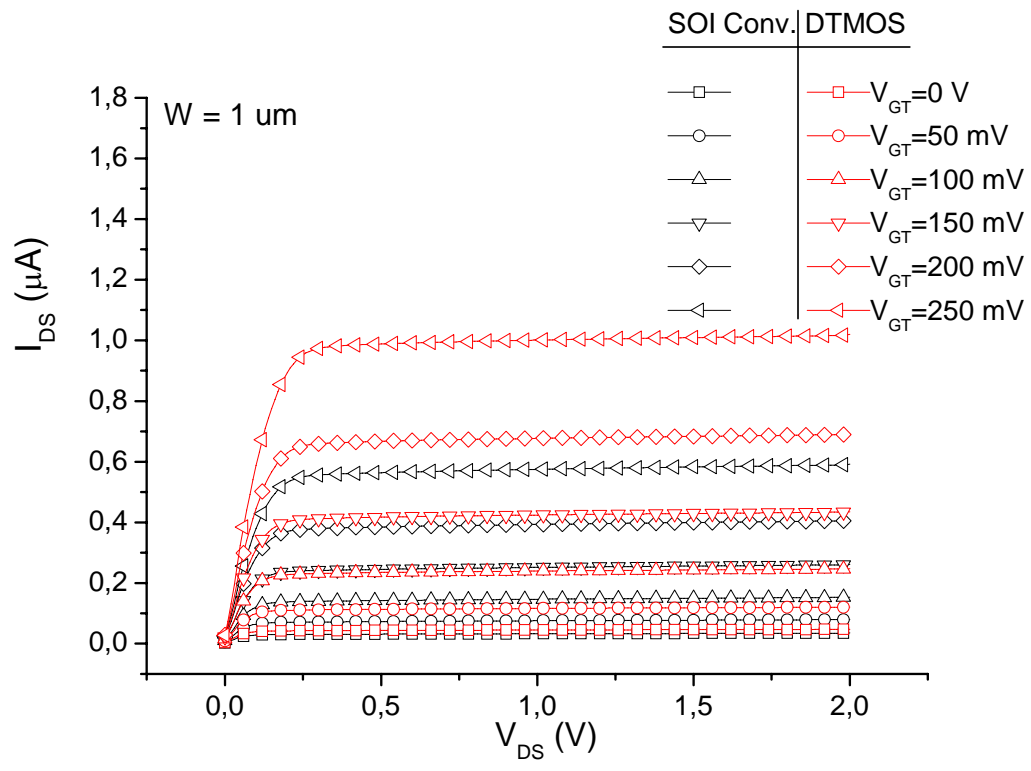

Figura 4.12: Curva da corrente de dreno em função da tensão aplicada no dreno do dispositivo PDSOI e DTMOS para largura (W) de $1 \mu \mathrm{m}$.

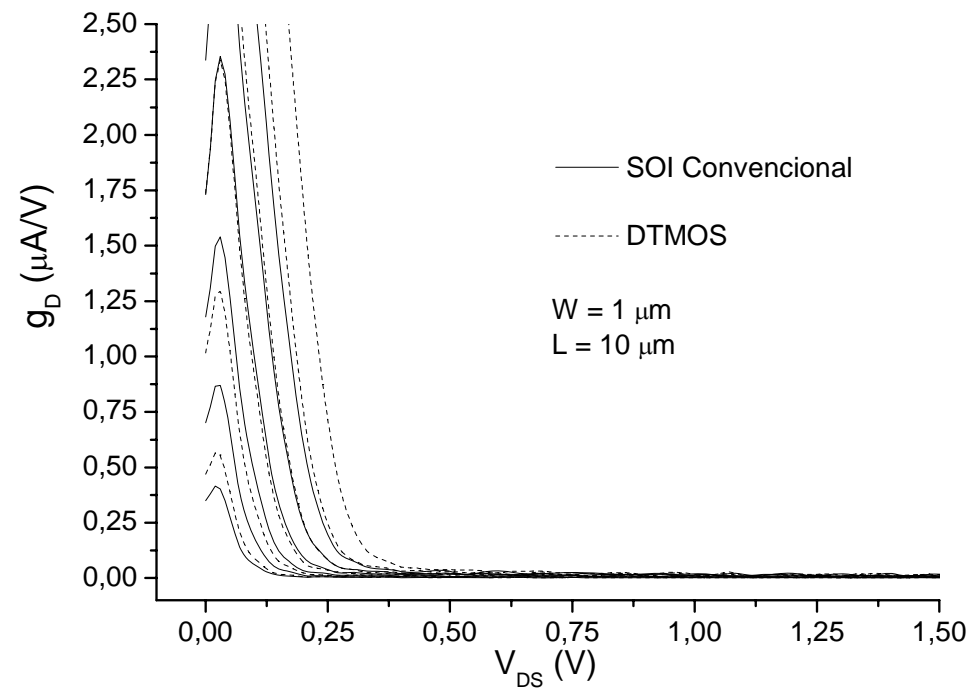

Figura 4.13: Curva da condutância de saída $\left(\mathrm{g}_{\mathrm{D}}\right)$ em função da tensão aplicada no dreno do dispositivo PDSOI e DTMOS para largura (W) de $1 \mu \mathrm{m}$. 


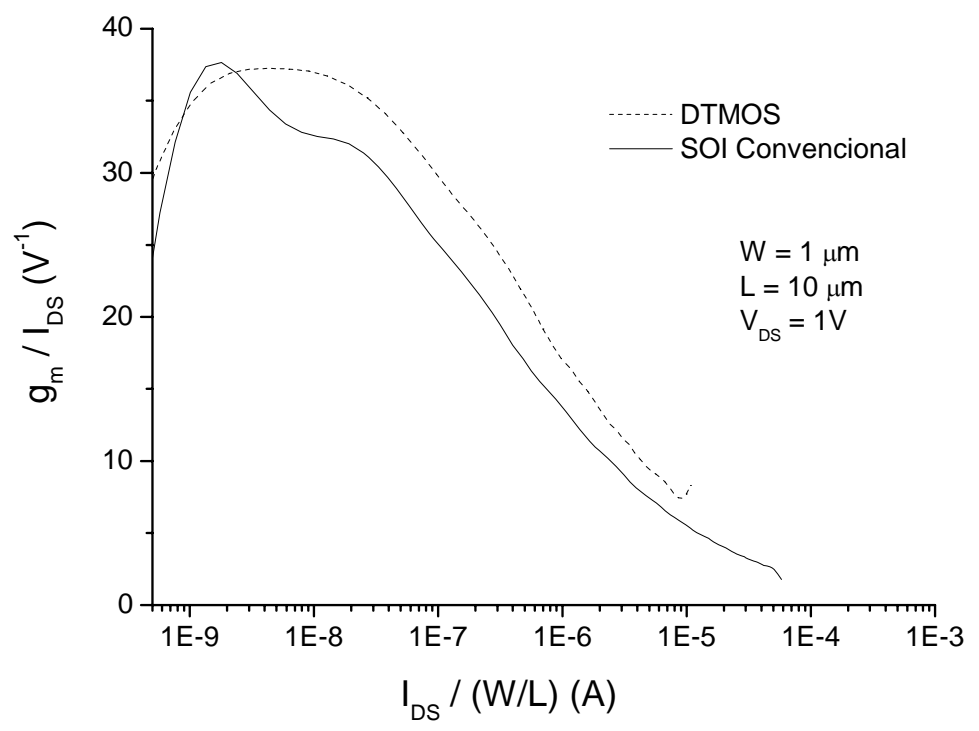

Figura 4.14: Curva da relação $g_{m} / I_{D S}$ em função da corrente normalizada $I_{D S}$ do dispositivo PDSOI e DTMOS para largura (W) de $1 \mu \mathrm{m}$.

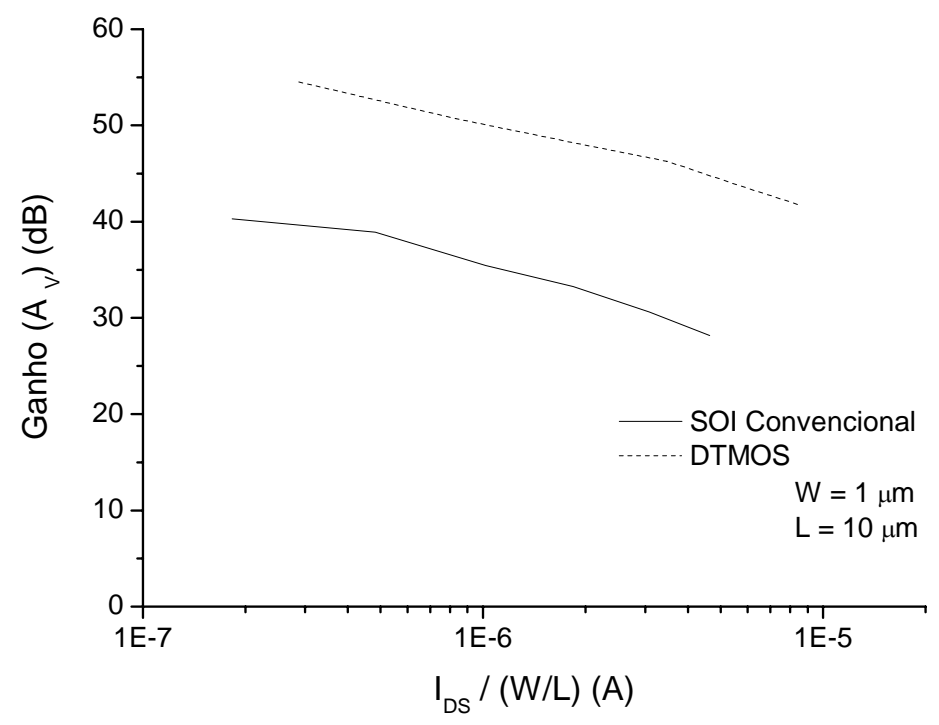

(A) 


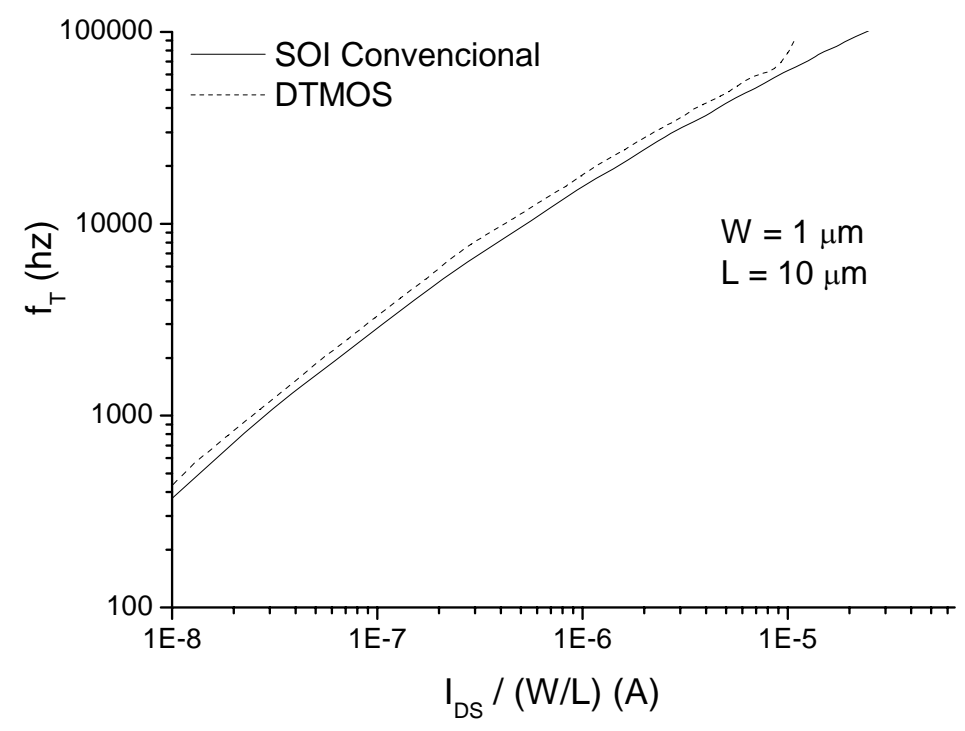

(B)

Figura 4.15: Curva do ganho DC em função da corrente normalizada $I_{D S}(A)$ e da freqüência de ganho unitário $\left(\mathrm{f}_{\mathrm{T}}\right)$ do dispositivo PDSOI e DTMOS para largura $(\mathrm{W})$ de $1 \mu \mathrm{m}$ e capacitância de carga de 14 pF (B). 


\section{Conclusões e Seqüência do Trabalho}

Este trabalho foi desenvolvido com o objetivo de analisar o desempenho analógico do dispositivo SOI DTMOS em comparação com o SOI convencional (canal flutuando).

Os resultados apresentados foram baseados em simulações numéricas bidimensionais, realizadas através do simulador ATLAS, e de resultados experimentais, obtidos através de uma cascata de transistores com variação do comprimento de canal e da largura. Foram analisados os principais parâmetros analógicos, que são fundamentais para a aplicação de circuitos analógicos, tais como: transcondutância, relação de $\mathrm{g}_{\mathrm{m}} /$ $\mathrm{I}_{\mathrm{DS}}$, tensão Early, ganho intrínseco DC e freqüência de ganho unitário.

Observou-se que o valor efetivo do $\mathrm{V}_{\mathrm{TH}}$ do DTMOS manteve-se constante com a redução do comprimento do canal, enquanto o SOI convencional apresentou os indesejáveis efeitos de canal curto dentro da faixa estudada. A corrente de dreno e a transcondutância do DTMOS são maiores que o SOI convencional. O aumento expressivo da transcondutância indica que o DTMOS tem um melhor desempenho para trabalhar em aplicações analógicas de baixa tensão e baixa potência, visto que o ganho intrínseco DC e a freqüência de ganho unitário têm uma relação direta com este parâmetro.

A tensão Early obtida tanto para os resultados simulados quanto experimentais também foram maiores no DTMOS. Isto ocorre porque o DTMOS apresenta na região de saturação curvas com menos inclinação quando comparado com o PDSOI. Mesmo diminuindo o comprimento do canal, foi possível observar que a tensão Early se manteve maior em todos os casos analisados.

Como o DTMOS possui uma corrente maior e uma maior transcondutância, a relação $\mathrm{g}_{\mathrm{m}} / \mathrm{I}_{\mathrm{DS}}$ apresentou-se maior no DTMOS tendo valores próximos a $40 \mathrm{~V}^{-1}$ na região de inversão fraca, enquanto o PDSOI teve valores próximo de $35 \mathrm{~V}^{-1}$. Nos resultados experimentais, apesar de os valores serem um pouco diferentes do obtido através da simulação, mostrou-se a mesma tendência, quando comparado com o SOI convencional.

Foi também observado um aumento significativo no ganho de tensão intrínseco DC, tendo uma média de diferença de $8 \mathrm{~dB}$ para comprimentos de canais grande e acima de $10 \mathrm{~dB}$ considerando o comprimento de canal de 1 e $0,22 \mu \mathrm{m}$ em relação ao 
SOI convencional, e da freqüência de ganho unitário, tanto nos resultados simulados como nos experimentais. Isto se deve ao fato de o DTMOS apresentar melhores características nos parâmetros de $g_{\mathrm{m}} / \mathrm{I}_{\mathrm{DS}} \mathrm{e} \mathrm{V}_{\mathrm{EA}}$.

Em resumo, todos os parâmetros analógicos analisados no DTMOS apresentam melhores resultados do que os obtidos em dispositivo SOI convencional. Uma desvantagem do DTMOS é que o mesmo não pode ser utilizado para um valor de tensão superior a $0,7 \mathrm{~V}$ na porta pois, devido à existência do contato de corpo, ocorre a polarização direta da junção canal/fonte e apresentar menor área.

Com este trabalho, foi possível observar o comportamento dos parâmetros analógicos do dispositivo SOI DTMOS em comparação com o PDSOI tanto em simulações quanto em resultados experimentais.

Finalizando, sugere-se para futuros trabalhos, um estudo mais detalhado dos efeitos da variação da temperatura no DTMOS e da variação da dopagem do canal, além do escalamento desta estrutura através de simulações tridimensionais. 


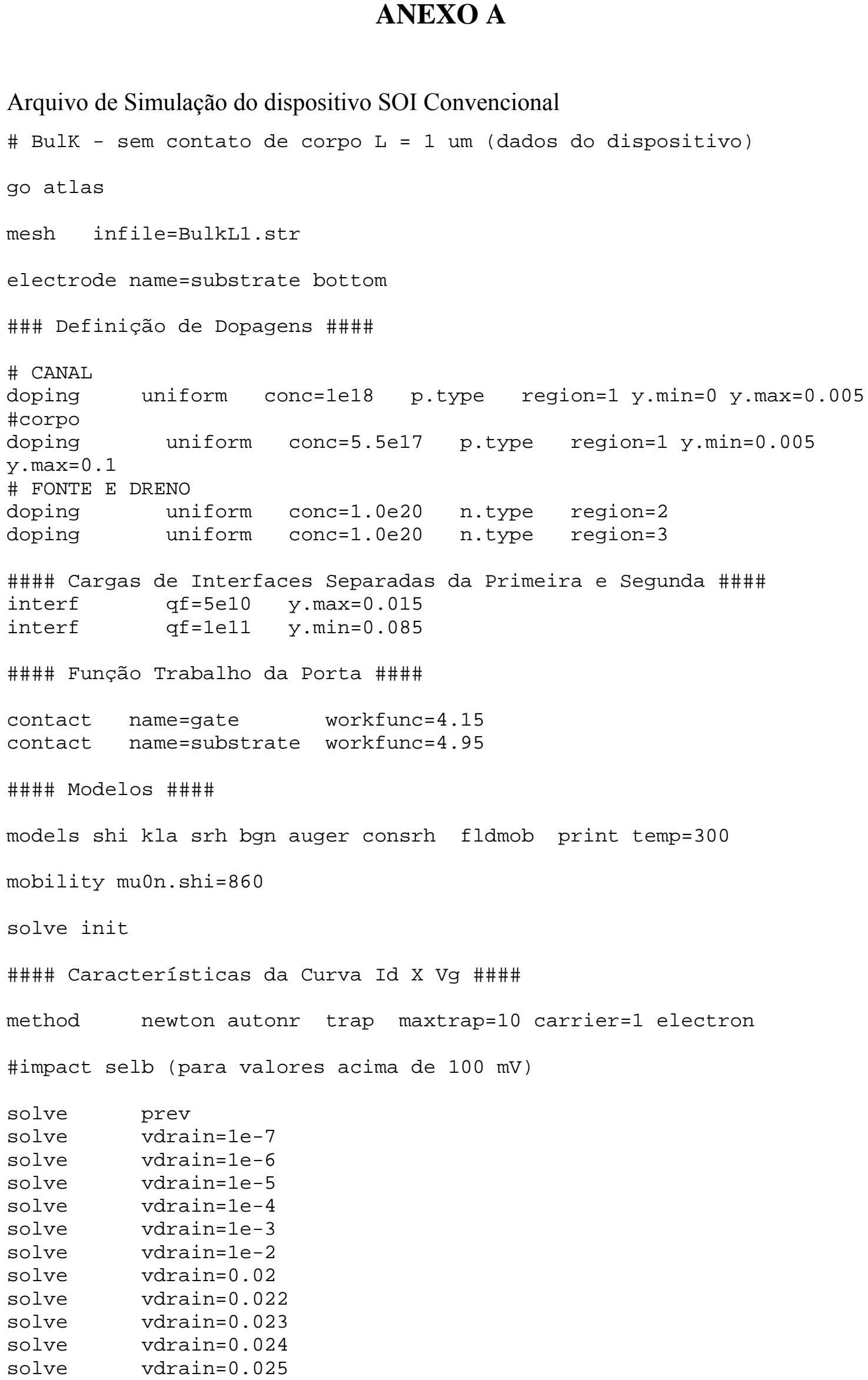




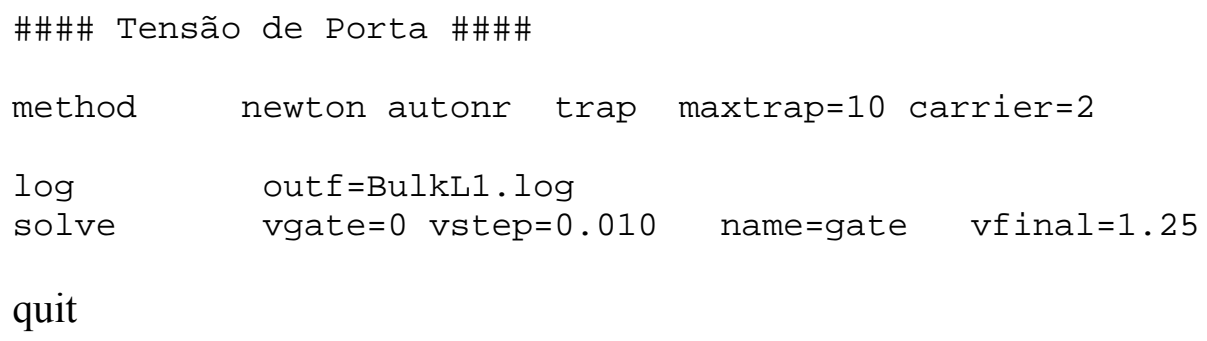




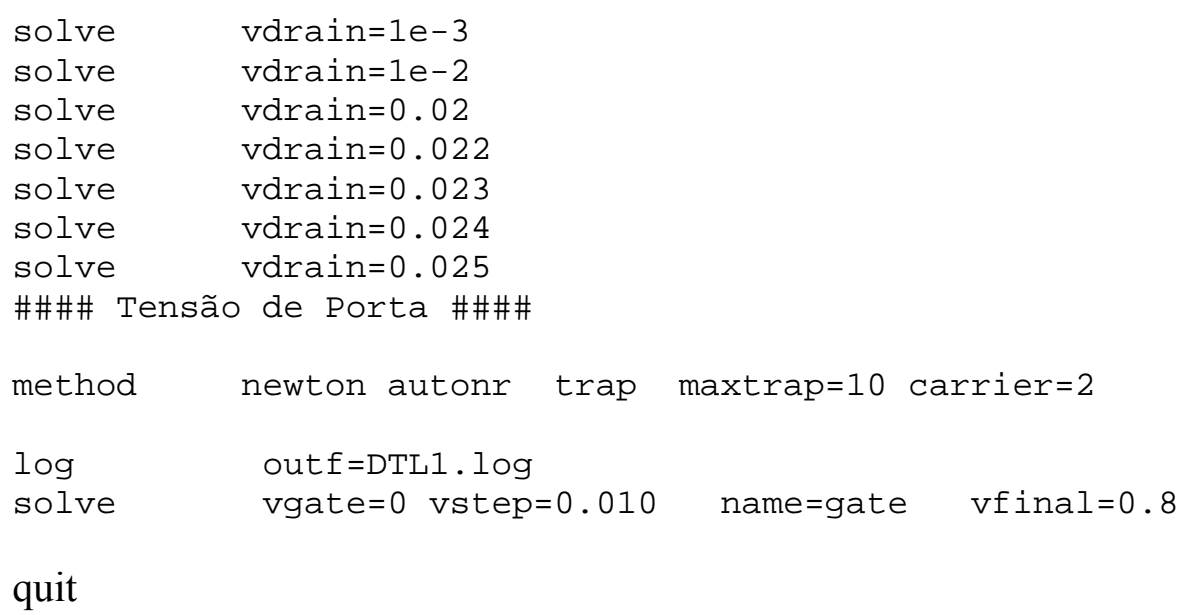

quit 


\section{Referências Bibliográficas}

[1]. YOUNG K.K. Short-channel effect in SOI MOSFET. IEEE Transactions on Electron Devices, v.36, n.2, p.399, 1989.

[2]. TAUR, Y.; BUCHANAN, D. A. et al., CMOS scaling into nanometer regime. Proceedings of IEEE, v.85, p.486, 1997.

[3]. FUJISHIMA, M. et al., Low-power $1 / 2$ frequency dividers using $0.1 \mathrm{~m}$ CMOS circuits built with ultrathin SIMOX substrates, IEEE Journal Solid-State Circuits, v.28, no. 4, p.510, 1993.

[4]. AUBERTON-HERVE, A.J.; Digest of Symposium on VLSI Technology, p.66, 1998.

[5]. YOSHIMI, M.; HAZAMA, H.; TAKAHASHI, S.; KAMBAYACHI, S.;TANGO H.; Observation of mobility enhancement in ultrathin SOI MOSFET, Electronics Letters, v.24, n.17, p.1078-1079, 1988.

[6]. COLINGE, J. P.; An SOI Voltage Controlled Bipolar MOS Device, IEEE Transactions on Electron Devices, Vol.44, no.4, p.845, 1987.

[7]. COLINGE, J. P.; Voltage Controlled Bipolar MOS (VCBM) Ring Oscillators, Electronics Letters, Vol.23, no.9, p.1023-4, 1987.

[8]. TERAUCHI, M.; Threshold Voltage Fluctuation Analysis in Hybrid Bipolar MOS (HBMOS) Based on Charge-Sharing, IEEE Transactions on Electron Devices, p. 53-4, 2001.

[9]. ASSEDARAGUI, F.; PARKE, S.; A Dynamic Threshold Voltage MOSFET (DTMOS) for Very Low Voltage Operation, IEEE Transactions on Electron Devices, Vol.15, no.12, p.510-512, 1994. 
[10].YAN, Z.; DEEN, M.J.; MALHI, D.S.; Gate Controlled Lateral PNP BJT: Characteristics, Modeling and Circuits Application, Transactions on Electron Devices, Vol.44, n.1, p.118-128, 1997.

[11].DOUSEKI, T.;SHIGEMATSU, S.; YAMADA, J.; HARADA, M.; NOKAWA, H.; TSUCHIYA, T.; A 0.5 V MTCMOS/SIMOX Logic, Journal of Solid State Circuits, Vol.32, n.10, p.1604-1609 1997.

[12].DOUSEKI, T.;SHIGEMATSU, S.; YAMADA, J.; HARADA, M.; NOKAWA, H.; TSUCHIYA, T.; A 0.5 V SIMOX-MTCMOS circuits with 200 ps ogic gate, IEEE Transactions on Electron Devices, p84-85 1996.

[13].BURKE, F.; RAMBHATLA, A.; ZAURAK, J.; PARKE, S.; Source/Drain Optimization of the Dynamic Threshold DTMOS Device in a 0.15 um SOI Embedded DRAM Technology, IEEE Transactions on Electron Devices, p.336-337.

[14].SHAO, T.S.; LEE, Y.J.; HUANG, T.Y.; High Voltage and High Temperature Applications of DTMOS With Reverse Schottky Barrier on Substrate Contacts, IEEE Transactions on Electron Devices, vol.25, n.2, pag.86-88, 2004.

[15].XIA, Z.; GE, Y.; ZHAO, Y.; A Study of Varied Threshold Voltage MOSFET (VTMOS) Performance and Principle, IEEE Transactions on Electron Devices, vol.1, pag.159-162, 2000.

[16].CHANG, C.Y.; SU, J.G.; HSU, H.M.; WONG, S.C.; HUANG, T.Y.; SUN, Y.C.; Investigations of Dynamic Threshold Voltage MOSFET with $65 \mathrm{Ghz}$ "Normal Mode" Ft and 220 Ghz "Over Drive Mode" Ft for RF Application, Digest of Symposium on VLSI Technology, p.89-90, 2001.

[17].LEE, J. K.; CHOI, N. J.; YU, C. G.; COLINGE, J. P.; PARK, J. T.; Temperature Dependence of DTMOS Transistor Characteristics, Solid States Electronics, v.48, no. 6, p. 183-187, 2004. 
[18]. ASSEDARAGUI, F.; PARKE, S.; A Dynamic Threshold Voltage MOSFET (DTMOS) for Very Low Voltage Operation, IEEE Transactions on Electron Devices, Vol.15, no.12, p.510-512, 1994.

[19].CAVROIS, V.F.; PAILLET, P.; MUSSEAU, O.; LERAY, J.L.; FAYNOT, O.; RAYNAULD, C.; PELLOIE, J.L.; Total Dose Behavior of Partially Depleted SOI Dynamic Threshold Voltage MOS (DTMOS) for Very Low Supply Voltage Applications (0.6-1V).

[20].COLINGE, J.P.; Silicon-on-Insulator Technology: Materials to VLSI, Bostom, Kluwer Academic Publishers, $3^{\text {a }}$ edição, 2003 366p.

[21].SILVARAM P.; AMAND B.; DESAI M. P.; Silicon Film Thickness Considerations in SOI-MOSFET, IEEE Transactions on Electron Devices Letters, v. 23, no. 5, p. 276-278, 2002.

[22].PATRICK W.; MACKIE W. S.; BEAUMONT, S. P.; Very Short Gate Length SOI MOSFET, IEEE Transactions on Electron Devices, p.471-475, 1985.

[23].DUAN, F.L.; IOANNOU, D.E.; JENKINS, W.C.; HUGHES, H.L.; LIU, M.S.T, Channel Coupling Imposed Tradeoffs on Hot Carrier Degradation and Single Transistor Latch-up in SOI MOSFETS, IEEE Transactions on Electron Devices, v. 31, no. 3, p. 194-202, 1998.

[24]. MARTINO, J.A.; PAVANELLO M.A.; VERDONCK, P.B.; Caracterização Elétrica de Tecnologia e Dispositivos MOS, Thomson, 2004 193p.

[25].TERAO, A.; FLANDRE, D.; LORA-TAMAYO, E.; VAN DE WIELE, F.; Measurement of threshold voltage of thin-film accumulation-mode pMOS/SOI transistors, IEEE Transactions on Electron Devices Letters, v. 12, no. 12, 1991. 
[26].KUMAR, M. J.; VERMA, V.; Elimination of Bipolar Induced Drain Breakdown and Single Transistor Latch in Submicron PD SOI MOSFET, IEEE Transactions on Electron Devices, v. 51, no. 3, p. 367-370, 2002.

[27].HAFEZ, I.M.; GHIBAUDO, G.; BALESTRA, F.; Analysis of the kink effect in MOS transistors, IEEE Transactions on Electron Devices, v. 37, no. 3, p. 818-821, 1990.

[28]. MERKEL, G.; Nato Course on Process and Devices Modeling for Integrated Circuit Design, Ed. by F. Van de Wyele, W. Engl and P. Jespers, Groningen, The Netherlands, Noordhoff, pag. 725-738, 1977.

[29]. COLINE, J.P.; Reduction of Kink Effect in Thin-Film SOI MOSFETs, IEEE Electron Devices Letters, v. 9, no. 2, p. 97-99, 1988.

[30]. DUAN, F. L.; SINHA, S. P.; IOANNOU, D. E.; BRADY, F. T.; LDD Design Tradeoffs for Single Transistor Latch-up and Hot Carrier Degradation Control in Accumulation Mode FD SOI MOSFET, IEEE Transactions on Electron Devices, v. 44, no. 6, p. 972-977, 1997.

[31]. SILVEIRA, F.; FLANDRE, D.; GESPERS, P.G.; A $g_{m} / I_{D s}$ Based Methodology for the Design of CMOS Analog Circuits and its Application of the Synthesis of a Silicon-on-Insulator Micropower OTA, IEEE Transactions on Electron Devices, v. 31, no.9, p. 1314-1319, 1996.

[32]. SEDRA, A.S.; SMITH, K.C.; Microeletrônica, Makron Books-Pearson Education, $4^{\text {a }}$ edição, 1270 pag., 2000.

[33]. AMARO, J.O.; AGOPIAN, P.G.D.; MARTINO, J.A.; Analog Performance of

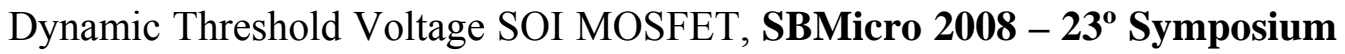
of Microelectronics, Vol.14, 2008. 
[34]. Atlas user's manual, Device simulation software, Silvaco International, v.2, 2007.

[35].Erlebach, A.; Feudel, T.; Schenk, A.; Zechner, C.; Influence of HALO and drain-extension doping gradients on transistor performance, Materials Science and Engineering, pag.15-19, 2004.

[36].FATHI, E.; AFZAL, B.; FATHIPOUR, M.; Effective Channel Length Extraction of MOS Transistor with HALO/POCKET Implants, IEEE Transactions on Electron Devices, v. 42, p. 314-318, 2003. 